\title{
Wissen in der Predigt
}

Ein zentraler Baustein der Gattungstheorie Luckmannscher Tradition ist die Auseinandersetzung mit ,Wissen“, denn ,das menschliche Handeln setzt menschliches Wissen notwendig voraus“ (Luckmann 1986:191). Und so definiert Luckmann kommunikative Gattungen als "Grundformen der gesellschaftlichen Vermittlung des Wissens" (Luckmann 1986:191) und beschreibt damit zum einen Wissen als Voraussetzung sozialer Interaktion, das sich in einem spezifischen Gattungsund Handlungswissen manifestiert und zur erfolgreichen Realisierung der jeweiligen Gattung dient, und zum anderen Wissen als Produkt und Gegenstand der Interaktion, das im situativen Vollzug aktualisiert, vermittelt und ggf. revidiert wird (vgl. Luckmann 1986:192). Wie explizit dies geschieht und welches Wissen relevant gesetzt wird, ist jedoch gattungsspezifisch und abhängig von der kommunikativen Funktion des Umgangs mit Wissen (vgl. zu Lehr-Lern-Gattungen wie Unterrichtsgesprächen Brünner (2011), zu Bewerbungsgesprächen Birkner (2001) und zu Klatschgesprächen Bergmann (1987)). Wissen ist somit ein fester Bestandteil sozialer Interaktion und die Wissensvermittlung kann sowohl die übergeordnete kommunikative Funktion einer Gattung sein, aber auch Teil der Bewältigung kleinerer kommunikativer Aufgaben, die zur Realisierung der spezifischen kommunikativen Funktion der jeweiligen Gattung beitragen.

Die bisherigen Ausführungen in der vorliegenden Arbeit hatten bereits das implizite und explizite Gattungswissen, d. h. das Wissen der anwesenden Personen über die Gattung der Predigt zum Gegenstand. Dieses manifestiert sich vor allem in der Art und Weise, wie die Predigt als Ereignis interaktiv hergestellt und durchgeführt wird, in der Nutzung vorhandener Räume und der Etablierung

Elektronisches Zusatzmaterial Die elektronische Version dieses Kapitels enthält Zusatzmaterial, das berechtigten Benutzern zur Verfügung steht https://doi.org/10.1007/978-3-658-33855-8_16. 
einer typischen Interaktionsordnung mit ihren unterschiedlichen Beteiligungsrollen, verbunden mit einer spezifischen Rederechtsverteilung (siehe Kapitel 13-15). Dadurch legen die Beteiligten ihr geteiltes Wissen über die Predigt, deren interaktive Verfasstheit und Struktur offen, aktualisieren und ratifizieren es.

Sowohl innerhalb der Gattungsforschung als auch der Wissensforschung blieb die Predigt als Form institutioneller (Wissens)Kommunikation bislang jedoch unberücksichtigt. Luckmann geht in seiner Darstellung zu Moralpredigten lediglich sehr verkürzt auf Aspekte des Wissens ein, wenn er die Predigt als Teil langsam in Vergessenheit geratender Rituale bestimmt und die These aufstellt, dass die Predigt in vergangener Zeit ein fester Bestandteil der Lebenswirklichkeit und Teil des kommunikativen Haushaltes der Menschen war, dies jedoch in der Moderne nicht mehr der Fall sei (vgl. Luckmann 1999b:84f; siehe Kapitel 5). Unklar bleibt darüber hinaus, welche Wissensbestände tatsächlich eine Rolle in der Predigt und speziell im Wortbeitrag spielen. Die nachfolgende Analyse greift dieses Forschungsdesiderat auf und stellt die Frage nach dem Wissen in der Predigt. Wissen ist dann nicht mehr nur die Voraussetzung zur erfolgreichen Durchführung der Predigt, sondern selbst Gegenstand (wie sich zeigen wird, speziell des Wortbeitrags). Folgende Teilfragen sind dabei leitend:

- Welche Rolle spielt die Aktualisierung, Tradierung und Vermittlung von Wissen in den Wortbeiträgen christlicher Predigten des 21. Jahrhunderts?

- Welche Wissensbestände werden von den Predigern relevant gesetzt und vermittelt? Welche Wissensarten lassen sich erkennen?

- Welche interaktiven Praktiken setzen die Prediger zur Realisierung der Wissensvermittlung ein?

- Kann die Predigt als Gattung der Wissensvermittlung bestimmt werden?

Die Analyse konzentriert sich vor allem auf den Wortbeitrag, der neben dem Gang zum Predigtort und dem Verlassen des Predigtortes das dritte obligatorische Predigtelement und den zentralen Aktivitätstyp der Gattung bildet (siehe Kapitel 9 und Abschnitt 15.3). Da die untersuchten Wortbeiträge immer auf der Grundlage mindestens eines Bibeltextes gestaltet sind, richtete sich der Fokus der nachfolgenden Analyse zudem auf die Art und Weise, wie die Prediger biblische Texte und in diesem Zusammenhang Wissen vermitteln.

Der Analyse ist zunächst ein theoretisches Kapitel vorangestellt, das sich mit dem Wissensbegriff innerhalb der Interaktionalen Linguistik und der Wissenssoziologie auseinandersetzt und vor allem das Beschreibungsmodell nach Heritage vorstellt, das dann zur Analyse der Wortbeiträge herangezogen wird (Abschnitt 16.1). Diese beginnt mit der Untersuchung der Annahmen und Zuschreibungen der Prediger hinsichtlich vorhandener oder nicht vorhandener Wissensbestände sowie hinsichtlich geteilten Wissens mit der Gemeinde 
(Abschnitt 16.2). Im Zentrum steht dabei die Frage, welche Wissensbestände bei den Rezipierenden vorausgesetzt und welche neu vermittelt werden (Abschnitt 16.3). Obwohl auf das engste miteinander verknüpft, ist es erst ein diesen Vermittlungen folgender Schritt, die Texte hinsichtlich ihres überzeitlichen Geltungsanspruchs herauszustellen und zu interpretieren, indem z. B. Handlungsanweisungen für die anwesenden Personen formuliert werden (Abschnitt 16.4).

Die Aktivitäten der Wissenszuschreibung, Wissensvermittlung und Veranschaulichung müssen dabei nicht in der hier besprochenen Reihenfolge realisiert werden. Vielmehr ist innerhalb der untersuchten Wortbeiträge eine große Flexibilität hinsichtlich der Durchführung und Ausgestaltung der einzelnen Aspekte erkennbar. So bildet die nachfolgende Kapitelstruktur den Prototypen ab, bei dem der Predigttext zu Beginn des Wortbeitrags gelesen wird, der Prediger aufgrund seiner Wissenszuschreibungen den Text selbst erläutert, indem er spezifische Wissensbestände aktualisiert und ggf. neu vermittelt und schließlich die Relevanz der im Text dargestellten Ereignisse für die Gegenwart aufzeigt und Möglichkeiten für Anschlusshandlungen der anwesenden Personen benennt.

\subsection{Wissen in der Interaktion}

Sowohl aus wissenssoziologischer als auch aus interaktionsanalytischer Perspektive wird ,Wissen" als ein zentraler und vorwissenschaftlicher Bestandteil individueller und kollektiver, ontogenetischer und phylogenetischer Entwicklung, als gesellschaftliches Konstrukt (vgl. Berger/Luckmann 2012) bzw. als eine interaktiv-soziale Herstellungsleistung (vgl. Deppermann 2015:2, Reineke 2016:2) und grundlegend als ein Bestandteil menschlicher Interaktion verstanden (vgl. Knoblauch 2005:146, Deppermann 2015, Groß/Harren 2016), denn Wissen ist

an fast jeder Interaktion zugleich als Voraussetzung, als thematischer Gegenstand sowie als Produkt des Miteinandersprechens beteiligt. Alle Arten von Kompetenzen, die für die Konstitution interaktiven Handelns von Belang sind, sind in Form von Wissensbeständen organisiert. [...] Wissen ist die Voraussetzung für Wahrnehmung und Kategorisierung, für Verstehen, Erklären und Antizipieren von Handlungen und Ereignissen und für die Planung von Handlungen. (Deppermann 2015:1)

Der ,erfolgreiche Erwerb, die Transformation und optimale Weitervermittlung von Wissen sind von jeher gleichzeitig individuelle und kollektive sowie identitätsbildende und identitätssichernde Grundnotwendigkeiten“ (Beckers 2012:33). 
Für die wissenschaftliche Auseinandersetzung bedeutet dies, dass mithilfe empirischer Methoden herausgearbeitet wird, was die Interagierenden selbst als Wissen ansehen und wie sie in der Interaktion auf bestimmte Wissensbestände zurückgreifen, diese aushandeln und auf der Grundlage dieses Wissens Interaktion gestalten und Handeln organisieren.

Auch die moderne Wissenssoziologie fragt nach dem Zusammenhang zwischen Wissen und Handeln. Ziel ist es dann, deren enge Verbindung aufzuzeigen und zu beschreiben, denn , alles menschliche ,Wissen “ [wird] schließlich in gesellschaftlichen Situationen entwickelt, vermittelt und bewahrt" (Berger/Luckmann 2012:3). Entsprechend erscheint Wissen in der Wissenssoziologie als ,gesellschaftlich relevante[r], gesellschaftlich objektivierte[r] und gesellschaftlich vermittelte[r] Sinn“ (Knoblauch 2005:159), der sich u. a. in der Struktur und Funktion kommunikativer Gattungen zeigt, die ihrerseits als intersubjektive und verfestigte Muster subjektiv gemachter sinnhafter Erfahrungen und damit von Wissen konzeptualisiert werden (siehe Kapitel 8). Die Gesamtheit der Wissensbestände einer Gesellschaft bezeichnet Luckmann als den „kommunikativen Haushalt" (Luckmann 1986 und 1997:16).

Während die Wissenssoziologie eine gesellschaftliche Theorie des Wissens erarbeitet, fragt die Interaktionsanalyse nach dem konkreten Vollzug des Umgangs mit Wissen in der Interaktion und den aktiven „Produktions- und Verstehensleistung[en]" (Groß/Harren 2016:11) der Interagierenden, die spezifisches Wissen in der jeweiligen Interaktionssituation einbringen, zuschreiben, erzeugen und lenken (vgl. Dausendschön-Gay et al. 2010:11, Stivers et al. 2011:7, Deppermann 2015:2). Dabei liegt der Forschungsfokus auf der Rekonstruktion und Bestimmung der Wissensträger (wer weiß was, wer hat Zugang zu bestimmten Wissensbeständen, wer besitzt die epistemische Autorität, d. h. wer hat das Recht, ein bestimmtes Wissen zu haben, welche epistemischen Erwartungen sind mit bestimmten sozialen Rollen verbunden etc.), der jeweils relevanten Wissensbestände bzw. der Referenz (was wird gewusst), der epistemischen Qualität und Gewissheit (wie sicher wird etwas gewusst) sowie der spezifischen Manifestationsebene des jeweiligen Wissens im Vollzug der sozialen Interaktion (vgl. Janich/Birkner 2015:200).

Heritage unterscheidet in diesem Zusammenhang zwischen ,epistemic stance“ und ,epistemic status'. Mit dem Begriff des epistemischen Status (epistemic status) bezeichnet er, "what is known, how it is known (through what method, with what degree of definitness, certainty, recency, etc.) and persons' rights, responsibilities and obligation to know" (Heritage 2013:377) und stellt ihn als epistemischen Gradienten zwischen den zwei Polen K+ und K- dar (vgl. Heritage 2012:7). Kommuniziert eine Person in der Interaktion, dass sie über einen spezifischen 
Wissensbestand verfügt und das mit großer Sicherheit, so weist Heritage ihr die Variable $(\mathrm{K}+)$ zu. Macht eine Person im Gegensatz dazu deutlich, dass sie über ein spezifisches Wissen nur mit geringer Sicherheit verfügt oder das Wissen nicht besitzt (Nichtwissen), so verortet Heritage sie als (K-) (vgl. Heritage 2013:376f). Die dichotome Einteilung in $(\mathrm{K}+)$ und $(\mathrm{K}-)$ wurde in der Folge zurecht als zu strikt und ungenau kritisiert. Dabei täuscht die Benennung jedoch darüber hinweg, dass Heritage selbst ein skalares Modell anstrebt:

Thus relative states of knowledge can range from circumstances in which speaker A may have absolute knowledge of some item, while speaker B has none, to those in which both speakers may have exactly equal information, as well as every point in between. (Heritage 2012:4)

Weiterhin schließt sich Heritage in seiner Konzeptualisierung des epistemischen Status an die Theorie der Wissensterritorien bzw. Informationsterritorien (vgl. Kamio 1997) an und geht davon aus, dass jede Person Zugang zu unterschiedlichen ,Domänen' und dem dabei relevanten Wissen hat (vgl. Heritage 2013:375). Treffen Personen in einer Interaktionssituation aufeinander, stellt sich die Frage, wieviel die Beteiligten über die für die Interaktion relevante Wissensdomäne wissen bzw. nicht wissen und wie sich der Ausgleich von Wissensasymmetrien vollzieht. „It begins from the notion that any two speakers, A and B, each have their own territories of information, and that any specific element of knowledge can fall into both of them, but often to different degrees" (Heritage 2013:376). Das Wissen darüber, ob etwas gewusst wird, fällt z. B. allein in das Territorium des Wissenden selbst. Heritage verweist zudem auf die von Labov und Fanshel erstellte Wissensklassifikation mit Bezug auf die Vorbedingungen der Äußerung und den Wissensträger, d. h. darauf, wer ein bestimmtes Wissen hat. Sie unterscheiden fünf Konstellationen: A-events (das Wissen ist für den Sprecher (A) bekannt und dem Rezipienten (B) unbekannt; der Sprecher besitzt die epistemische Autorität in Bezug auf den verhandelten Wissensbestand), B-events (das Wissen ist dem Rezipienten (B) bekannt, nicht aber dem Sprecher (A)), $A B$ events (A und B verfügen über das Wissen), O-events (alle anwesenden Personen verfügen über das Wissen) und D-events (das relevante Wissen ist verhandlungswürdig für beide Seiten; vgl. Labov/Fanshel 1977:100; siehe dazu auch Heritage 2013:374 und Deppermann 2015:13).

In Abgrenzung zum epistemischen Status definiert Heritage den epistemic stance folgendermaßen: 
If epistemic status is conceived as a somewhat enduring feature of social relationships vis-à-vis an epistemic domain, epistemic stance by contrast concerns the moment-bymoment expression of these relationships, as managed through the design of turns-attalk. (Heritage 2013:377)

Es handelt sich also nicht wie beim epistemischen Status einer Person um ,eine soziale Zuschreibung an Interaktionsbeteiligte“ (Deppermann 2015:14), sondern um ,die Haltung, die ein Interaktionsteilnehmer mit seinem Turn in Bezug auf einen bestimmten Wissensgegenstand einnimmt" (Deppermann 2015:14) und die er mithilfe unterschiedlicher sprachlicher Praktiken in der Interaktion ausdrückt. Die konversationsanalytische Forschung zeigt dabei, wie in und durch die sequenzielle Struktur Wissensannahmen funktional und geordnet geäußert, getestet, verteidigt, revidiert etc. werden (vgl. Heritage 2013:370). In dieser Perspektive ist Wissen keine vor der eigentlichen Analyse feststehende Entität, die es zu definieren gilt, sondern eine ,,(inter)subjektive und damit grundsätzlich dynamische Größe - sowohl in der sprachlich-interaktiven Gestaltung durch Individuen als auch in der sozialen Aushandlung" (Groß/Harren 2016:8). Die Definition dessen, was Wissen ist, kann also nur unter der jeweiligen Forschungsperspektive geleistet werden (vgl. auch Beckers 2012:34).

Innerhalb der interaktionsanalytischen Forschung stehen neben Formen der Vermittlung und Dokumentation von Wissen und dem Verstehen in nichtinstitutionellen Alltagsinteraktionen vor allem institutionelle Kontexte im Fokus der Untersuchungen (vgl. Groß/Harren 2016:8, Birkner/Burbaum 2016:83f). In diesem Zusammenhang wird Wissen immer wieder mit der Dichotomie Experte/Laie kurzgeschlossen und danach gefragt, wer sich in Bezug auf welches Wissen als Experte bzw. als Laie konstruiert - bzw. konstruiert wird - und welches Wissen von den Beteiligten geteilt wird (vgl. Birkner/Burbaum 2016:87). Besonders die Rolle geteilten Wissens bei der Herstellung von Intersubjektivität und die Bereitstellung, Aushandlung und Relevantsetzung geteilten Wissens in den jeweiligen Settings ist von Interesse (vgl. Birkner/Burbaum 2016:85; siehe auch Deppermann 2015:6f). In diesem Zusammenhang fragt die interaktionsanalytische Forschung nicht danach, welches Wissen eine Person tatsächlich hat bzw. nicht hat, sondern danach, welches Wissen sie in der jeweiligen Situation als vorhanden bzw. nicht vorhanden darstellt und erkennbar macht (vgl. Keisanen/Kärkkäinen 2014:300), denn das tatsächlich vorhandene Wissen des Gegenübers entzieht sich „direkter Beobachtbarkeit“ (Bergmann/Quasthoff 2010:23). Aus diesem Grund gehen Betrachtungen in der Tradition der Konversationsanalyse davon aus, dass situativ relevantes Wissen über „die Beobachtung und Interpretation von Verhalten, und [...] die ,accounting practices * 
der Akteure selbst“" (Bergmann/Quasthoff 2010:23) antizipiert und (re)konstruiert werden kann. Als Konsequenz daraus wird nach den "Manifestationsformen“ (Birkner/Burbaum 2016:85) gefragt, in denen und durch die (geteiltes) Wissen in der Interaktion für die Beteiligten - sowie für die Forschenden - erkennbar wird (vgl. Janich/Birkner 2015:202).

Da es sowohl der Gattungstheorie als auch der Konversationsanalyse um die Frage geht, welche (kommunikativen, sozialen, interaktiv-sequenziellen) Probleme durch ein bestimmtes beobachtbares kommunikatives Phänomen bearbeitet werden, geschieht auch die Auseinandersetzung mit ,Wissen“ im Hinblick darauf, welche Gesprächsaufgaben mit der je spezifischen Form der Verstehensaushandlung und Verstehensdarstellung, d. h. mit der Herstellung von Intersubjektivität durch die Relevantsetzung bestimmter Wissensbestände, bearbeitet werden (vgl. Groß/Harren 2016:11). In der nachfolgenden Betrachtung der Wortbeiträge christlicher Predigten stehen zum einen die Wissensträger, die spezifischen vermittelten Wissensbestände, die epistemische Qualität und Gewissheit der Wissensträger bezüglich der Wissensbestände sowie die Manifestationsebenen des Wissens im Vordergrund.

\subsection{Wissenszuschreibungen in Predigten}

Stellt man die Frage nicht nur danach, welches Wissen für die Etablierung und Durchführung einer Predigt notwendig ist, sondern auch danach, welche Wissensbestände speziell im Aktivitätstyp des Wortbeitrags aktualisiert bzw. neu vermittelt werden, so muss untersucht werden, mithilfe welcher sprachlichen und kommunikativen Praktiken dies geschieht und welche kommunikativen Aufgaben gerade mit diesem speziellen Wissen bearbeitet werden. Ein erster Schritt zur Beantwortung dieser Fragen kann die Analyse von Wissensannahmen und daraus resultierenden Wissenszuschreibungen sein, denn grundsätzlich gilt:

Gesprächspartner orientieren sich bei der inhaltlichen Gestaltung und Perspektivierung ihrer Beiträge an angenommenen Wissensvoraussetzungen ihres Gegenübers, sie verdeutlichen sprachlich-interaktiv den (wissensbezogenen) Handlungscharakter ihres Sprechens [...] und gestalten auf diese Weise wechselseitig ihre sozialen Rollen. Letzteres zeigt sich zum Beispiel, indem sie sich und/oder anderen Gesprächsteilnehmer/innen Wissen zuschreiben oder absprechen oder indem sie ihre eigene epistemische Sicherheit herausstellen oder verschleiern. (Groß/Harren 2016:11)

Notwendig wird dies durch das grundlegende Prinzip der „Intransparenz des Fremdbewusstseins“ (Bergmann/Quasthoff 2010:22): „Was ich ,weiß“, ist den 
anderen auf direktem Weg nicht zugänglich, und was die anderen ,wissen', ist mir erst einmal versperrt. [Es gibt] [...] keinen direkten Zugang, es muss indirekt aus Manifestationen - Äußerungen und Verhalten - erschlossen werden“ (Bergmann/Quasthoff 2010:22). Sowohl in nicht-institutionellen als auch in institutionellen Interaktionssituationen produzieren die Interagierenden ihre jeweiligen Beiträge in diesem Zusammenhang ,,auf der Grundlage der Unterstellung eines geteilten Wissens“ (Bergmann/Quasthoff 2010:23) und damit hinsichtlich eines common ground bzw. aufgrund von Annahmen hinsichtlich nicht geteilter Wissensbestände. Dies zieht in den meisten Fällen eine Vermittlung des relevanten Wissens nach sich. Zentral ist dabei, dass den beteiligten Personen nicht nur das gleiche Wissen bekannt ist, sondern „dass sie dies auch voneinander wissen“ (Deppermann 2015:8). Grundsätzlich gilt also: Die wechselseitige Zuschreibung von Wissen bildet den Ausgangspunkt für die eigentliche Äußerungsproduktion (vgl. Deppermann 2015:8). Störungen ergeben sich in den meisten Interaktionssituationen dann, wenn die Wissensannahmen zu als vom Interaktionspartner falsch markierten Wissenszuschreibungen führen und so z. B. Reparaturen initiiert werden müssen, um die Intersubjektivität der Interaktion aufrecht zu erhalten.

Bei der Realisierung christlicher Predigten wird durch die typische Interaktionsordnung als Bühnenformat die Zuschreibung von Wissen in besonderer Weise virulent. Denn der Prediger sieht sich nicht nur einer einzelnen Person gegenüber, sondern einer mehr oder weniger großen Gruppe. Dadurch ist er gezwungen eine Mehrfachadressierung vorzunehmen und seinen Wortbeitrag auf diese Gruppe von Anwesenden und deren potentiell vorhandene Wissensbestände hin zu orientieren und zuzuschneiden. Da der Wortbeitrag ein gescriptetes Ereignis ist, muss der Prediger bereits in der Predigtvorbereitung Überlegungen hinsichtlich der potentiell vorhandenen bzw. nicht vorhandenen Wissensbestände der möglicherweise anwesenden Personen anstellen. Der Prediger trifft dabei Annahmen über die „kognitiven Vorbedingungen verschiedener Empfänger“ (Hitzler 2013:113; siehe auch Bergmann/Quasthoff 2010:23), also darüber, über welche Wissensbestände der Großteil der Rezipierenden aus seiner Sicht verfügt bzw. nicht verfügt. Die Gemeinde erscheint dabei nicht zuerst als einzelne Individuen, sondern als Wissensgemeinschaft (epistemic community, Heritage 2013:371), d. h. als eine Gruppe von Personen, deren Mitglieder typischerweise spezifische Wissensbestände, Erfahrungen, einen z. T. idiosynkratischen Sprachgebrauch sowie eine bestimmte Kultur, bestimmte Werte, Vorstellungen und, in dem hier untersuchten Datenmaterial, einen bestimmten Glauben teilen (vgl. zum Konzept der Wissensgemeinschaft Heritage 2013:371; siehe dazu aus theologischer Perspektive Stebler 2006:117). Gerade die Konstruktion einer Wissensgemeinschaft innerhalb eines 
speziellen institutionellen Settings bietet dabei für den Prediger Entlastungspotenziale, wenn es um die Unterstellung von Wissen geht, das typisch mit der anwesenden Gruppe assoziiert wird. Auf der anderen Seite ist es für die kommunikative Gattung der christlichen Predigt, wie die nachfolgenden Analysen zeigen werden, aufgrund ihrer Interaktionsordnung untypisch, dass die Prediger ihre Wissensannahmen einer Prüfung unterziehen oder die anwesenden Personen eine unmittelbare verbale Rückmeldung darüber geben, ob die vom Prediger gemachten Annahmen und Zuschreibungen zutreffen oder nicht. Häufiger ist der Fall zu beobachten, dass die Prediger selbst ihre gemachten Zuschreibungen in ihrer Reichweite und Gültigkeit einschränken, indem sie sie als subjektive Vermutungen kontextualisieren oder nur einzelne Teile der Gemeinde in die Zuschreibung einbeziehen. Dies führt dazu, dass in den Wortbeiträgen die Frage, wer über bestimmte Wissensbestände verfügt und wer sich in diesem Zusammenhang als Experte bzw. als Laie positioniert bzw. positioniert wird, immer wieder relevant gesetzt wird.

Darüber hinaus wird eine Praktikengemeinschaft (community of practice) hergestellt, die ,durch regelmäßige Zusammenkünfte und die gemeinsame Sozialisation geteilte Werte, Normen, Ressourcen und kommunikative Praktiken“ (Spreckels 2009:27) ausbildet. Dieses Praktikenwissen erstreckt sich dabei nicht nur auf die gottesdienstliche Agenda an sich, sondern auch auf ein spezielles Gattungswissen über die Predigt und instrumentelles Wissen z. B. über den Aufbau und die Handhabung der Bibel, da diese mit ihren Texten den zentralen Bezugspunkt der Wortbeiträge darstellt. In den hier untersuchten Wortbeiträgen setzen die Prediger das Vorhandensein dieses Wissens in den meisten Fällen voraus und schreiben es als von allen Anwesenden geteilt zu (O-event). Dies wird u. a. daran erkennbar, dass die Prediger die genannten Siglen zum jeweiligen biblischen Text (i. d. R. in der Form ,biblisches Buch/Kapitel/Vers ' angegeben) nicht erklären, sondern implizit zuschreiben, dass die anwesenden Personen diese dechiffrieren können, es sich dabei also um einen common ground der Beteiligten handelt. Die Gemeinde muss also Wissen über den Aufbau der Bibel haben, an welcher Stelle sich das jeweilige Buch befindet und dass die einzelnen Bücher in Kapitel und Verse eingeteilt sind. Nur in evangelistischen Wortbeiträgen, die sich speziell an Rezipierende richten, die die Bibel nicht bzw. nicht häufig lesen, wurde dieses instrumentelle Wissen expliziert. Das nachfolgende Beispiel zeigt in diesem Zusammenhang nicht nur, welche Wissensbestände vermittelt werden, sondern auch, dass dieses Wissen über den Aufbau der Bibel als Voraussetzung für eine erfolgreiche Durchführung der Predigt vom Prediger relevant gesetzt wird. 


\section{Beispiel 20: Glücksworte}

01 P: jesus: hat aUch einmal vom GLÜCK gesprochen. (1.5)

02 ich wErde ihnen EInige,

03 <<acc>verse vorlesen aus der ! BI!bel.>(---)

04 aus dem nEuen testaMENT.

05 im hinteren TEIL der bibel.(-)

06 das ist dOrt wo die geschichte von JEsus erzählt wird. (--)

07 und es gibt eine sehr bekANNte stelle, =

08 =wo jesus vom GLÜCK gesprochen hat.

$09{ }^{\circ}$ hh die sogenannten sE:ligPREIsungen;

10 die GLÜCKlichpreisungen; =

11 =er begInnt damit seine BERGpredigt;

12 die wohl (.) bekAnnteste rede aller ZEIten.(1.0)

13 und auch die FELDrede die (.)

14 LUkas überliefert.

15 der evangeLIST,

16 der (.) die lebensgeschichte von jesus AUFgeschrieben hat.

17 (1.0)auch diese fEldrede beGINNT? (--)

18 mit dieser rEde vom GLÜCK.

19 GLÜCKSworte.

20 lukas SECHS,

21 vers ZWANzig;

22 bis dreiundzWANzig.

An diesem Auszug lässt sich der Zusammenhang zwischen dem Charakter des Gottesdienstes und dem im Wortbeitrag vorgenommenen und darauf bezogenen Rezipientenzuschnitt erkennen, denn der Prediger folgt mit seiner Zuschreibung von Wissen und Nichtwissen der Ausrichtung als ökumenischer evangelistischer Veranstaltung, die auf den speziellen Rezipientenkreis von Nichtchristen hin orientiert ist. So wird zum einen das Buch der Bibel als hoch relevantes Objekt etabliert, indem der Prediger zum einen die erste Silbe des Wortes stark betont (ich wErde ihnen EInige, verse vorlesen aus der ! BI! bel, Z.2-3), durch den bestimmten Artikel zumindest die Bekanntheit des Buches an sich zuschreibt und das Buch parallel zu dieser Ankündigung von seinem beweglichen Rednerpult hochhebt und es den anwesenden Personen aufgeschlagen präsentiert. Nachdem die Bibel als Objekt eingeführt wurde, vermittelt der Prediger spezielles Bibelwissen, d. h. Wissensbestände bezüglich des Aufbaus und des Inhalts der Bibel (Aufteilung in AT und NT, Namen und 
Anordnung der einzelnen Bücher - vor allem innerhalb der Unterteilung in AT und NT, Einteilung der Bücher in Kapitel und Verse), die in allen anderen untersuchten Wortbeiträgen, die innerhalb von nicht bzw. weniger stark evangelistisch ausgerichteten Gottesdiensten gehalten wurden, unexpliziert blieben. Der Prediger in Beispiel 20 hingegen benennt nicht nur die Textstelle, die er im Folgenden vorlesen wird (Lukas SECHS, vers ZWANzig;bis dreiundZWANzig, Z.20-22), sondern macht zusätzlich Angaben darüber, wo diese Textstelle im Gesamtaufbau der Bibel verortet ist. Dazu nutzt er zum einen die theologische Fachterminologie (verse vorlesen aus der !BI! bel aus dem nEuen testaMENT, Z.3-4) und bestimmt sie zusätzlich lokal (im hinteren TEIL der bibel, Z.5). Darüber hinaus ordnet der Prediger die Position der Bibelstelle im Gesamtaufbau des Buches in einen größeren inhaltlichen Kontext ein (das ist DORT wo die geschichte von JEsus erzählt wird, Z.6). Dadurch schreibt er implizit zu, dass es unter den anwesenden Personen Menschen gibt, die über dieses Wissen nicht verfügen, und weist ihnen einen niedrigen epistemischen Status zu, d. h. ein Nichtwissen (K-). Der Prediger wiederum markiert dadurch, dass er über das Wissen mit einer großen epistemischen Sicherheit verfügt $(\mathrm{K}+)$. Er nimmt jedoch keine Differenzierung hinsichtlich der Gültigkeit seiner Zuschreibung für alle Anwesenden oder nur einen Teil der Gemeinde vor, sondern lässt den Adressatenkreis offen.

Es folgt eine weitere Konkretisierung, in der der Prediger das Buch, aus dem er vorlesen wird, benennt sowie Kontextwissen bezüglich des Autors liefert (und auch die FELDrede die, LUkas überliefert. der evangeLIST. der (.) die lebensgeschichte von jesus AUFgeschrieben hat, Z.13-16). Der Auszug zeigt, dass der Prediger ein bestimmtes Wissen über die Handhabung der Bibel bei den anwesenden Personen nicht als exklusives Expertenwissen des Predigers behandelt, sondern als common ground, d. h. als ein notwendig von allen Anwesenden geteiltes Wissen. Dadurch wird bereits die Bedeutung der biblischen Texte für die Wortbeiträge der hier untersuchten Predigten deutlich, die u. a. auch darin besteht, dass die anwesenden Personen die im Wortbeitrag durch den Prediger geäußerten Gedanken selbst durch die Lektüre der besprochenen biblischen Texte nachbereiten und überprüfen können. 
Häufiger als das Bibelwissen, das in dem hier untersuchten Korpus lediglich in diesem einen Wortbeitrag expliziert wurde, steht die Kenntnis a) der einzelnen biblischen Texte und Geschichten und b) grundsätzlicher Glaubensgewissheiten und Glaubensüberzeugungen im Fokus der Zuschreibungen innerhalb der Wortbeiträge. Dieses Wissen wird auch in regulären Sonntagsgottesdiensten, Jugendgottesdiensten und zu anderen Anlässen vermittelt und relevant gesetzt.

\section{Beispiel 21: Nix neues}

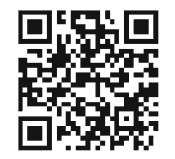

35 P: nun neben der erheblichen tatsache dass gott alLEIN mein schöpfer ist,

36 und er al!LEIN! über leben und tod beSTIMMT,

$37{ }^{\circ} \mathrm{h}$ sind mir noch zwei andere dinge bei paulus AUFgefallen.(1.0)

38 und (.) über die werd ich heute abend (.) $\mathrm{n}$ bissel was erZ̈̈Hlen.

39 ERTStens; (-)

$40<<\mathrm{f}>$ ! PAU!lus lebt in dem beWUSSTsein, (1.0)

41 !ALLES! - (.)

42 in meinem LEben,

43 ! DIENT! ;

44 dem HEIL.> (2.0)

45 und dasZWEIte?

46 paulus lebt in dem beWUSSTsein, (1.5)

47 !CHRIS!tus; (.)

48 alLEIN. (-)

49 ist mein LEben.(2.0)

$50<<\mathrm{pp}>\mathrm{ja}$ ? $>(-)$

49 mal ganz EHRlich; (-)

50 LEUte; $(-)$

$\rightarrow 51$ ich glaub ich erzëhL euch nix NEUes.

52 ja?=

53 haut noch nIemand vom STUHL heute abend, (-)

54 aber (.) biblische WAHRheit. 
In diesem Auszug aus einer ökumenischen Predigt setzt sich der Prediger in seinem Wortbeitrag über einen Text aus dem Philipperbrief (Phil. 1, 19-16) unter dem Thema „Zwischen Lebensangst und Todessehnsucht“ mit der provokant überspitzten Frage auseinander, ob Paulus selbstmordgefährdet war. Dabei schreibt er Wissen über die biblische Person des Paulus zu und positioniert die anwesenden Personen in diesem Zusammenhang als Wissensgemeinschaft, die sich bereits intensiver mit den Handlungen und Glaubensgrundsätzen der Person Paulus auseinandergesetzt hat. Der Auszug beginnt damit, dass der Prediger eine Glaubensgewissheit äußert, die als gesichertes und nicht zur Diskussion stehendes Wissen präsentiert wird: „nun neben der erheblichen tatsache dass gott alLEIN mein schöpfer ist und er al!LEIN! über leben und tod beSTIMMT" (Z.35-36). Dieses Wissen nimmt der Prediger als Grundlage, um in Bezug auf den biblischen Text Aussagen über die Person Paulus zu treffen, die von ihm als exegetisches Wissen und mithilfe des Pronomens ,mir“ als subjektive Lesart präsentiert werden (sind mir noch zwei andere dinge bei paulus AUFgefallen, Z.37). Als syntaktisch parallele Deklarativsätze formuliert, bilden sie zwei Thesen, die der Prediger im weiteren Verlauf des Wortbeitrags genauer betrachtet (und über DIE werd ich heute abend n_bissel was erZÄHlen, Z.38):

- $<<\mathrm{f}>$ ! PAUl!us lebt in dem beWUSSTsein !ALLES! in meinem Leben !DIENT! dem HEIL.>(Z.40-44)

- paulus lebt in dem beWUSSTsein CHRIStus allEIN ist mein LEben. (Z.46-49)

Diese von ihm in der Predigtvorbereitung herausgearbeiteten Befunde werden dann von dem Prediger als auch unter den anwesenden Personen bekannt und damit als von allen Anwesenden geteiltes Wissen zugeschrieben (mal ganz EHRlich LEUte ich glaub ich erzÄhL euch nix NEUes ja, Z.51-54). Bei diesem Wissensbestand handelt es sich um ein AB-event, bei dem die Gemeinde einen hohen epistemischen Status zugeschrieben bekommt $(\mathrm{K}+)$ und der Prediger selbst einen hohen epistemic stance markiert $(\mathrm{K}+)$. Eingeleitet wird dies durch die äußerungskommentierende rhetorische Formel ,mal ganz EHRIich; LEUte (Z.51-52), mit der der Prediger die Anwesenden adressiert, die Verhandlung des Neuigkeitswertes (nicht aber des Wahrheitswertes!) seiner Aussagen und damit eine subjektive Stellungnahme vorbereitet, und den thematisierten Sachverhalt als in irgendeiner Weise problematisch rahmt. „mal ganz EHRlich LEUte" bekommt zusammen mit der folgenden Äußerung dadurch die Charakteristik eines misplacement markers, der die vorangegangene 
Äußerung als redundant kontextualisiert. Die Zuschreibung der Bekanntheit wird jedoch mithilfe des Personalpronomens ,ich“ (Z.53) und des mentalen Verbs ,glauben" als subjektive Annahme markiert. Dadurch kennzeichnet der Prediger einen niedrigen Grad epistemischer Gewissheit hinsichtlich der Richtigkeit seiner Aussage. Es folgt die Bewertung und Zuschreibung, dass die Anwesenden über das vermittelte Wissen - hier: seine persönlichen Erkenntnisse aus der Lektüre des Bibeltextes (exegetisches Wissen) - in ähnlicher Weise verfügen und die Aussagen über Paulus somit einen geringen Neuigkeitswert haben. So werden die Aussagen über die biblische Person des Paulus zwar als von allen Anwesenden geteilte und als gleichermaßen vorhandene Wissensbestände markiert (AB-event), die Gewissheit darüber, wie zutreffend diese Annahme ist, wird jedoch vom Prediger selbst abgeschwächt. Der Prediger weist damit einen exklusiven Expertenstatus gegenüber der Kenntnis des Bibeltextes zurück, indem er erneut sich selbst und schließlich auch den anwesenden Personen einen hohen epistemischen Status $(\mathrm{K}+)$ zuschreibt. Darüber hinaus fungiert das Rückversicherungssignal (ja?, Z.54) als „progression check“ (Schleef 2006:934): „They focus the listeners' attention on the preceding information and mark it as important or potentially hard to understand" (Schleef 2006:934). Es ist damit eine Praktik des Predigers zur Verstehensaktivierung bzw. der Konsensaktivierung auf Seiten der Rezipierenden (vgl. Hagemann 2009:151) und eine weitere Markierung als geteilt zugeschriebenen Wissens.

Die Frage ist nun, warum der Prediger trotz der zugeschriebenen Bekanntheit das entsprechende Wissen aktualisiert. Zum einen betont er, dass er sich genauer mit den gemachten Aussagen sowie mit der Person des Paulus auseinandersetzen wird (Z.39-41), die im weiteren Verlauf des Wortbeitrags vermittelten Wissensbestände also einen potentiell höheren Neuigkeitswert haben werden, und zum anderen verweist er auf die Autorität des biblischen Textes (aber biblische WAHRheit, Z.54) und den Charakter der Aussagen als Glaubensgewissheiten. In diesem Fall handelt es sich also nicht um eine Wissensvermittlung (neues, zuvor unbekanntes Wissen wird vermittelt), sondern um eine Wissensaktualisierung (als bekannt zugeschriebenes Wissen wird wieder aufgerufen und damit zum common ground der anwesenden Personen), um Wissensbestände als besonders relevant zu betonen oder eine gemeinsame Wissensbasis unter den anwesenden Personen zu schaffen, von der aus der Prediger dann weiterführende und häufig als weniger bekannt zugeschriebene Aspekte des biblischen Textes thematisiert. Dieser Auszug zeigt damit die erste Form der Wissenszuschreibungen in christlichen Wortbeiträgen: die Aktualisierung von Wissen, das der Prediger als allen anwesenden Personen bekannt zuschreibt. Im nachfolgenden Auszug nimmt derselbe Prediger in einem anderen Wortbeitrag (ökumenische Sonntagspredigt) 
eine vielschichtige Differenzierung seiner Zuschreibungen vor. Der Wortbeitrag beginnt (im nachfolgenden Transkript nicht abgebildet) mit einer biographischen Erzählung des Predigers und einem kurzen Rückblick auf eine Woche der Evangelisation, zu der der ökumenische Gottesdienst den Abschluss bildet. ${ }^{1}$ Beides führt auf das Thema des Wortbeitrags hin, in dem es um Vertrauen geht.

Beispiel 22: Hochzeit zu Kana
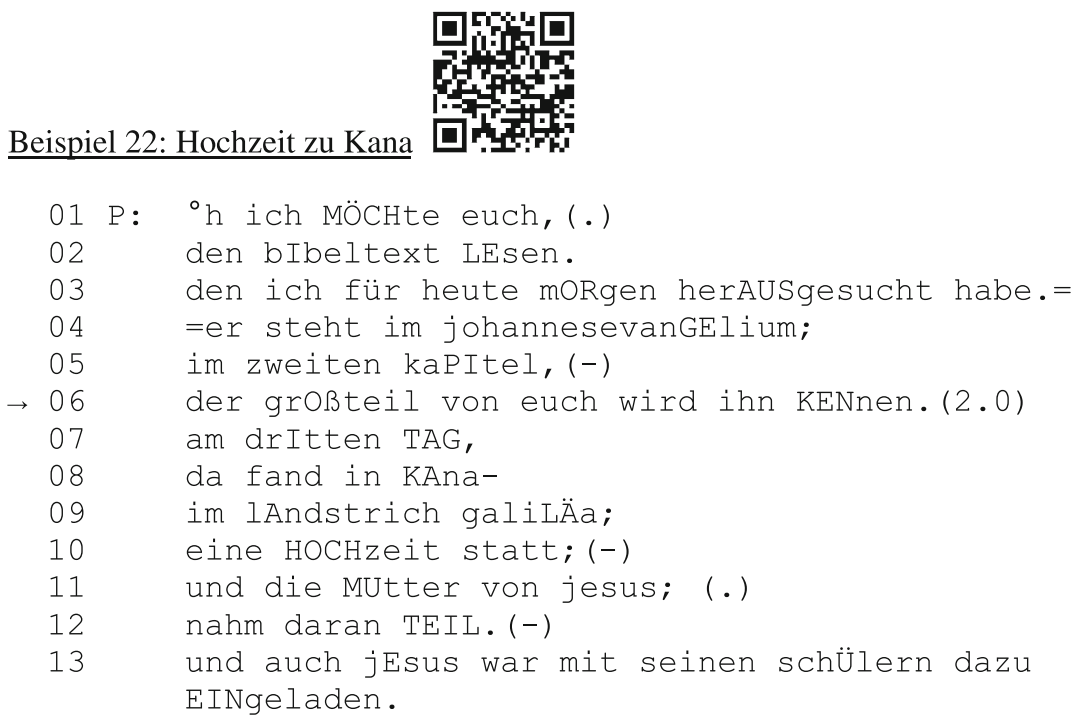

Noch bevor er den Bibeltext vorliest, schreibt der Prediger die Bekanntheit des Textes mithilfe eines Metakommentars und der Verwendung des mentalen Verbs ,kennen" unter den anwesenden Personen zu (der großteil von euch wird ihn KENNen, Z.6). Jedoch ist dieses Wissen kein kollektiv geteiltes, denn der Prediger lässt Raum für Personen, die über dieses Wissen nicht verfügen, indem er nur einen Teil der Gruppe (der grOßteil von euch, Z.6) in seine Zuschreibung einschließt. Mithilfe der spezifischen Adressierung schreibt der Prediger gleichzeitig das Vorhandensein $(\mathrm{K}+)$ und das Nicht-Vorhandensein (K-) des thematisierten Wissens innerhalb der Gemeinde zu. Seine Aussage impliziert zudem, dass auch er über den relevanten Wissensbestand verfügt $(K+)$.

\footnotetext{
${ }^{1}$ Der Gottesdienst bildet zwar den Abschluss der Evangelisationswoche, ist selbst aber nicht evangelistisch ausgerichtet, sondern vor allem auf die Personen orientiert, die während der Evangelisation mitgearbeitet haben. Daher besteht die Gemeinde vor allem aus Christen und glaubensnahen Personen unterschiedlicher Gemeinden.
} 
Es handelt sich also sowohl um ein AB-event als auch um ein A-event. Die Gewissheit über die Richtigkeit der Zuschreibung schwächt er durch das Hilfsverb ,werden“ (,wird“, Z.6) ab, das in diesem Auszug der epistemischen Markierung einer Vermutung dient. Im Anschluss daran liest der Prediger den entsprechenden biblischen Text vor (ab Z.7). Dieser Auszug zeigt damit eine weitere Form der Wissenszuschreibung, bei der der Prediger zwischen Personen, die über das Wissen verfügen und Personen, die über das Wissen nicht verfügen, differenziert. Gleichzeitig schafft der Prediger damit die legitimatorische Grundlage für die Auseinandersetzung mit Wissensbeständen, die einigen aus der Gemeinde möglicherweise bereits bekannt sind. Dazu dient u. a. die Zurücknahme der epistemischen Sicherheit, mit der die Aussage gerahmt wird. Sie verweist zudem implizit auf die interaktionsordnungsbedingte Mehrfachadressierung, die der Prediger vornehmen muss, und legitimiert nicht nur, dass der Prediger einen potenziell bekannten biblischen Text vorliest, sondern auch, dass der Text zum Gegenstand des Wortbeitrags wird. Die Zuschreibung bildet darüber hinaus den Ausgangspunkt für Verfahren der Wissensvermittlung, der Veranschaulichung und der moralischen Kommunikation des Predigers (siehe Abschnitt 16.3 und 16.4).

Im nachfolgenden Auszug geht es im Gegensatz dazu um die Vermittlung von Wissensbeständen, die vom Prediger als unbekannt zugeschrieben werden, und damit um die Markierung eines Wissensgefälles zwischen dem Prediger und den anwesenden Personen (A-event). Thema des Wortbeitrags ist das Gebet im Allgemeinen und das Gebetsleben von Jesus im Besonderen. So bestimmt der Prediger Jesus als Jude und damit innerhalb eines jüdischen Kontextes mit speziellen Gebetsritualen, die der Prediger anhand eines mitgebrachten Bildes über PowerPoint verdeutlicht. Der Prediger spricht darüber, dass Jesus nicht nur hinsichtlich der Kleidung und der Körperhaltung während des Gebets als Jude handelte, sondern auch mit jenen Worten betete, die Juden auch heute noch verwenden (und jesus bEtet mit genau den gleichen woRten, Z.434). 
Beispiel 23: Überraschung
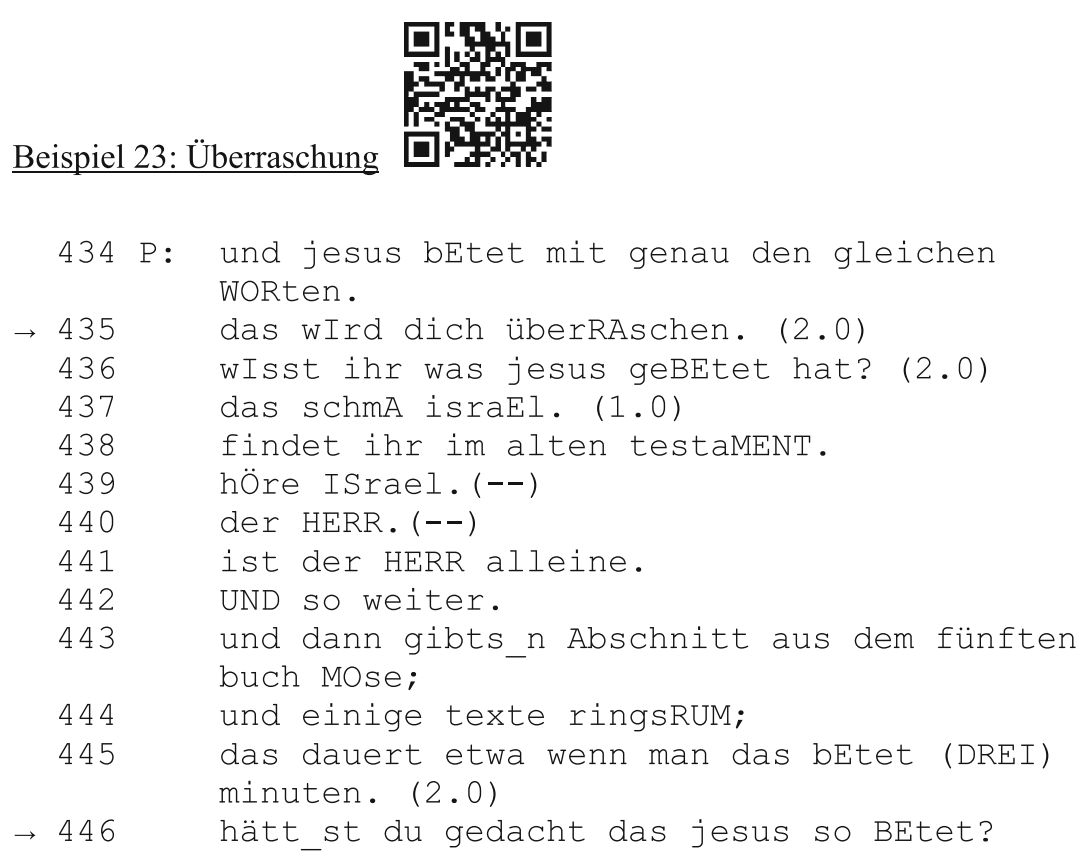

Die zunächst vermittelte Information, dass Jesus mit den gleichen Worten gebetet hat, mit denen Juden auf der ganzen Welt auch heute noch beten (Z.434), wird kommentiert, indem der Prediger u. a. durch das Futur anzeigt, dass es sich um eine subjektiv gemachte Vermutung handelt: „das wIrd dich überRAschen“ (Z.435). Damit verbunden ist die Abschwächung des Grades der epistemischen Gewissheit des Predigers darüber, wie zutreffend seine Aussage tatsächlich ist. Einen niedrigeren epistemic stance (K-) zeigt der Prediger also gegenüber dem tatsächlichen Wissensbestand der Gemeinde, bzw. hier durch das Pronomen „dich“ (Z.435) markiert, dem einzelnen Hörer. Es handelt sich um eine Annahme darüber, was die Gemeinde potenziell (nicht) wissen könnte. Hinsichtlich der thematisierten Wissensbestände selbst (sowohl über jüdische Gebetspraxis als auch über das Gebetsleben Jesu) schreibt der Prediger den anwesenden Personen ein Nichtwissen und damit einen niedrigen epistemischen Status (K-) zu. Gleichzeitig positioniert er sich damit selbst als Experte (K+), der über dieses Wissen mit deutlicher Gewissheit und Gesichertheit verfügt. Dadurch dokumentiert der Prediger eine Wissenshoheit, aktualisiert seine rollenbedingte Wissensautorität und kennzeichnet bei seinen Ausführungen einen hohen Neuigkeitswert. Die sequenzielle Positionierung dieser Wissenszuschreibung nach 
einer gegebenen Information erklärt und legitimiert rückwirkend die Vermittlung des relevant gesetzten Wissens. Nach einer längeren Pause (Z.436) erweitert der Prediger seinen Aussage-Bewertungs-Komplex, indem er zunächst das Interrogativ „wIsst ihr was jesus geBEtet hat?" (Z.436) produziert und dies mit der Aussage „das SCHMA israEl“ (Z.437) selbst beantwortet (siehe Kapitel 17). Damit schreibt der Prediger implizit erneut zu, dass die anwesenden Personen nicht über das entsprechende und hier relevante Wissen verfügen. Im Anschluss daran zitiert er mit dem Verweis auf die Quelle seines Wissens (findet ihr im alten testamenT, Z.438; 5. Mose 6,4) den ersten Teil des Gebets (Z.439-441) und gibt den Hinweis darauf, dass die Gebetspraxis weitere Elemente enthält (Z.442-444; Insgesamt wird 5. Mose 6,4-9; 5. Mose 11,13-21 und 4. Mose 15,37-41 rezitiert). Durch den Verweis auf die Textquelle kennzeichnet der Prediger, dass die anwesenden Personen zumindest zu einem Teil des Wissens in gleicher Weise Zugang haben wie er. Es handelt sich in Bezug auf den zu betenden biblischen Text also nicht um ein exklusives Expertenwissen. Im Gegensatz dazu wird das Wissen, welche Textstellen überhaupt Teil des Schma Israel sind, als Expertenwissen zugeschrieben. Seine Ausführungen schließt der Prediger mit einer rhetorischen Frage (hätt_st du gedacht das jesus so BEtet, Z.446), mit der er nochmals markiert, dass das von ihm gelieferte Wissen als zuvor unbekannt qualifiziert wird.

Die drei bisher gezeigten Zuschreibungsrichtungen (AB-event, AB-event und A-event, A-event) können zu jeder Zeit des Wortbeitrags realisiert werden. Zudem können innerhalb eines Wortbeitrags für unterschiedliche Aspekte unterschiedliche Zuschreibungen formuliert werden. So verbalisiert der Prediger im nächsten Auszug aus einer Jugendgottesdienstpredigt verschiedene Zuschreibungen über die Bekanntheit spezifischer Wissensbestände und formuliert gleichzeitig unterschiedliche Grade seiner epistemischen Gewissheit. Dabei geht er von der Zuschreibung kollektiv geteilten und damit vorhandenen Wissens zu einer Zuschreibung von Nicht-Wissen über. Dies zeigt, dass innerhalb dieser Zuschreibungssequenz zudem unterschiedliche Wissensterritorien, Zugänglichkeiten und Wissensautoritäten verhandelt werden. Dazu nutzt der Prediger sowohl verbale, vokale als auch visuelle Ressourcen (Das Video beginnt in Zeile 34 des Transkripts). 
Beispiel 24.1: Ihr kennt alle die Geschichte $\square$

25 P: ich weiß nich ob ihr den letzten satz der maria noch im OHR habt. (3.0)

26 ich will dir geHORchen (--)

$((\ldots))$

34 P: in vOrbereitung auf diesen adVENTSjugendgottesdienst;

35 sind wir über diesen vers nämlich ganz schön geSTOLpert. (-)

36 marla die SAGT-

37 ich gehöre dem HERRN;

38 ich bin beREIT;

39 es soll an mir geschEhen was du geSA:GT hast.

$\rightarrow 40$ (1.5) ihr KENNT alle die geschichte.

41 ihr habt die tausendmal (.) gesEhen und geHÖRT ;

42 mal MELden-

43 wer hatt $n$ alles schon maria im krIppenspiel geSPIELT,

$44 \quad(1.0)<<$, behaucht, :-) >ne: h>

45 ja,

46 GUCKT mal.

$\rightarrow 47$ ihr habt das Alle schon mal an euch erLEBT;

48 wart alle schon mal so HILFSschwanger und so;

49 ne?

$50 \quad{ }^{\circ}$ hhh $(4.0)$

51 ich möcht euch mal vOrlesen wie diese geschichte !WEI!tergeht.

52 nach diesem(-) ANruf-

53 der in die maria da erHALten hat.

((gelesener Text Lk 1,39-56 ausgelassen))

$\rightarrow 54$ ich denke die meisten von euch KENNen diesen bibeltext;

55 aus dem ersten kapitel des lUkasevanGEliums. (1.5)

$\rightarrow 56{ }^{\circ} \mathrm{h}$ aber ich weiß nicht ob euch bewUsst ist was da pasSIERT. 
Der Predigt geht ein Anspiel voraus, das von Mitarbeitern des Gottesdienstes realisiert wird und thematisch auf den Wortbeitrag hinführt. Nachdem das Anspiel beendet ist, verlassen die Spieler den Altarraum der Kirche, setzen sich in die Bänke und der Prediger vollzieht den Gang zum Predigtort (hier: eine Kanzel; siehe Beispiel 4). Zu Beginn des Wortbeitrags referiert der Prediger auf das Anspiel und ein dort zitiertes Bibelwort (ich weiß nich ob ihr den letzten satz der maria noch im OHR habt, Z.25). Nach einer kurzen Dialogsequenz (hier nicht abgebildet) nimmt der Prediger wieder Bezug auf die relevant gesetzte Aussage der Maria und erweitert sie, indem er die Bibelstelle aus dem Lukasevangelium zitiert (marIa die SAGT ich gehöre dem HERRN; ich bin beREIT; es soll an mir geschEhen was du geSA:GT hast, Z.36-39; Lk 1,38 nach Gute Nachricht Bibel). Bereits im Vorfeld rahmt der Prediger die biblisch tradierte Äußerung als verhandlungswürdig (in vOrbereitung auf diesen adVENTSjugendgottesdienst; sind wir über diesen vers nämlich ganz schön geSTOLpert, Z.34-35). ${ }^{2}$ Im Anschluss daran produziert er nach einer längeren Pause (Z.40) eine Sequenz der Wissenszuschreibung, in der er die Kenntnisse der anwesenden Personen in Bezug auf den biblischen Text thematisiert. Diese beginnt mit einer expliziten Zuschreibung sicheren kollektiven Wissens (ihr KENNT alle die geschichte, Z.40), die er damit begründet, dass die anwesenden Personen die Geschichte um Maria und die Ankündigung ihrer Schwangerschaft schon zum wiederholten Male zur Kenntnis genommen haben (ihr habt die tausendmal (.) gesEhen und geHÖRT, Z.41). Der Prediger zeigt mit der generalisierenden Referenz auf sämtliche Anwesende ( $\mathrm{alle}$ ) sowie der übertriebenen Frequenzmarkierung (tausendmal) eine starke Gewissheit und Festlegung seiner eigenen Wissensannahme. Dadurch schreibt er sich selbst und der Gemeinde einen hohen epistemischen Status $(\mathrm{K}+)$ in Bezug auf die Textkenntnis zu und konstruiert damit eine spezifische Gruppenidentität als Wissensgemeinschaft. Die im Anspiel gezeigte und von ihm vorgelesene biblische Begebenheit hat damit einen geringen Neuigkeitswert. Dies wird auch visuell kontextualisiert, indem der Prediger eine abtönende, der Relativierung dienende Handbewegung ausführt, mit der er darauf verweist, dass die Kenntnis des thematisierten Bibeltextes von ihm als

\footnotetext{
${ }^{2}$ Mit dem Pronomen „wir“ referiert der Prediger auf die spezifische Arbeitsteilung in der Vorbereitung des Gottesdienstes. So weist er die alleinige Verantwortung für das Thema und die Inhalte des Wortbeitrags zurück und verweist auf das Vorbereitungsteam, das gemeinsam über das Thema des Gottesdienstes und auch über den für die Predigt relevanten Bibeltext spricht. Die Hervorhebung des Satzes der Maria und die Irritation darüber ist also keine alleinige Beobachtung des Predigers, sondern eine des gesamten Predigt-Vorbereitungsteams.
} 
gemeinsam geteilter Wissensbestand (AB-event) angenommen wird. Um dies zu verdeutlichen, wird der entsprechende Transkriptausschnitt nachfolgend nochmal mit den Zeichen des ISWA gezeigt.

Beispiel 24.2: abtönende Handbewegung

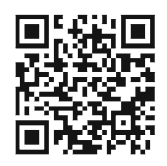

$\rightarrow 40 \quad(1.5)^{\circ} \mathrm{h}$ ihr KENNT alle die geschichte.

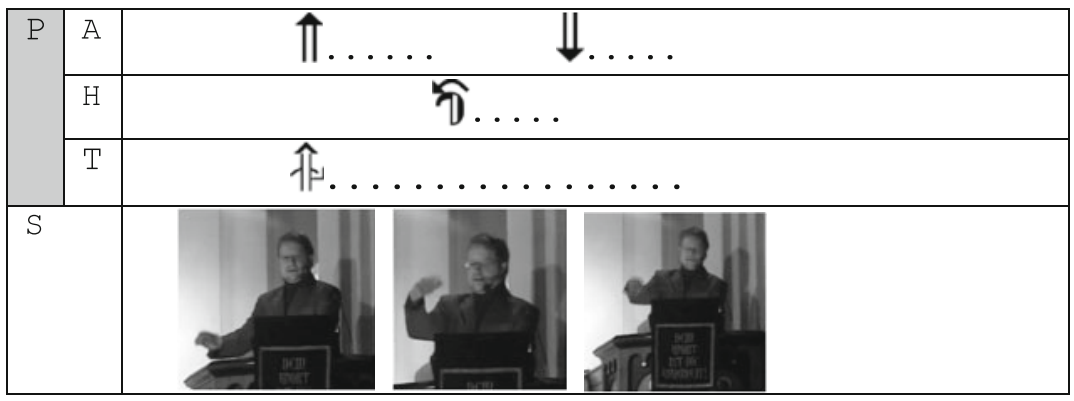

Der Prediger hebt dazu seine rechte Hand vom Kanzelrand ( $\uparrow$, Z.40) und beschreibt mit abknickendem Handgelenk ( $\curlyvee$, Z.40) einen Bogen vor seinem Körper und führt den Arm wieder nach unten $(\downarrow$, Z.40). Gleichzeitig mit der Geste verändert der Prediger auch die Position seines Oberkörpers, indem er der Bewegung der Hand folgt und seine Schultern nach links bewegt und dabei gleichzeitig mit dem Oberkörper nach oben geht ( $\hat{\equiv}$, Z.40).

In diesem Wortbeitrag bleibt die mit hoher epistemischer Gewissheit geäußerte Zuschreibung jedoch nicht einfach eine Annahme, sondern wird durch den Prediger geprüft und bestätigt, indem er dem deklarativen Wissen der Textkenntnis das individuell situative Erfahrungswissen der Anwesenden gegenüberstellt und so seine Wissensbehauptung stützt: „mal MELden wer hatt_n alles schon maria im krIppenspiel geSPIELT $(1.0)<$ p, behaucht, $(\dot{)}>$ ne:h>ja GUCKT mal ihr habt das Alle schon mal an euch erLEBT wart alle schon mal so HILFSschwanger und so ne?" (Z.42-49).Der Prediger bricht hier den Kanzelmonolog unter erhöhtem interaktivem Aufwand auf und fordert von den anwesenden Personen eine Reaktion in Form einer Meldung auf seine Frage ein (siehe Abschnitt 17.3.2). Dies bestätigt seine Wissenszuschreibung 
als korrekt: Die sich meldenden Personen haben bereits bei einer speziellen religiösen Aktivität (einem Krippenspiel zu Weihnachten) mitgewirkt und kennen daher die vom Prediger thematisierte Geschichte. Es wird dadurch nicht nur eine Wissensgemeinschaft konstruiert, sondern auch eine Praktikengemeinschaft. Darüber hinaus nutzt der Prediger die erfolgte Reaktion, um das Erfahrungswissen der Predigtrezipienten zu aktivieren (ihr habt das ALLE schon mal an euch erLEBT, Z.47). Dazu dient auch in diesem Auszug das Rückversicherungssignal (ne?, Z.49) als Form des ,progression check“ (Schleef 2006:934). Bei der zugeschriebenen und explizit erfragten Kenntnis der Geschichte und der Thematisierung der biblischen Personen bleibt der Prediger jedoch nicht stehen. Der eigentliche Fokus des Predigers liegt nicht auf der Geschichte, wie Maria durch den Engel von ihrer Schwangerschaft erfährt, sondern auf dem Fortgang des Textes (Z.51). Nachdem er den Bibeltext gelesen hat (Lk 1,39-56; nicht im Transkript abgebildet), nimmt er erneut eine Wissenszuschreibung gegenüber der Gemeinde vor (ich denke die meisten von euch KENNen diesen bibeltext, Z.54). Im Gegensatz zur ersten Zuschreibung trifft der Prediger keine kollektive Aussage mehr über das vorhandene Wissen der Anwesenden, sondern differenziert zwischen Personen, die das Wissen haben, und denen, die das Wissen nicht haben: aus zuvor „ALLE“ wird nun "die meisten von euch“. Der Prediger schreibt also einem Teil der anwesenden Personen einen hohen epistemischen Status und die Kenntnis des Textes zu $(\mathrm{K}+)$ und einem, wenn auch kleineren Teil, einen niedrigen epistemischen Status und ein Nichtwissen (K-). Aus einem vermeintlichen A-event wird durch die Veränderung des Pronomens ein geteiltes $\mathrm{A} / \mathrm{AB}$-event. Zudem reduziert der Prediger seine epistemische Gewissheit darüber, wie gesichert seine Aussage ist, und markiert die Wissenszuschreibung als subjektive Annahme, d. h. als Vermutung darüber, was ein bestimmter Teil der Anwesenden wissen könnte. Mithilfe einer initial platzierten epistemischen Markierung in Form des mentalen Verbs, denken ' und eines Personalpronomens 1. Pers. Sg. (ich denke, Z.54) verweist der Prediger auf seinen eigenen kognitiven Zustand und gibt die in der ersten Zuschreibung gemachten „Verallgemeinerungsansprüche“ (Deppermann 2015:16) auf. Die epistemische Sicherheit seiner Zuschreibung nimmt er dann in der Folge noch weiter zurück, indem er eine über die Kenntnis des reinen Textes reichende tiefere Einschätzung der theologisch-semantischen Deutungsdimensionen anspricht (aber ich weiß nicht ob euch bewUsst ist was da passIERT, Z.56) und damit implizit auch darauf verweist, dass er dieses Wissen als eher nicht vorhanden annimmt. Der Prediger spricht in diesem kurzen Auszug aus seinem Wortbeitrag also unterschiedliche Wissensterritorien an, schreibt unterschiedliche Wissensbestände als bei unterschiedlichen Teilen der Gemeinde bekannt 
und unbekannt $\mathrm{zu}$ und verdeutlicht, dass er aufgrund der je unterschiedlichen Zugangsmöglichkeiten $\mathrm{zu}$ den Wissensterritorien unterschiedlich gesicherte Aussagen über das Vorhandensein des Wissens treffen kann:

- In Bezug auf seine eigene Textkenntnis kann er absolut gesicherte Aussagen treffen und sich selbst als wissend positionieren.

- In Bezug auf die Textkenntnis der Gemeinde über die Geschichte der Berufung der Maria schreibt er mit einer hohen epistemischen Sicherheit (,,ihr kennt") ein kollektiv geteiltes Wissen zu (,alle“). Die Sicherheit erhält er zum einen durch die Kenntnis der Gemeinde, zum anderen über das Wissen um religiös-kulturelle Rituale (traditionelle Aufführung der Berufungsgeschichte zu Weihnachten) und schließlich durch die Rückversicherung über die Richtigkeit seiner Annahme durch die Etablierung einer Dialog-Sequenz mit den anwesenden Personen.

- In Bezug auf die Textkenntnis der weiteren Geschichte (Marias Besuch bei Martha) schreibt der Prediger nur noch einem Teil der Anwesenden das Vorhandensein des Wissens zu (,die meisten von euch“) und nimmt die epistemische Sicherheit schrittweise zurück (,ich denke").

- In Bezug auf die Deutung des vorgelesenen Bibeltextes markiert er große epistemische Unsicherheit (,ich weiß nicht") und trifft somit keine konkreten Zuschreibungen. $\mathrm{Zu}$ diesem Wissensterritorium des tatsächlich vorhandenen Wissens der Rezipierenden reklamiert er keinen Zugang.

In den Wortbeiträgen der hier untersuchten Predigten wird von den Predigern immer wieder die epistemische Konstruktion ,ich weiß nich“ produziert, die ein Nicht-Wissen des Predigers anzeigt. In der bisherigen Forschung wurde diese Formulierung vor allem als Markierung von Nicht-Wissen im Anschluss an eine Frage oder als epistemic hedge innerhalb von multi-unit-turns untersucht (vgl. z. B. Lindström et al. 2016 und Helmer et al. 2017). Dabei wurden verschiedene epistemische, pragmatische und propositionale Funktionen herausgearbeitet (vgl. Helmer et al. 2017:377). Wird die Konstruktion von Predigern in deren Wortbeiträgen geäußert, verweisen diese damit auf die Zugänglichkeit bestimmter Wissensterritorien und nehmen gleichzeitig ihre Wissensautorität zurück. So markiert der Prediger im obigen Beispiel mithilfe der ,ich weiß nicht'-Konstruktion einen niedrigen epistemic stance gegenüber den kognitiven Zuständen der Anwesenden und schreibt diesen gleichzeitig einen exklusiven Zugang zu ihren subjektiven Wissensbeständen zu. Das mentale Verb ,wissen “ verweist in den meisten interaktionalen Kontexten und auch in Wortbeiträgen christlicher Predigten auf ,a speaker's state of access to some piece of knowledge, 
or in the negated form, a lack of such access" (Lindström et al. 2016:73). Sehr markant ist im oberen Beispiel die adversativ gebrauchte Konjunktion ,aber“ (Z.56), die auf diese komplexe (Nicht)Zuschreibung bestimmter Wissensbestände verweist, die gemachte Unterscheidung zwischen reiner Textkenntnis und inhaltlicher Einordnung der Geschichte verdeutlicht und die schrittweise Zurücknahme epistemischer Sicherheit zu ihrem Schlusspunkt führt. Die Konstruktion „,ich weiß nich" stellt dabei sowohl in Zeile 25 als auch in Zeile 56 eine Praktik der epistemische Selbstpositionierung des Predigers dar und kennzeichnet den Umstand der Unzugänglichkeit zum Wissensterritorium fremder Erfahrungen, Erinnerungen etc. (B-event). Der Prediger stellt somit die Fähigkeit der anwesenden Personen ,to access or keep in mind some prior knowledge or experience" (Lindström et al. 2016:73) heraus mit dem Hinweis, dass er darüber keine Aussagen treffen kann. Funktional wird die negative epistemische Markierung in christlichen Predigten dann gebraucht, um die Vermittlung bestimmter Wissensbestände zu legitimieren. Durch die prototypisch monologische Realisierung des Wortbeitrags ist ein Ausgleich des Wissensdefizits auf Seiten des Predigers nicht erwartbar. So ging es in Zeile 25 um die nochmalige Wiederholung eines bereits gehörten Satzes und in Zeile 56 um exegetisches Wissen, bei dem unklar bleibt, ob die Gemeinde darüber verfügt oder nicht. In beiden Fällen räumt der Prediger die Möglichkeit ein, dass die anwesenden Personen das thematisierte Wissen bereits haben, sich noch erinnern können oder die theologische Deutungsdimension bereits erfasst haben.

So rechtfertigt auch der Prediger im nachfolgenden Beispiel die von ihm gegebene Definitionen des Begriffs ,Lobpreis‘ über seine Offenbarung des Nicht-Wissens bezüglich der Einstellung der Anwesenden:

\title{
Beispiel 25: Lobpreis
}

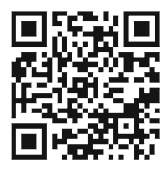

\author{
47 P: ${ }^{\circ}$ hh OKAY. \\ $\rightarrow 48$ ich WEIB nich ähm- \\ 49 mit welcher einstellung ihr in den lobreis \\ REIngeht; \\ 50 aber lobpreis ist n STÜCK- \\ 51 oder $n$ Ausdruck davon jesus zu LIEben.
}


Der Prediger verweist auch hier explizit auf die Unzugänglichkeit des Wissens um die Gefühle und inneren Haltungen (Einstellungen) der Anwesenden. Die Formulierung ,ich WEIß nich ähm mit welcher einstellung ihr in den 1obreis REIngeht; " (Z.48 und 49) erscheint sequenziell als Prä-Sequenz zu einer sich anschließenden Definition des Begriffs ,Lobpreis“: „Lobpreis ist_n STÜCK oder n Ausdruck davoN jesus zu LIEben." (Z.50 und 51). Ähnlich wie im vorherigen Beispiel nutzt der Prediger hier den Verweis auf sein eigenes Nicht-Wissen, um bestimmte Inhalte zu kommunizieren. Dass diese in der Auseinandersetzung und Differenz mit den Wissensbeständen der Anwesenden stehen können, zeigt auch hier die adversative Konjunktion ,aber“ (Z.50).

In den untersuchten Wortbeiträgen wird die Konstruktion „ich weiß nicht“ stets in der syntaktischen Realisierung Subjekt - negiertes Verb - Objekt(Satz) erkennbar. Zunächst formuliert der Prediger die epistemische Markierung (ich WEIß nicht), an die sich der Referent anschließt, also dasjenige Wissen bzw. die Kenntnis, über die der Prediger keine Aussagen treffen kann bzw. das Territorium, zu dem der Prediger keinen Zugang hat. In den meisten Fällen folgt dann eine Ergänzung, in der der Prediger den thematisierten Gegenstand näher bestimmt, Begriffe definiert, mögliche innere Einstellungen darstellt oder relevant gesetztes Bibeltextwissen vermittelt. Die Konstruktion , ich WEIß nicht“ als negative epistemische Markierung hat damit einen prospektiven Verweischarakter auf noch zu äußernde Sachverhalte und rechtfertigt zukünftige Handlungen des Predigers. Die Legitimierung der Wissensvermittlung entsteht gerade durch den explizit angezeigten Grad des Nicht-Wissens des Predigers, das aufgrund des Gattungsformats des Wortbeitrags als Bühnenformat mit der Interaktionsordnung one-face-to-many-faces nicht ohne erhöhten kommunikativen Aufwand erfragt und damit das Wissensdefizit überwunden werden kann (siehe Abschnitt 17.3.2). Die negative epistemische Markierung ,ich weiß nicht' ist in Predigten also keine Antwort auf eine Informationsfrage, in der der epistemic stance einer Person als zweiter Paarteil formuliert wird (vgl. Lindström et al. 2016:74) oder ein epistemischer Diskusmarker, sondern sie verhandelt den Zugang zu Wissensterritorien in der Form von Selbstpositionierungen und verweist damit auf B-events im Sinne Labovs (siehe Abschnitt 16.1). In einem der untersuchten Wortbeiträge wurde der Mangel an Wissen und Zugänglichkeit zu Wissen vom Prediger zudem nicht nur dazu genutzt, um bestimmte Inhalte und Äußerungen zu wiederholen, sondern auch, um eine grundsätzliche Abgrenzung zwischen ihm und Gott aufzubauen. Letzterem wird dabei im Gegensatz zum Prediger die Zugänglichkeit zu Wissensterritorien wie Gefühlen, Einstellungen, Erinnerungen und Erfahrungen zugeschrieben. Mit der epistemischen Markierung werden vom 
Prediger gleichzeitig zwei unterschiedliche Handlungen ausgeführt. Zum einen kennzeichnet er seinen eigenen epistemischen Status (K-) und schreibt zum anderen den anwesenden Personen einen bestimmten epistemischen Status $(\mathrm{K}+) \mathrm{zu}$. Insgesamt produzierten sieben Prediger 35 Äußerungen mit der epistemischen Markierung ,ich weiß nicht" in 15 der untersuchten Predigten.

Die gezeigten Auszüge aus unterschiedlichen Wortbeiträgen christlicher Predigten haben deutlich gemacht, dass sich die Prediger implizit und explizit mit den vorhandenen bzw. nicht vorhandenen Wissensbeständen der anwesenden Personen auseinandersetzen und darauf verweisen, indem sie Wissen bzw. Nicht-Wissen und damit einen hohen oder niedrigen epistemischen Status gegenüber der Gemeinde zuschreiben. Gegenstand der Zuschreibungen sind vor allem Wissensbestände hinsichtlich

- spezifischer (religiöser) Praktiken und Traditionen (Religionswissen; Abschnitt 16.3.1). Diese werden in den meisten Fällen als common ground vorausgesetzt und bleiben unexpliziert. Dazu gehört auch das Wissen über den Aufbau der Bibel und wie auf die einzelnen biblischen Texte verwiesen wird (Bibelwissen),

- überindividueller Glaubensgewissheiten (Moralwissen; Abschnitt 16.3.5),

- die Kenntnis biblischer Texte und biblischer Personen (Bibeltextwissen; Abschnitt 16.3),

- individueller Erfahrungen der anwesenden Personen (Exegesewissen und Glaubenswissen).

Neben diesen Aspekten thematisieren die Prediger auch unterschiedliche kontextuelle Wissensbestände bezogen auf den im Wortbeitrag gelesenen biblischen Text (siehe Abschnitt 16.3 und 16.7). Hinsichtlich dieses Wissens schreiben die Prediger in den meisten Fällen ein Nicht-Wissen auf Seiten der Gemeinde zu. Abbildung 16.1 fasst noch einmal die in den untersuchten Wortbeiträgen erkennbaren Zuschreibungsformen und die Wissensbestände, die typischerweise vom Prediger $(\mathrm{P})$ der Gemeinde $(\mathrm{G})$ zugeschrieben werden, zusammen.

Wissenszuschreibungen können in den Wortbeiträgen christlicher Predigten zu jedem Zeitpunkt realisiert werden, sowohl im Vorfeld einer Textlesung als auch im Nachgang. Gegenstand der Zuschreibung sind Wissensbestände bezüglich des gesamten Bibeltextes, einzelner Aspekte und Begebenheiten, bestimmter Personen oder auch nur spezifischer Begriffe, die ggf. näher ausgeführt werden. Darüber hinaus wird auf das Erfahrungswissen der anwesenden Personen referiert, das dann in eine direkte Relation zum jeweiligen biblischen Text gestellt wird. Die 


\begin{tabular}{|c|c|c|}
\hline \multicolumn{2}{|c|}{ Episemischer Status } & \multirow[b]{2}{*}{$\begin{array}{l}\text { Wissensbestand } \\
\text { - Kenntnis biblischer Texte und bibli- } \\
\text { scher Personen [Personenwissen] } \\
\text { - überindividuelle Glaubensgewissheiten } \\
\text { [Glaubenswissen und Moralwissen] } \\
\text { - religiöse Praktiken und Traditionen der } \\
\text { eigenen Religion [Religionswissen] }\end{array}$} \\
\hline $\begin{array}{l}\mathbf{P}(\mathbf{K}+) \\
\mathbf{G}(\mathbf{K}+) \\
(=>\text { O-events) }\end{array}$ & $\begin{array}{l}\text { Der Prediger schreibt sich und } \\
\text { der Gemeinde einen hohen epis- } \\
\text { temischen Status zu. Der thema- } \\
\text { tisierte Wissensbestand gilt als } \\
\text { bekannt und von allen Anwesen- } \\
\text { den geteilt (common ground) }\end{array}$ & \\
\hline $\begin{array}{l}\mathbf{P}(\mathbf{K}+) \\
\text { Teil von } \mathbf{G}(\mathbf{K}+) \\
\text { Teil von } \mathbf{G ( K - )} \\
(=>\mathrm{A} / \mathrm{AB}- \\
\text { events) }\end{array}$ & $\begin{array}{l}\text { Der Prediger schreibt sich und } \\
\text { einem Teil der Gemeinde einen } \\
\text { hohen epistemischen Status und } \\
\text { das Vorhandensein des Wissens } \\
\text { zu. Dem anderen Teil der Ge- } \\
\text { meinde jedoch schreibt er einen } \\
\text { niedrigen epistemischen Status } \\
\text { zu. }\end{array}$ & $\begin{array}{l}\text { Kenntnis biblischer Texte und bibli- } \\
\text { scher Personen [Personenwissen] }\end{array}$ \\
\hline $\begin{array}{l}\mathbf{P}(\mathbf{K}+) \\
\mathbf{G}(\mathbf{K}-) \\
(=>\text { A-events) }\end{array}$ & $\begin{array}{l}\text { Der Prediger schreibt sich einen } \\
\text { hohen und der Gemeinde einen } \\
\text { niedrigen epistemischen Status } \\
\text { zu. Der thematisierte Wissens- } \\
\text { bestand gilt als unter den Rezi- } \\
\text { pierenden nicht bekannt. }\end{array}$ & $\begin{array}{l}\text { Wissen zum Kontext des biblischen } \\
\text { Textes (historische, kulturelle und reli- } \\
\text { giöse Einordnung) [Bibelwissen] } \\
\text { - Kenntnis biblischer Texte und bibli- } \\
\text { scher Personen (meist nur bei Evangeli- } \\
\text { sationen) [Personenwissen] } \\
\text { - religiöse Praktiken und Traditionen der } \\
\text { eigenen Religion (meist nur bei Evan- } \\
\text { gelisationen) [Religionswissen] } \\
\text { - religiöse Praktiken und Traditionen an- } \\
\text { derer Religionen (v.a. Judentum) [Reli- } \\
\text { gionswissen] }\end{array}$ \\
\hline $\begin{array}{l}\mathbf{P}(\mathbf{K}-) \\
\mathbf{G}(\mathbf{K}+) \\
(=>\text { B-events })\end{array}$ & $\begin{array}{l}\text { Der Prediger schreibt sich selbst } \\
\text { einen niedrigen epistemischen } \\
\text { Status und damit Nicht-Wissen } \\
\text { zu, während die Gemeinde über } \\
\text { den Wissensbestand verfügt. Ihr } \\
\text { schreibt der Prediger einen ho- } \\
\text { hen epistemischen Status zu. }\end{array}$ & $\begin{array}{l}\text { Individuelle Erfahrungen und Erinne- } \\
\text { rungen der Gemeinde [Glaubenswis- } \\
\text { sen] }\end{array}$ \\
\hline
\end{tabular}

Abb. 16.1 Übersicht Wissenszuschreibung

Prediger selbst verorten sich dabei in einem komplexen Gefüge zwischen Wissensbeständen, die vom Prediger und der Gemeinde in gleicher Weise geteilt werden und der Unzugänglichkeit zu unterschiedlichen Bereichen und Territorien des Erfahrungswissens und den kognitiven Zuständen der Anwesenden. Die Rezipierenden des Wortbeitrags werden dadurch zu kompetenten Beteiligten, die hinsichtlich ihres Umgangs mit der Bibel, der Kenntnis biblischer Geschichten und Personen sowie in Bezug auf ihre individuelle Glaubensbiographie als Wissensträger kategorisiert werden. Die Prediger schwächen zudem immer wieder ihren vermeintlichen Expertenstatus ab oder heben ihn auf und zeigen damit eine „Nichtbeanspruchung primärer epistemischer Rechte“ (Reineke 2016:198). Im 
Falle von , ich weiß nicht" und anderen, als B-event markierten Wissensbeständen, wird der Expertenstatus gar auf die Gemeinde übertragen.

Die Frage ist nun, warum Prediger in ihren Wortbeiträgen explizite und implizite Wissenszuschreibungen vornehmen. Die gezeigten Auszüge machen in diesem Zusammenhang deutlich, dass die Wissensannahmen Teil des spezifischen Rezipientenzuschnitts sind (vgl. zur Abstimmung von Äußerungen auf den Wissensstand der Rezipierenden Heritage 2013:373). Aufgrund der Charakteristik der Predigt als Bühnenformat und der Notwendigkeit der Mehrfachadressierung haben die Prediger auch hinsichtlich der Wissenszuschreibungen die Heterogenität der Anwesenden im Blick und markieren diese u. a., indem sie die Gültigkeit bzw. den Grad der epistemischen Gewissheit bezüglich der Zuschreibungen einschränken. Dies geschieht z. B. durch Subjektivierungen mithilfe von mentalen Verben (,ich denke'; , ich glaube'), Differenzierungen in der Adressierung (,ihr alle', , die meisten von euch') oder von Selbstoffenbarungen hinsichtlich nicht vorhandener oder nicht zugänglicher Wissensbestände (,ich weiß nicht'). Die Zuschreibungen variieren dabei je nach der Zusammensetzung der Gemeinde. Während in speziellen Zielgruppengottesdiensten (wie die gezeigten Jugendgottesdienste) expliziter Bezug auf die Wissensannahmen des Predigers genommen wird, bleiben diese in Sonntagsgottesdiensten, bei denen die Gemeinde dem Prediger vertrauter ist, i. d. R. implizit. Darüber hinaus werden die Wissenszuschreibungen dazu genutzt, um zum einen Wissensbestände, die als bekannt angenommen werden, zu aktualisieren, dadurch eine Verstehenssicherung zu ermöglichen und ggf. das unterschiedlich stark vorhandene Wissen innerhalb der Gemeinde und damit ein mögliches Wissensdefizit zwischen den anwesenden Personen auszugleichen. Reineke spricht von einer face-wahrende Funktion der Wissenszuschreibung: Die Zuschreibung ,schützt die jeweiligen Sprecher [...] vor einem möglichen Vorwurf der Redundanz, da sie ihre Äußerungen selbst schon vorab als redundant rahmen“ (Reineke 2016:197). Dies lässt sich auch in den untersuchten Wortbeiträgen beobachten. Wie die Ausführungen in dieser Arbeit gezeigt haben, kann diese Rahmung im Wortbeitrag sowohl vor der möglicherweise redundanten Äußerung erfolgen als auch nachträglich.

Zum anderen dient vor allem die Zuschreibung von Nichtwissen dazu, die Vermittlung neuen Wissens zu legitimieren. In den meisten Fällen handelt es sich dabei um Wissensbestände, die helfen sollen, einen thematisierten Bibeltext zu verstehen und die im Text beschriebenen Handlungen und Ereignisse nachzuvollziehen. Welche Wissensbestände dabei vermittelt werden und welche Praktiken dazu von den Predigern genutzt werden, ist Gegenstand des nachfolgenden Kapitels. 


\subsection{Wissensvermittlung in Predigten}

Christliche Verkündigungen legitimieren sich aus dem biblisch tradierten Lehrauftrag, der das Evangelium, also die Rettungs- und Liebesbotschaft Gottes an die Welt, weiterzusagen vorgibt (vgl. Mt.28,18-20, Mk.16,15-16, Apg.2,42, Kol.3,17, Tim.1,5). Es ist dort von ,lehren' bzw. ,unterweisen' die Rede und dem Weitererzählen der Geschichten, Gleichnisse und Gebote Jesu. Der Prediger, in der theologischen Tradition der Apostel, wird gleichsam zu einem Lehrer, der biblisches Wissen und göttliche Aussagen tradiert (vgl. Engemann 2008:130) und dabei nicht nur wörtliche Überlieferungen weitergibt, sondern auch deren (inter)subjektive Deutung vornimmt (die theologische Literatur spricht von ,Auslegung '/,Exegese') und die gegenwärtige Relevanz und die Aktualität biblischer/göttlicher Aussagen aufzeigen soll (vgl. u. a. Härtner/Eschmann 2008:17, Weißenborn 2008:37). Die Aufgabe des Wortbeitrags besteht also aus theologischer Perspektive in der Weitergabe, Vermittlung und Vergegenwärtigung des Evangeliums - speziell vor dem Hintergrund der aktuellen Lebenswelt der Rezipierenden (vgl. Engemann 2015:122). Dieser Anspruch ist dabei konfessionenübergreifend relevant (vgl. aus katholischer Perspektive Bundschuh-Schramm 2009:149 f. und aus evangelischer Perspektive Danzeglocke 2009:151): ,altes', aber nach wie vor als gültig betrachtetes biblisches Wissen soll in seiner Aktualität so vermittelt werden, dass die Anwesenden seinen Wert in der Gegenwart erkennen und daran ihr Leben ausrichten. Diese Anforderung ist Gegenstand zahlreicher homiletischer Auseinandersetzungen, die es immer wieder als herausforderndes Problem christlicher Verkündigung betrachten, unter den Verhältnissen des 20. und 21. Jahrhunderts gelingend zu predigen (vgl. Daiber 1991, Engemann 2002 und 2008; siehe Kapitel 6). Eine zentrale Rolle spielen dabei die biblischen Texte, die von den Predigern in vielen Fällen mit einer übergeordneten Autorität aufgeladen werden. „Predigt ist deshalb im Kern immer Auslegungspredigt. Sie arbeitet an der Schrift, versucht, sie in ihrem Selbstverständnis zu erfassen und dann der Gemeinde zu entfalten und als Anrede Gottes nahezubringen“ (Klippert 2008:22). Viele Homileten betonen in diesem Sinne den unmittelbaren Bezug zwischen biblischem Text und Wortbeitrag und sprechen von der Predigt als „Überlieferungsprozess“ (Engemann 2002:238). Das Verstehen des biblischen Textes ist jedoch nur ein Teil des Überlieferungsprozesses, dem zwingend ein zweiter Schritt nachgestellt sein muss: die Predigtrezipierenden sollen unter Anleitung des Predigers und unter Bezugnahme auf den (historischen) biblischen Text ,sich selbst als von Gott geliebt, erlöst und erwartet wahrnehmen“ (Engemann 2002:238). In diesem Sinne definiert Mertens die Predigt als ,eine öffentliche Verkündigung von religiös gegründeter Glaubens- und Verhaltenslehre 
durch einen damit beauftragten Vertreter einer Religionsgemeinschaft" (Mertens 2009:575) und bestimmt neben den Merkmalen der Interaktionsordnung und der Institutionalität auch die Lehre, und damit die Tradierung und Vermittlung unterschiedlicher Wissensbestände, als zentrales Merkmal christlicher Predigten. Dass es jedoch zu kurz greift allein von ,Glaubens- und Verhaltenslehre' zu sprechen, zeigen die nachfolgenden Ausführungen, denn sowohl grundlegende glaubenskonstitutive Aspekte (wie Glaubensgewissheiten) als auch moralische Aspekte bilden nur einen Teil dessen, was Prediger in ihren Wortbeiträgen tatsächlich vermitteln.

Der homiletische Blick auf Wissen und Überlieferung führt darüber hinaus zu kontroversen Diskussionen vor allem mit Blick auf historisch-kritische Zugänge zu den Bibeltexten (vgl. Schneider 2016:194). Die Frage ist dabei, ob die Erarbeitung eines Wortbeitrags auf historisch-kritischen Recherchen basieren und wie präsent die Ergebnisse dieser Bibeltextbetrachtung in einem Wortbeitrag sein sollten (vgl. Schneider 2016:195). Die scharfe Trennung in Befürworter und Gegner einer historischen Betrachtung biblischer Texte mag mit dazu beigetragen haben, dass der Begriff des Wissens innerhalb der homiletischen Forschung nur sehr vorsichtig und unter großem Legitimierungsaufwand verwendet wird. Nichtsdestotrotz gilt es zu reflektieren, dass Wissen, wie die nachfolgenden Kapitel zeigen werden, in unterschiedlichen Ausprägungen und Arten, eine zentrale Rolle in den Wortbeiträgen christlicher Predigten spielt, denn

[d]er biblische Text entstammt einer fremden Zeit, einem fremden Kontext. [...] Die Texte selbst sind einer anderen Zeit und Kultur zuzuordnen und daher von der Gegenwart mit einem ,garstgen Graben' getrennt. Damit wird zweitens aber klar, dass die Bibel ein von mir Fremdes ist, ich damit keinen unmittelbaren Zugang zu den Texten habe, alle Texte der Interpretation, der Auslegung bedürfen. (Schneider 2016:204)

In den untersuchten Wortbeiträgen wird deutlich, dass diese Fremdheit vor allem hinsichtlich religiöser, historischer, kultureller und sprachlicher Unterschiede besteht und von den Predigern explizit und implizit markiert und bearbeitet wird. In der vorliegenden Arbeit wird in diesem Zusammenhang von ,Distanzen “ gesprochen, die zwischen dem Bibeltext mit den darin geschilderten Ereignissen und den Predigtrezipierenden im 21. Jahrhundert bestehen. Am häufigsten wird dann Bibeltextwissen vermittelt. Dabei handelt es sich zum einen um das grundlegende Wissen über biblische Personen und biblisch tradierte Begebenheiten (siehe Abschnitt 16.3.4). Zum anderen geht es um spezifisches Kontextwissen. Die Prediger stehen hier in der Auseinandersetzung mit den biblischen Texten, um herauszuarbeiten, ,was der Text in seinem Kontext bedeutet“ (Keller 
2017:23f). Nach Keller ist das zunächst ein dreifacher Kontext: a) die Einordnung des jeweiligen Textes im Verhältnis zur unmittelbaren Textumgebung (bzw. zum jeweiligen Buch), b) im Verhältnis zur gesamten Bibel (dem kanonischen Kontext) und c) die Einordnung des Textes in den sozio-kulturellen Kontext seiner Zeit. Dabei füllen die Prediger im Bibeltext vorhandene Leerstellen durch die Vermittlung als unbekannt zugeschriebener kultureller, religiöser, politischer und sozio-ökonomischer Wissensbestände. Zusätzlich geben sie Erklärungen und Begründungen für die im Bibeltext geschilderten Ereignisse und interpretieren die Motive für das Handeln der im Text dargestellten Personen. Auffällig ist in diesem Zusammenhang, dass die Prediger zunächst Wissen bezüglich der Kenntnis der Texte, der darin handelnden Personen, der gemachten Aus- und Zusagen Gottes und auch bezüglich grundlegender Glaubensüberzeugungen gegenüber der Gemeinde zuschreiben (siehe Abschnitt 16.2). Dies dient in allen Fällen als Ausgangspunkt für die Vermittlung spezifischer, neuer und als unbekannt zugeschriebener Wissensbestände. Es ist also zunächst ein Schritt des Predigers den jeweiligen biblischen Text als ein historisches Dokument zu erfassen, dessen spezifische Entstehungs- und Überlieferungsgeschichte es zu reflektieren gilt (vgl. Engemann 2002:238). Wie Engemann (vgl. 2006:119) richtig bemerkt, impliziert die Vermittlung von Bibelwissen, Bibeltextwissen und Kontextwissen nicht das Verstehen des Textes, aber die Prediger der hier untersuchten Wortbeiträge nutzen neben anderen Verfahren auch die Wissensvermittlung, um die Herstellung von Intersubjektivität zu ermöglichen.

Da die vorliegende Arbeit keine Wirkungsforschung betreibt, können keine Aussagen darüber getroffen werden, welche Wissensbestände von den Rezipierenden tatsächlich aufgenommen werden, also an welche Aspekte des Wortbeitrags sich die Gemeinde erinnert und ob ein Verstehen erreicht wird. Die hier durchgeführte Analyse hat vielmehr das Ziel, anhand authentischer Wortbeiträge empirisch-qualitativ die Praktiken herauszuarbeiten, die von den Predigern eingesetzt werden, um Intersubjektivität zu ermöglichen und ein Verstehen zu initiieren. 


\subsubsection{Vermittlung von Religionswissen (religiöse Distanz)}

Die religiöse Distanz zeigt sich vor allem da, wo die Prediger die Bibel als ein Dokument konzeptualisieren, in dem die Geschichte des jüdischen Volkes und seine Beziehung zu Gott aufgezeichnet ist. Daran schließt sich die Frage an, was jüdische Traditionen mit christlichen Glaubenstraditionen zu tun haben, warum und in welchem Maße die biblischen Texte nach wie vor - auch für Christen - gültig sind und glaubenskonstitutive Kraft besitzen. In der Auseinandersetzung mit dieser religiösen Distanz und dem damit verbundenen Religionswissen leisten die Prediger nicht nur Vermittlungsarbeit, sondern auch eine komplexe gruppenstiftende Identitätsarbeit, die die anwesenden Personen zu einer Wissens- und Glaubensgemeinschaft formt. So verweist der Prediger in den nachfolgenden zwei Auszügen aus einem Jugendgottesdienst explizit auf die Kategoriensets Christen und Juden, während er sich in seinem Wortbeitrag mit der Frage auseinandersetzt, wie Jesus gebetet hat und welche Relevanz dieses Wissen für die anwesenden Personen und ihre eigene Glaubenspraxis haben kann. Dabei betont er, dass es sich um in der jüdischen Religion verankerte Praktiken handelt und dass diese für die anwesenden Personen fremd sind. Nach einer Begrüßung, der Selbstvorstellung des Predigers und einer längeren Hinführung auf das Thema des Wortbeitrags, liest der Prediger den Predigttext (Lk 11,1-4). Im Anschluss daran nennt der Prediger das Thema und den Gegenstand des Wortbeitrags. Es schließt sich eine erste Sequenz der Vermittlung von Religionswissen an, in der der Prediger auf den Religionsgründer John Wesley (Methodisten) eingeht. Bevor er sich dann näher mit dem gelesenen Bibeltext auseinandersetzt, spricht der Prediger ein eingeleitetes lautes Gebet, das er mit ,Amen“ abschließt (siehe Abschnitt 15.1.4). Das Transkript setzt nach dem Gebet ein. 
Beispiel 26: Wie Juden beten

356 P: wisst ihr wir haben einen wUnderbaren(.) MEISter.

357 JEsus. (-)

358 und ich wIll von ihm LERnen.

$359{ }^{\circ} \mathrm{h}$ und DESwegen-

360 lAsst uns mal kurz einen augenblick drauf SCHAUen,

361 wie jEsus geBEtet hat.(2.0)

$362{ }^{\circ} \mathrm{h}$ im lukasevangelium lesen wir ganz VIEL darüber. $=$

363 =wie das gebEtSleben von JEsus aussah;

364

365

366

367

368

369

370

371

372

373

374

375

376

$\rightarrow \quad 377$

378

379

380

381

382

383

384

385

386

es lohnt sich das NACHzustudieren.

und das RAUSzufinden.

es geSCHAH-

so begInnt unser TEXT;

${ }^{\circ} \mathrm{h}$ als er an einem ORT war;

und BEtete.

jEsus der sohn gottes WAR,

oder besser gesagt jesus der sohn gottes IST, ein BEter. (2.0)

und wie jEsus geBTtet hat-

kriegen wir lEider aus diesem text nicht

RAUS.

das is SCHAde.(1.0)

aber wir kriegen das RAUS; (2.0)

wenn wir ins Alte testaMENT schaun.

wir lernen bei lukas WANN jesus gebetet hat, nähmlich HÄUfig,

REgelmäßig,

MoRgens,

an stIllen ORTen,

an EINsamen plätzen, (2.0)

${ }^{\circ} \mathrm{h}$ und im ALten testament kannst du

RAUSbekommen, wAs jesus geBEtet hat.

${ }^{\circ} \mathrm{h}$ du musste dir VORstellen? 


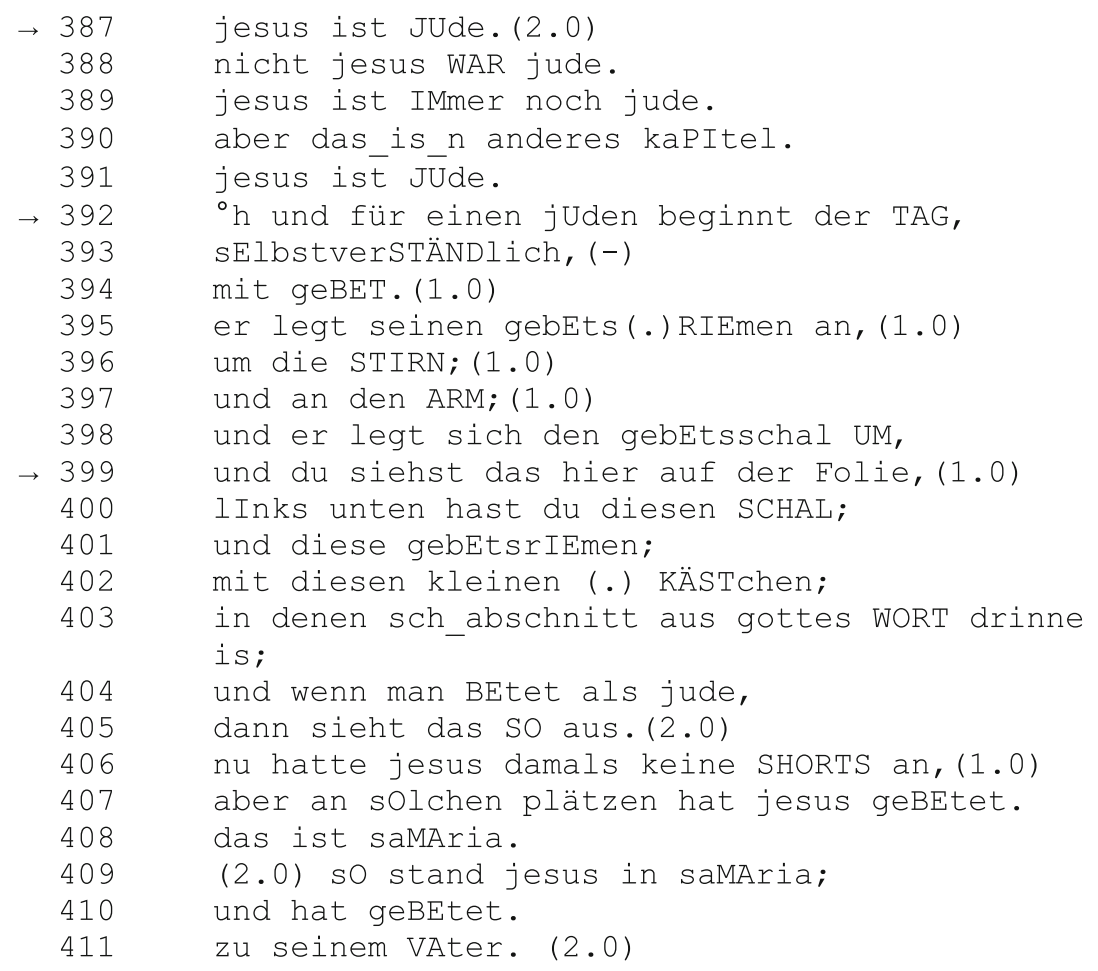

Auf der Grundlage des Bibeltextes setzt sich der Prediger mit dem Gebetsleben Jesu auseinander und ordnet dazu die im Text dargestellten Ereignisse in ihren religiösen Hintergrund ein. Damit füllt er textliche Leerstellen und schreibt das vermittelte Wissen implizit als nicht vorhanden, aber notwendig zu wissen zu. Zunächst stellt der Prediger die Relevanz der biblisch basierten Wissensvermittlung heraus, indem er die Autorität Jesu betont: ,wir haben einen wUnderbare MEISter JEsus und ich wIll von ihm LERnen"

(Z.356-358). Durch den Gebrauch des Personalpronomens „,ich“ (Z.358) positioniert sich der Prediger selbst als Lernender und nicht in erster Linie als Lehrender. Auf der Oberfläche nimmt er dadurch einen persönlichen Wissensvorsprung und eine Wissensautorität zurück, indem er sich einer höheren Instanz unterstellt und sich einen niedrigen epistemischen Status zuschreibt (K-). Mit Blick auf den weiteren Verlauf des Wortbeitrags, die Positionierung der 
Äußerung und die Rolle der Person als Prediger zeigt sich jedoch, dass es sich um eine rhetorische Kaschierung handelt und dass der Prediger tatsächlich einen hohen epistemischen Status mit Blick auf das relevante Religionswissen hat. Das Pronomen ,ich` erhält dadurch den Charakter eines Kollektivierungspronomens (im Sinne von, wir alle müssen von Jesus lernen'). Darüber hinaus wird die Autorität des Predigers dadurch aufgeladen, dass die Wissensvermittlung an dieser Stelle damit begründet wird, dass der Prediger ein Lernender ist. In diesem Zusammenhang kategorisiert er auch die übrigen Anwesenden implizit als Lernende mit einem niedrigen epistemischen Status (,ich bin ein Lernender, also seid ihr auch Lernende; ${ }^{\circ} \mathrm{h}$ und DESwegen lAsst uns mal kurz_n augenblick drauf SCHAUen wie jEsus geBEtet hat, Z.359-361). Das ,lernen“ knüpft der Prediger direkt an den für die Predigt relevanten Bibeltext ( ${ }^{\circ} \mathrm{h}$ im lUkasevangelium lesen wir ganz VIEL darüber wie das gebEtsleben von JEsus aussah, Z.362-363) und benennt damit eine erste Wissensquelle. Diese ist auch den anwesenden Personen zugänglich. Der Prediger kennzeichnet das Wissen darüber, wo die Informationen zum Gebetsleben Jesu zu finden sind, als potentiell durch Bibellektüre erwerbbar und damit nicht als exklusives Expertenwissen (es 1Ohnt sich das NACHzustudieren und das RAUSzufinden, Z.364-365). Es folgt eine Wiederholung des Bibeltextes (Z.366-368) und eine Charakterisierung Jesu (jesus der sohn gottes IST ein BEter, Z.371-372), die eine Schlussfolgerung des Predigers aus dem gelesenen Text darstellt. Der Prediger zieht so eine Linie vom Bibeltext zum Thema des Wortbeitrags und begründet die Relevanz seiner Ausführungen mit der Autorität biblisch tradierter Begebenheiten. Zusätzlich verweist er intertextuell auf andere Bibelstellen, wenn es um die genaue und konkrete Ausformung der Religionspraktik des Betens geht (aber wir kriegen das RAUS wenn wir ins Alte testaMENT schaun, Z.376-377). Die Vermittlung dieser Wissensbestände begründet der Prediger schließlich mit einer grundlegenden kulturellen und vor allem religiösen Distanz zwischen den anwesenden Personen und dem Bibeltext: „ ${ }^{\circ} \mathrm{h}$ du musste dir VORstellen? jesus ist JUde."(Z.386-387). An dieser Stelle positioniert sich der Prediger implizit als Experte $(\mathrm{K}+)$ und schreibt den anwesenden Personen in dieser Hinsicht einen niedrigen epistemischen Status zu (K-; A-event). Der Prediger kennzeichnet damit zugleich, dass Jesus außerhalb des Traditionsbereichs der anwesenden Personen gehandelt und auf eine andere Art und Weise gebetet hat, als dies Christen in Europa im 21. Jahrhundert tun. Der Prediger steht in diesem Zusammenhang vor der Herausforderung, der Gemeinde zu verdeutlichen, dass sie an einen Juden glauben und dass sie, um ihren eigenen Glauben und die Aussagen Jesu, wie sie in den biblischen 
Texten tradiert sind, verstehen zu können, das Judentum und seine spezifischen Traditionen kennen sollten bzw. müssen. Die Aufgabe des Predigers ist es nun, das (alte) Judentum mit dem (modernen) Christentum in Verbindung zu setzen und für die Anwesenden als fremd und unbekannt unterstellte Wissensbestände über die Praktiken einer anderen Religionsgemeinschaft und damit spezifisches Religionswissen zu vermitteln. Dazu bedient er sich u. a. medialer Ressourcen, indem er das Bild eines betenden Juden über PowerPoint visualisiert (Z.399) und das damit verbundene Wissen, wie (orthodoxe) Juden beten, verbal vermittelt (Z.392-405). Von den gegenwartsbezogenen Informationen schließt er auf die im Bibeltext gegebenen Leerstellen und impliziert dadurch einen Kontinuitätsanspruch der thematisierten Religionspraxis. In diesem Auszug vermittelt der Prediger also sowohl Bibelwissen (Unterschied zwischen Altem und Neuem Testament) als auch Bibeltextwissen (Jesus betet) und darauf aufbauend Religionswissen, indem er Kontextwissen zu dem gelesenen Bibeltext bereitstellt. Dieses wird dadurch zu einem für den Prediger relevanten Wissensbestand, der für das Verstehen des Bibeltextes notwendig ist. Aufgrund der Zuschreibung von Nichtwissen auf Seiten der Gemeinde legitimiert der Prediger seine Handlung der Wissensvermittlung.

Ein zweiter Auszug aus demselben Wortbeitrag zeigt sowohl die vom Prediger angenommene religiöse Distanz als auch den Zusammenhang von Wissensannahmen und Wissensvermittlung noch einmal deutlich auf. Es ist darüber hinaus eines jener seltenen Beispiele, in denen der Prediger seine Wissensannahme prüft. 


\section{Beispiel 27: Gottes Name}

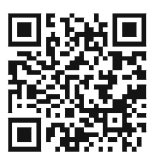

530 P: WEIBt du, (-)

531 wenn nicht jEsus geSAGT hätte. (-)

532 sAg doch EINfach (.) !VA!ter.

533 wenn ihr bEtet so sprecht VAter. (-) wenn es nicht jEsus (.) AUSgesprochen hätte; = =wenn es nicht gott SELber ausgesprochen hätte. (-)

536 wäre das eine Absolute ! UN! geheuerlichkeit. (1.5)

$\rightarrow 537$ wir sind von allen dingen die die juden betreffen weit WEG.(1.5) wir haben wEnig erFAHrung gemacht; =ich vermute niemand von EUCH, (-) KENNT, (-) und wir sind von vIelen dingen WEG, die diesen (.) die diesen jüdischen kontext der bibel AUSmachen.=

553 =deswegen will ich uns das (.) will ich uns das SAgen.=

554 =weil das wIchtig ist dass wir das verSTEHen. (1.0)

$\rightarrow 555$ ein Jude,

556 spricht gottes Namen, (.) 


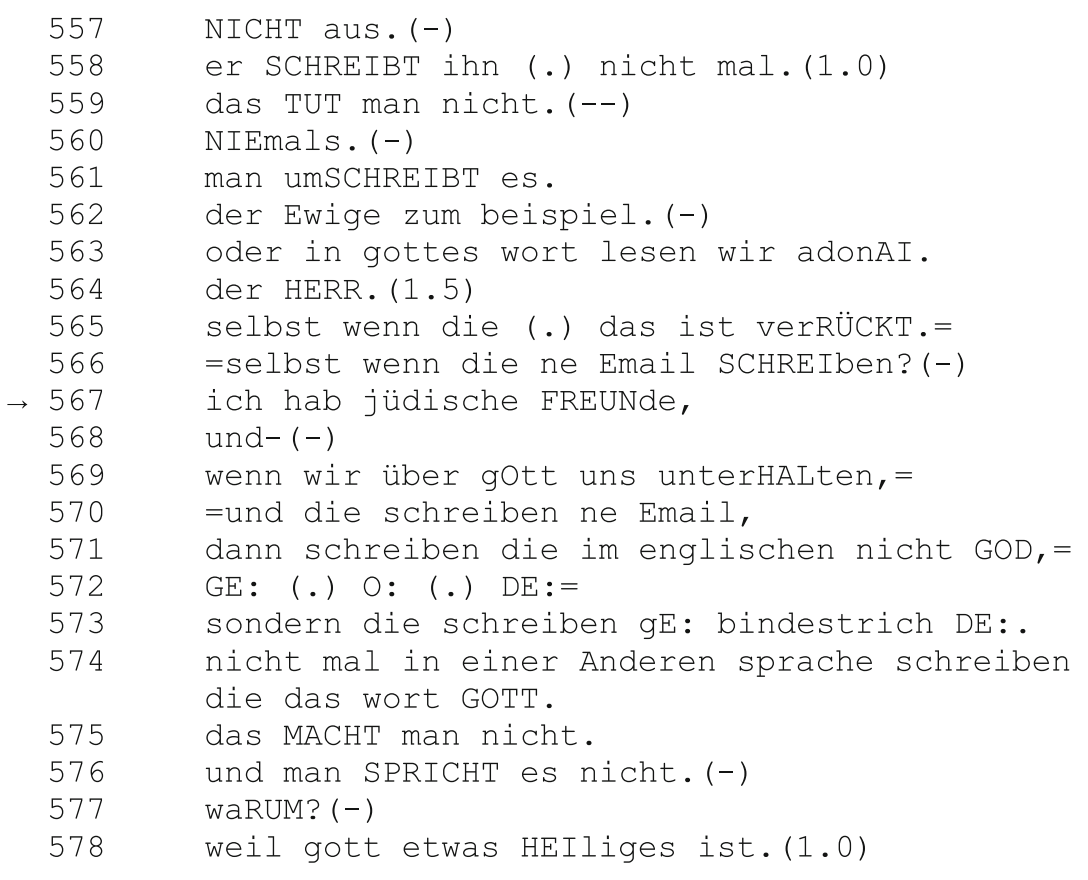

Unmittelbar vor dem hier gezeigten Auszug hat der Prediger das VaterUnser (Lk 11,1-4) als Teil des Predigttextes vorgelesen. Nun begründet er im Verweis auf diesen Bibeltext die christliche Glaubenspraxis, Gott den Schöpfer als ,Vater ${ }^{\text {" }}$ zu adressieren, als durch Jesus legitimiert und grenzt sie von der jüdischen Glaubenspraxis ab (wenn es nicht gott SELber ausgesprochen hätte. (-) wäre das eine Absolute !UN!geheuerlichkeit, Z.535-536 und ,ein JUde sprIcht gottes NAmen NICHT aus er SCHREIBT ihn (.) nicht mal, Z.555-558). Der Prediger setzt damit die Differenzierung zwischen Judentum und Christentum, die bereits in dem zuvor gezeigten Auszug deutlich wurde, fort, aktualisiert sie und expliziert die Annahme einer bestehenden religösen Distanz (wir sind von allen dingen die die jUden betreffen weit WEG, Z.537 undwir sind von vIelen dingen WEG, die diesen (.) die diesen jüdischen kontext der bibel AUSmachen, Z.551-552), die er mit dem Pronomen „wir“ als für alle anwesenden Personen (als Teil der größeren Kategorie 
,Christen') gültig benennt. Zunächst bestimmt er also hinsichtlich religiöser Glaubenspraktiken ein kollektives Nichtwissen (K-; D-event).

Wie der weitere Verlauf des Wortbeitrags jedoch zeigt, positioniert sich der Prediger auch in diesem Teil des Wortbeitrags als Wissensträger mit einem hohen epistemischen Status. Zuvor äußert er jedoch eine als Vermutung gerahmte Wissensannahme bezüglich des Erfahrungswissens der anwesenden Personen: „ich vermute niemand von EUCH, (-) KENNT, (-) einen JUden. (-) perSÖNlich. von Angesicht zu ANgesicht."(Z.539-543), die die Distanzzuschreibung (Z.537) als gerechtfertigt und richtig stützt. Die epistemische Markierung wird durch das Personalpronomen (ich, Z.539) und das Verb ,vermuten' realisiert, sowie der Referent der Zuschreibung benannt: die Gemeinde (,niemand von EUCH“). Das Erfahrungswissen grenzt er von einem grundlegenden Wissen um die Existenz von Juden ab, das er als vorhanden zuschreibt, aber für das Verständnis des Bibeltextes als nicht ausreichend bestimmt (ihr wisst dass es sie GIBT aber, Z.544). An dieser Stelle bricht der Prediger seine Zuschreibungen ab und unterzieht seine Annahmen einer Prüfung, indem er von den anwesenden Personen eine Ratifizierung verlangt. Dazu fordert er die Gemeinde auf, ein visuell wahrnehmbares Zeichen zu geben, wenn die gemachte Zuschreibung auf sie nicht zutrifft: ,oder würde jemand sagen DOCH ich KENN einen? mal kurz hAnd HOCH?" (Z.546-548; siehe Abschnitt 17.3.2). Er kommentiert daraufhin, dass sich tatsächlich wenige Personen melden und damit einen hohen epistemic stance anzeigen (OKAY. (-) verschwIndende MINderheit, Z.549-550). Allerdings reicht die Anzahl der Meldungen für ihn nicht aus, um seine Annahmen gänzlich zurückzunehmen oder seine Wissensvermittlung aufzugeben. Vielmehr aktualisiert der Prediger seine Annahmen des Nichtwissens nochmals, indem er explizit auf die religiöse Distanz, die durch die biblischen Texte entsteht, verweist und sie als Begründung für die folgenden Explikationen über jüdische Glaubenstraditionen heranzieht (deswegen will ich uns das (.) will ich uns das SAgen. weil das wIchtig ist dass wir das verSTEHen, Z.553-554). Dabei entsteht rhetorisch ein spannungsvolles Verhältnis, denn der Prediger positioniert sich zum einen als Experte (,will ich [...] das SAgen“), der im Gegensatz zur Mehrheit der anwesenden Personen über die vermittelten Wissensbestände verfügt $(\mathrm{K}+)$. Zum anderen positioniert sich der Prediger gleichzeitig als Christ, der das jüdische Spezialwissen normalerweise nicht hat (K-), indem er sich selbst erneut zu einem Teil der gesamten Gruppe macht (Personalpronomen „wir") und sich als jemand ausweist, der das erforderliche Wissen ebenfalls 
notwendig braucht, um den thematisierten Bibeltext einordnen und interpretieren zu können (dass wir das verstehen, Z.554). Daraufhin vermittelt der Prediger das entsprechende Wissen über die jüdische Religionspraxis, den Namen Gottes nicht auszusprechen (Z.555-576) und führt die theologische Begründung dafür an (Z.578).

In diesem Auszug - und in ähnlicher Weise auch in den Wortbeiträgen anderer Prediger - entsteht eine komplexe Zuschreibung und Kategorisierung, in der mithilfe der Personalpronomen zum einen die Wissensasymmetrie angezeigt und der Prediger als Wissensträger markiert wird (Z.552), und zum anderen die Hierarchie verschleiert wird, indem der Prediger zu einem Teil der Gemeinde wird (,uns“). Der Prediger kategorisiert sich gerade auch in diesem Auszug sowohl als Lernender als auch als Lehrender. Seine Expertise stützt er dabei nicht nur auf die Lektüre anderer Experten, sondern auf subjektiv gemachte Erfahrungen, d. h. Wissen aus erster Hand, das er aus dem wiederholten Kontakt zu Juden gewonnen hat, mit denen er sich zudem ein engeres soziales Verhältnis zuschreibt und die er hinsichtlich ihrer eigenen Glaubenspraxis gleichfalls als Experten ausweist (Z.567-572; A-event). Mit dieser kurzen Erzählung markiert der Prediger nicht nur eine große epistemische Gewissheit hinsichtlich der Richtigkeit seiner Aussagen $(\mathrm{K}+)$, sondern auch das grundlegende Recht und die epistemische Autorität, überhaupt Aussagen darüber treffen zu dürfen.

Der Prediger ordnet also die Begebenheiten des Bibeltextes in einen religiösen Kontext ein und füllt in der Vermittlung neuer Wissensbestände textliche Leerstellen auf. Dieses Wissen kontextualisiert er als relevant, um die Bedeutung des Textes zu erfassen und die Tragweite der im Text gemachten Aussagen in der Gegenwart zu identifizieren. Zudem gebraucht der Prediger das Wissen, um nicht nur die Motivation der im Text handelnden Personen aufzuzeigen, sondern aus dem Text heraus grundlegende Religions- und Glaubenspraktiken mit dem damit verbundenen Praktikenwissen zu tradieren. Der Prediger betont in diesem Wortbeitrag die grundlegende Relevanz des Gebets für die anwesenden Personen, thematisiert unterschiedliche Realisierungsformen des Gebets und bespricht die Funktion (Warum sollen wir als Christen überhaupt beten). Die Gemeinde wird dadurch als Glaubensgemeinschaft, Praktikengemeinschaft und Wissensgemeinschaft konstruiert, die über christliche Religionsgrenzen hinweg verortet wird. Dies wird schließlich weitergeführt, indem der Prediger auf der Grundlage des (interpretierten) Textes und den von ihm selbst gemachten Erfahrungen Handlungsoptionen für die anwesenden Personen aufzeigt (siehe Abschnitt 
16.6). Auffällig ist dabei gerade in diesem Wortbeitrag, dass es sich bei der Abfolge ,Textlesung - Textinterpretation/Wissensvermittlung - Übergang zum eigenen Glaubensleben` um einen zirkulären Prozess handelt, der im Wortbeitrag mehrmals mit Blick auf unterschiedliche Abschnitte des gelesenen Predigttextes wiederholt wird.

In ähnlicher Weise setzt auch der Prediger im nachfolgenden Auszug aus einer evangelisch-lutherischen Sonntagsgottesdienstpredigt die Kenntnis jüdischer Glaubenspraktiken für das Verständnis des Bibeltextes relevant. Der Prediger beginnt seinen Wortbeitrag unmittelbar mit dem Füllen textlicher Leerstellen, indem er die Ereignisse, die im Text (Hebräer 4,1-13) beschrieben werden, paraphrasiert und Kontextwissen zum Hintergrund der Entstehung des Hebräerbriefes, dessen Überlieferungsgeschichte und der im Text beschriebenen Personen vermittelt. Zudem fasst er die Kerngedanken des Textes kurz zusammen und bestimmt damit die Relevanz des Textes und des Themas für den Wortbeitrag. Schließlich widmet er sich dem Begriff der Ruhe und in diesem Zusammenhang den Religionskonzepten Shabbat und Sonntag: 


\section{Beispiel 28: Shabbat}

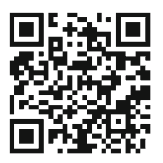

166 P: wir sehen also schon an diesem kUrzen überBLICK;

167 gottes BOTschaft;

168 hat VIEle wege.(-)

169 und was ist mit Uns HEUte? (3.0)

$170{ }^{\circ} \mathrm{h}$ wir mÜssen (.) einen UMweg machen.

171 geDANKIich.

172 um (.) der SPUR des hebräerbriefes, (-)

173 auf den SINN zu kommen.(2.0)

174

175

176

177

178

179

180

181

182

183

184

185

186

187

188 wAs (.) meint ER; (-)

mit dem wort GOTtes?

und wie erreicht es seine ZIEle.

interessAnt ist der gedanke der zuVOR kommt. ( - )

189

er beschreibt ein ZIEL,

das ganze kapItel EIgentlich,

und das IST, (.)

übersetzt MIT,

RUhe finden.

es Ist noch eine RUhe vorhanden;

für das volk GoTtes; =

ist vielleicht- (.)

der (.) bekAnnteste vers aus diesem

ABschnitt.

190

191

dAs kommt unmittelbar zuVOR.(-)

und ist noch etwas SCHWER verständlich-(2.0)

KLArer wird es aber-(2.0)

wenn wir das grIechische originAL

heranziehen. (1.0)

192

$\mathrm{DA} ;(-)$

$\rightarrow 193$

194

STEHT; (-)

195

es geht um die ruhe des schaBAT.(1.0)

196

197

der HEIlige wochentag.(1.0)

an dem die Arbeit RUHT, (2.0)

von ALlem. (2.0)

MÄGde; (--) 


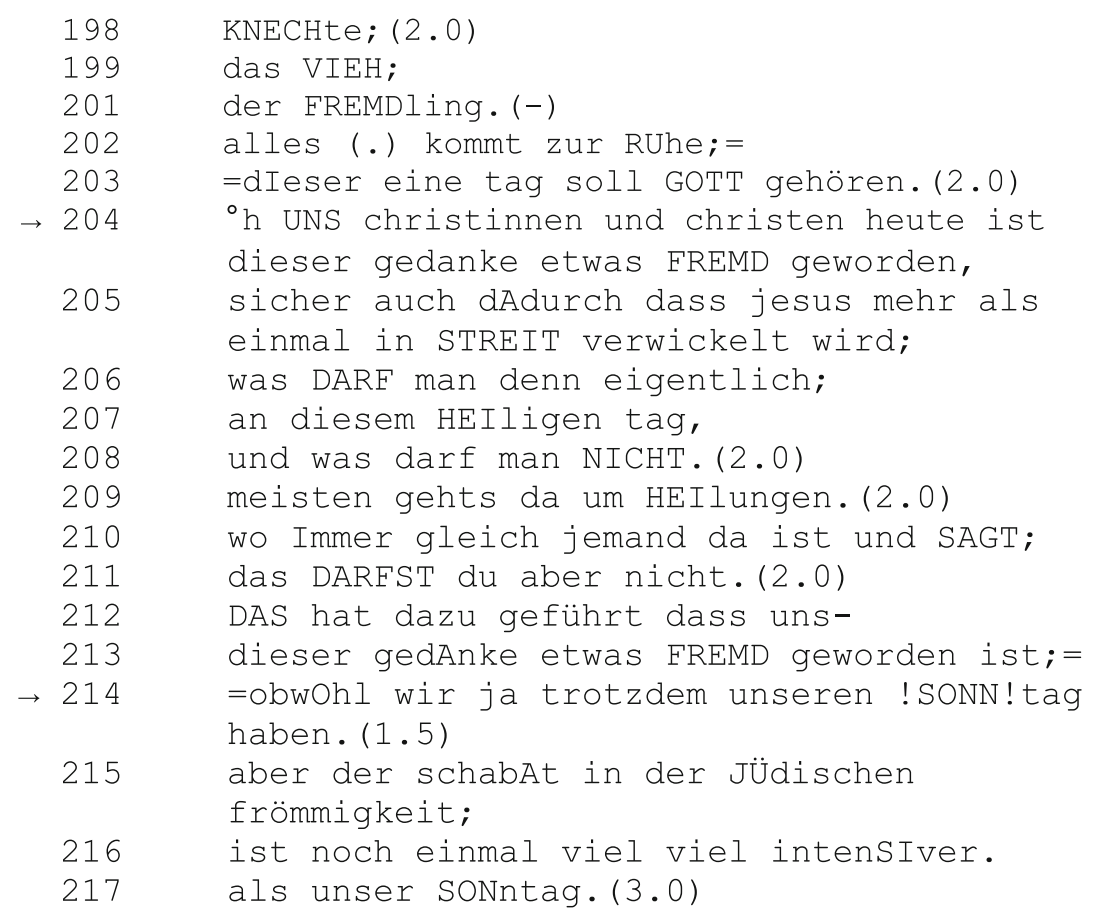

Auf der Grundlage des Bibeltextes (es IST noch eine RUhe vorhanden für das volk GoTTtes, Z.183-184) setzt sich der Prediger mit dem religiösen Konzept und der religiösen Praktik des Shabbat auseinander und stellt ihm die Tradition des christlichen Sonntags gegenüber. Deutlich wird das u. a. durch die inkludierende explizite soziale Kategorisierung „UNS christinnen und christen“ (Z.204), die der Prediger von der - wenn auch in Verbindung stehenden - Religion des Judentums abgrenzt. Darüber kennzeichnet er religiöse Distanzen und durch die Temporaldeixis "heute“ (Z.204) auch zeitliche Distanzen. Für letztere sieht der Prediger die Ursache zudem in der von ihm genutzten Bibelübersetzung (und ist noch etwas SCHWER verstëNDlich KLArer wird es aber wenn wir das grIechische origiNAL heranziehen, Z.188-190; siehe Abschnitt 16.3.3). Diese spricht lediglich von ,Ruhe', während im griechischen Originaltext zusätzlich das hebräische Wort ,Shabbat' zu finden ist (DA STEHT es geht um die ruhe des schaBAT, Z.191-193; siehe 
Abschnitt 16.3.3, Beispiel 34). Die explizit zugeschriebenen Verständnisschwierigkeiten und die Annahme kollektiver Fremdheit im Nachvollzug des Textes (UNS christinnen und christen ist dieser gedanke etwas FREMD geworden, Z.204; D-event) sieht der Prediger also durch die unterschiedlichen Distanzen bedingt. Zur Bearbeitung dieses Problems nimmt er eine inner- und interreligiöse Auseinandersetzung vor. Dazu verweist er auf die äquivalente Funktion der religiösen Praktik des Shabbat auf der einen Seite und des Sonntags auf der anderen Seite. Die Differenzierung expliziert er mit zwei Äußerungen, die jeweils mit adversativisch gebrauchten Konjunktionen eingeleitet werden und die sowohl Entsprechungen als auch konzeptionelle Unterschiede deutlich machen: „obwOh1 wir ja trotzdem unseren !SONN!tag haben. (1.5) aber der schabAt in der JÜdischen frömmigkeit; ist noch einmal viel viel intensIver. als unser sonntag." (Z.214-217). Der Prediger schreibt damit den anwesenden Personen einen niedrigen epistemischen Status (K-) hinsichtlich der Kenntnis der Religionspraktik des Shabbat zu und vermittelt aufgrund dieser Annahme von Nicht-Wissen lexikalisch-semantisches Wissen. Auch die als bekannt zugeschriebene Praxis des Sonntags und seine Bedeutung werden dadurch zu einem Wissensbestand, der zumindest in der Abgrenzung der zwei Religionskonzepte aktualisiert werden muss. Der Bibeltext wird damit als erklärungsbedürftig markiert.

Religionswissen umfasst in den untersuchten Wortbeiträgen jedoch nicht nur als fremd markierte Praktiken und Begriffe z. B. der jüdischen Religionstradition, sondern auch christliche Glaubensgewissheiten. Diese werden in den meisten Fällen als grundsätzlich bekannt zugeschrieben und bedürfen dadurch lediglich der Aktualisierung, nicht aber der gänzlich neuen Vermittlung. Anders verhält es sich lediglich bei evangelistischen Veranstaltungen, bei denen der Wortbeitrag an Personen gerichtet ist, die wenig oder keine eigene Erfahrung mit religiösen Konzepten und Traditionen haben. 


\subsubsection{Vermittlung von Kulturwissen (kulturelle Distanz)}

Neben der religiösen Distanz wird in den untersuchten Wortbeiträgen von den Predigern eine kulturelle Distanz bzw. eine kultur-historische Distanz zwischen dem Text und den anwesenden Personen markiert. Diese ergibt sich vor allem daraus, dass die biblischen Geschichten und Erzählungen im Nahen Osten und Ägypten, Griechenland und der heutigen Türkei verortet werden und zudem in einer anderen historischen Zeit anzusiedeln sind. Die Rezipierenden der in dieser Arbeit analysierten Predigten leben jedoch in Europa, genauer: in Deutschland des 21. Jahrhunderts. Die Unterschiede liegen nicht nur bei klimatischen Gesichtspunkten, sondern auch bei Lebensführung und Lebensrhythmus, Nahrung, Kleidung etc. In diesem Zusammenhang verweisen die Prediger auf die sozio-ökonomischen Systeme der orientalischen Gesellschaften und grenzen die Sozialsysteme, die gesellschaftlichen Normvorstellungen und Lebenswirklichkeiten von den Erfahrungen der anwesenden Personen im 21. Jahrhundert ab. Wird eine kultur-historische Distanz von den Predigern erkannt und zugeschrieben, geht es im Anschluss daran um die Vermittlung von Kontextwissen hinsichtlich übergeordneter sozio-kultureller Wissensbestände, indem z. B. Begriffe und die dahinterstehenden sozialen Konzepte expliziert werden. Sehr deutlich wird dies im nachfolgenden Beispiel aus dem Wortbeitrag einer freien Gemeinde. Der Prediger hat zuvor einen Text aus dem Galater-Brief vorgelesen (Gal. 4,4-7) und setzt sich nun mit dem dort verwendeten Begriff der Sklaverei auseinander, indem er das Konzept und den Text in seinen kultur-historischen Kontext einordnet und semantische Verschiebungen des Begriffs nachzeichnet. 
Beispiel 29: Sklaverei

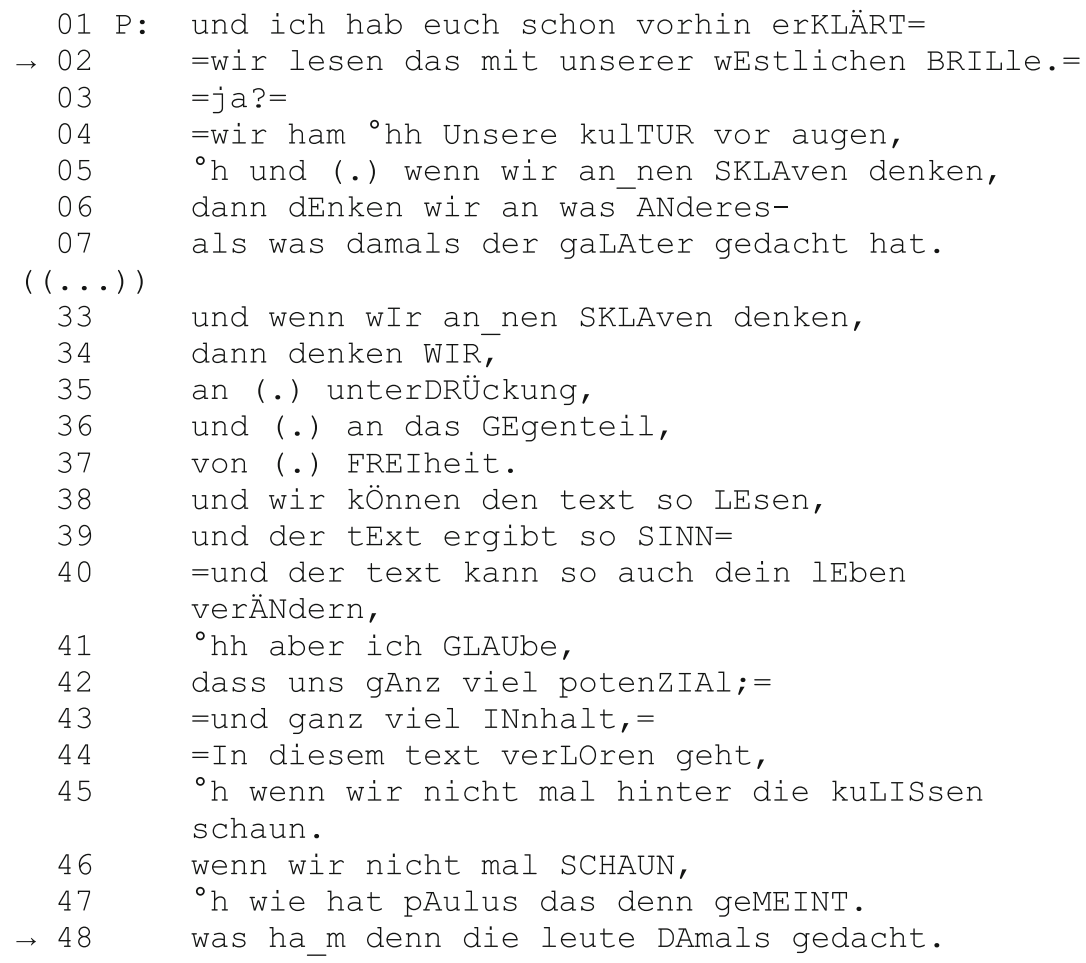

Der Prediger legitimiert seine Ausführungen, indem er die von ihm angenommene kulturelle Distanz zwischen dem Bibeltext und den anwesenden Personen relevant setzt (wir lesen das mit unserer wEstlichen BRILle, Z.2 und ${ }^{\circ} \mathrm{h}$ und (.) wenn wir an_nen SKLAven denken, dann dEnken wir an was ANderes als was damals der gaLAter gedacht hat, Z.5-7). Um aber den Kontinuitätsanspruch und die Überzeitlichkeit des Textes herauszuarbeiten, vermittelt der Prediger zunächst 
kulturbezogenes Wissen und verhandelt dabei das Konzept der Sklaverei. Er bestimmt dabei zunächst die Assoziationen, die ein Mensch im 21. Jahrhundert seiner Meinung nach gegenüber dem Begriff des Sklaven hat (Z.33-37), bevor er auf das Potenzial einer kultur-historischen Kontextbetrachtung für die Deutung des Bibeltextes verweist (Z.41-48). Im Anschluss an diese Positionierung des Predigers vermittelt er das Wissen über die semantische und kultur-historische Dimension und Veränderung des Begriffs des Sklaven zur Zeit der Entstehung des Bibeltextes:

Beispiel 30: Sozialsystem
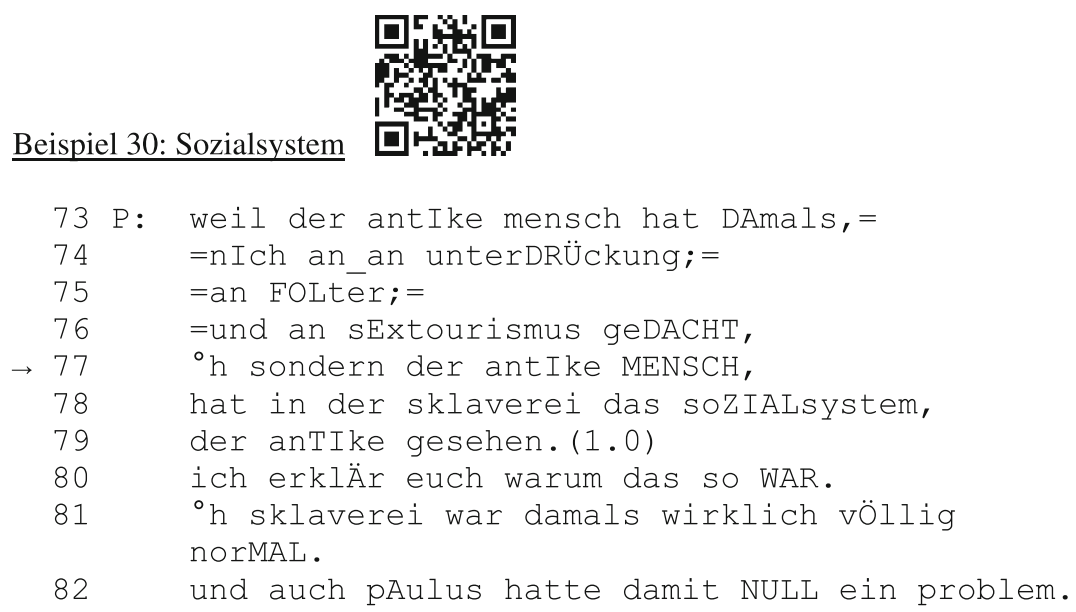

Der Prediger führt den Begriff der Sklaverei weiter aus und stellt die Ansichten der Antike immer wieder denen des 21. Jahrhunderts gegenüber, die jeweils auch mit einem bestimmten Gesellschaftssystem und kulturellen Einstellungen verknüpft sind. Dies zeigt sich hinsichtlich der normativen und moralischen Dimension des Begriffs, der auf der einen Seite negative soziale Handlungen umfasst (Unterdrückung, Folter, Sextourismus, Z.74-76) und auf der anderen Seite ein übergeordnetes soziales System (Z.77). Diese Gegenüberstellung äußert der Prediger mit großer epistemischer Sicherheit und einem hohen epistemic stance $(\mathrm{K}+)$. Der anwesenden Gemeinde schreibt er dabei implizit einen niedrigen epistemischen Status und damit Nichtwissen (K-) zu. Diese Zuschreibung legitimiert die Vermittlung von als unbekannt angenommenem historischem Wissen. Über das neu vermittelte Wissen kommt der Prediger im weiteren Verlauf 
des Wortbeitrags auf grundlegende Glaubensgewissheiten zu sprechen, zieht intertextuelle Bezüge zwischen dem Alten und Neuen Testament und vermittelt weiteres kulturelles Wissen über die altorientalische Art und Weise, Verträge abzuschließen. Auch hier ist die Grundlage für die Vermittlung spezifischer kultur-historischer Wissensbestände eine implizite Zuschreibung von Nichtwissen. Wieder positioniert sich der Prediger explizit als Experte für das Kontextwissen zum thematisierten Bibeltext.

Die Prediger verwenden z. T. viel Zeit dafür, den Text für die anwesenden Personen in seiner Vieldimensionalität aufzuschließen. So lässt der Prediger im nächsten Auszug die im Text benannte Begebenheit (das Pessachfest in Jerusalem) vor den Augen der Gemeinde entstehen, indem er sowohl Religionswissen als auch kulturelles Wissen vermittelt und beide Wissensarten stark aufeinander bezieht. Der Predigttext, der sich mit den letzten Tagen Jesu vor dessen Kreuzigung in Jerusalem auseinandersetzt, wurde unmittelbar vor der Predigt von einem Gottesdienstmitarbeiter vorgelesen (Joh. 12,12-19). Dabei steht die Gemeinde. Im Anschluss an die Textlesung vollzieht der Prediger den Gang zum Predigtort und formuliert die Aufforderung zu einem stillen Gebet, das er laut abschließt (siehe Abschnitt 15.1.3). Danach setzt sich die Gemeinde und der Prediger beginnt seinen Wortbeitrag. 


\section{Beispiel 31: Passah in Jerusalem}

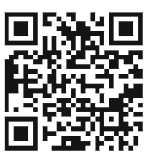

01 P: SEIN, (.)

02 LETZter, (.)

03 WEG, (-)

04 FÜHRT ihn; (.)

05 zum pAssahfest des jahres DREIBig;

$\rightarrow 06$ das sagen zumindest die meisten AUSleger, (-)

07 nach jeRUsalem. (2.0)

08 DORT; $(-)$

$\rightarrow 09$ feiern die juden dieses wIchtigste FEST.

10 PASsah das; (.)

11 erinnert an den Auszug aus äGYPten.

12 das erinnert DAran dass-(-)

13 die israeliten ein VOLK geworden sind;

14 ein volk GoTtes. (---)

15 es ist $n$ WEG der;

16 in die FREIheit geführt hat?(2.0)

17 es gab WUNder der bewAhrung; (-)

18 und diese geburtsstunde am SCHILFmeer.(2.0)

19 passah wurde immer wieder gefeiert jedes jahr $\mathrm{NEU},=$

20 =und immer wieder kamen zu gut dreißg bis fÜnfzigtausend einwohnern jeRUsalems;

21 =zur damaligen ZEIT,

22 HUNdertfünfigtausend pIlger daZU.

23 das kann mer sich heute gar_nimmer VoRstelln.

24 rein loGistisch. (2.0)

25 ( ) josephus ein jüdischer historiker beRICHtet;

26 dass vOr dem PASsahfest-

27 'h IM tempel;

28 prO TAG; (.)

29 etwa fÜnfzigTAUsend lämmer geschlachtet wurden. $(--)$ 


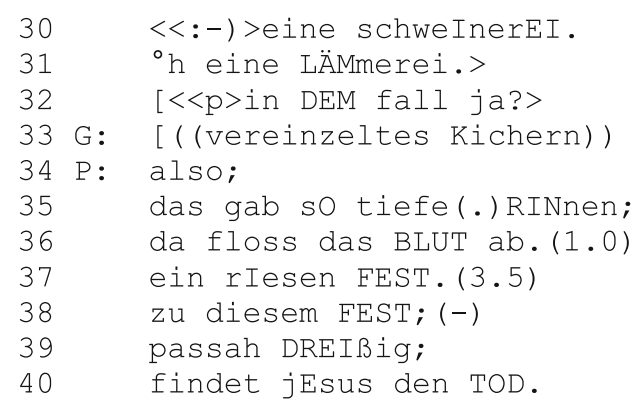

Thematisch setzt sich der Prediger in seinem Wortbeitrag mit den letzten Tagen Jesu auseinander. Dazu bespricht er zunächst eine der Kreuzigung vorausgehende Station im Leben Jesu: Er kommt mit seinen Jüngern nach Jerusalem, um mit ihnen an diesem Ort Pessach zu feiern (Z.1-7). Das Wissen über die Traditionsgeschichte und die rituellen Abläufe dieses Festes werden von dem Prediger implizit als unbekannt zugeschrieben und gleichzeitig für das Verständnis des Predigttextes relevant gemacht. Der Prediger verortet die Begebenheit zunächst historisch (des jahres DREIßig, Z.5) und stützt diese Aussage mit dem Verweis auf Experten (das sagen zumindest die meisten AUSleger, Z.6), bevor er die Ereignisse in ihren religiösen Traditionshintergrund einordnet und damit zunächst Religionswissen vermittelt. Er erklärt der Gemeinde, dass es sich a) um ein jüdisches Fest handelt, das zudem das wichtigste Fest der Juden ist (Z.10), bei dem b) die Juden an den Auszug aus Ägypten (siehe 2. Mose 12) und damit an ihren Gründungsmythos erinnern (Z.10-18). Durch den Verweis auf die Ritualität (passah wurde immer wieder gefeiert jedes jahr NEU, Z.19) ordnet der Prediger das Fest als Teil jüdischer Erinnerungs- und Religionskultur ein und entwirft anschlieBend das Bild des Pessachfestes, wie es im Jahr 30 n.Chr. gefeiert wurde. Dazu zeigt er den sozio-kulturellen Hintergrund auf (Z.20-22, 26-28 und 3840) und veranschaulicht die Situation, indem er u. a. drastische Bilder malt (das gab sO tiefe RINnen; da floss das BLUT ab, Z.35-36) und mithilfe von Zahlen und Relationen das Geschehen einordnet (IM tempel; prO TAG;(.) etwa fÜnfzigTAUsend lämmer geschlachtet wurden, Z.27-28). Diese Schilderung stützt er auf eine Expertenaussage (Z.24) und bewertet das Geschehen immer wieder unter aktuellen Maßstäben (das kann_mer sich heute gar_nimmer VORstelln. rein loGIStisch, Z.23-24 und $<<:-)>$ EIne schweInerEI. Oh eine LÄMmerei. $><<p>$ in DEM fall ja.>, Z.30-32). Nach einer Bewertung (ein RIEsen FEST, Z.37) ordnet der Prediger das als ein historisches Ereignis kontextualisierte 
Geschehen in den zuvor gelesenen Bibeltext ein (zu diesem FEST; (-) passah DREIßig; findet jEsus den TOD, Z.38-40). Dazu zeichnet er das Bild nicht nur vor dem Hintergrund biblischer Überlieferungen, sondern zeigt die außerbiblischen Zusammenhänge auf, um diese schließlich wieder biblisch rückzubinden. Durch die Vermittlung spezifischer Wissensbestände (Kultur- und Religionswissen) schreibt der Prediger den anwesenden Personen einen niedrigen epistemischen Status zu (K-) und arbeitet durch die Herstellung geteilten Wissens an der Überwindung des angenommenen Wissensdefizits. Dieses besteht in diesem Auszug aus der Distanz zwischen der christlichen Kultur der anwesenden Personen und der jüdischen Kultur des im Bibeltext erwähnten Ereignisses des Pessachfestes. So betont der Prediger mehrfach explizit, dass es sich um ein jüdisches Fest handelt, das - so das mögliche implizit-kulturelle Wissen - in der christlichen Religionstradition nicht gefeiert wird und daher erklärungswürdig ist. Auch andere Aspekte jüdischer Tradition expliziert er, indem er Erklärungen anführt und so implizit die von ihm gemachten Zuschreibungen von Nicht-Wissen demonstriert. So werden im weiteren Verlauf des Wortbeitrags vom Prediger die Motivationen der im Bibeltext handelnden Personen aufgezeigt und dabei Kulturund Religionswissen wieder sehr stark miteinander verwoben, denn das Pessachfest und die dabei durchgeführten Handlungen werden sowohl als religiöse als auch als historische und soziale Ereignisse kontextualisiert.

Der Prediger konstruiert sich dabei selbst als Experte mit einem hohen epistemischen Status $(\mathrm{K}+)$, der auch aufgrund unterschiedlicher Quellen von Zeitzeugen und theologischen Experten über bestimmte Wissensbestände verfügt, die er auf Seiten der Gemeinde implizit als nicht vorhanden zuschreibt (A-event), die aber als notwendiges Wissen kontextualisiert werden. Der Prediger nutzt in diesem Auszug die Vermittlung von Wissen und das Füllen von textlichen Leerstellen durch neues Wissen dazu, die angesprochenen Ereignisse und die im Text geschildete Szenerie für die Rezipierenden als soziales, kulturelles und religiöses Ereignis erlebbar und vorstellbar $\mathrm{zu}$ machen. Schließlich thematisiert er die religiöse Bedeutung des Tempels, indem er sie dem Wirkungsanspruch Jesu gegenüberstellt. In diesem Zusammenhang verweist er direkt auf biblische Überlieferungen und führt nicht nur religiöse Glaubensvorstellungen mit konkreten Praktiken eng, sondern auch die (überzeitliche) religiöse Bedeutung Jesu (für Christen in der ganzen Welt - auch im 21. Jahrhundert) mit jüdischen Traditionen und verortet ihn dadurch innerhalb dieses jüdischen Kontextes. 


\subsubsection{Vermittlung von Sprachwissen (sprachhistorische Distanz)}

Die sprachhistorische Distanz hängt eng mit der kulturellen Distanz zusammen und entsteht a) aus dem Abstand zwischen der Entstehung und schriftlichen Fixierung des Alten und Neuen Testaments und der Rezeption im 21. Jahrhundert und b) durch die Verwendung unterschiedlicher Übersetzungen und Übertragungen der biblischen Texte. Die Analyse des Korpus zeigt, dass Prediger vor der Herausforderung stehen, eine häufig sperrige, archaismenhaltige Bibelsprache mit zahlreichen von den Predigern als unbekannt oder unverständlich zugeschriebenen Lexemen für die Rezipierenden aufzuschließen. Immer wieder wird kritisiert, dass in den Wortbeiträgen diese Bibelsprache übernommen wird, die Sprache der Predigt dadurch lebensfern und unverständlich werde (vgl. u. a. Esser 1958:60, Flügge 2016) und Reformen notwendig seien (vgl. Vogt 2009:11). Auf der anderen Seite wird der stilistische Unterschied zwischen Bibelsprache, Predigtstil und Alltagsstil als gattungstypisch und damit auch als gattungskonstitutiv benannt. Dies führt zu einem ambivalenten Verhältnis: „Die Predigtsprache muss sich aus Verständlichkeitsgründen der Alltagssprache annähern, aber gleichzeitig Wert darauflegen, als Sozialform sui generis wahrgenommen zu werden“" (Ebert 2017:315). Bei der Bearbeitung und Überwindung der sprachhistorischen Distanz geht es um die lexikalisch-semantische und etymologische Arbeit an Begriffen sowie den damit verbundenen kulturellen und religiösen Konzepten, die auf der Grundlage einer expliziten und impliziten Zuschreibung von Nicht-Wissen vermittelt werden. Die Prediger sprechen selbst häufig von ,Übersetzungen " und bestimmen damit ihre Handlungen zunächst ethnokategorial. Ein genauerer Blick zeigt jedoch, dass auch aus wissenschaftlicher Perspektive an vielen Stellen im Wortbeitrag Übersetzungen in der Auseinandersetzung mit dem biblischen Text vorgenommen werden.

Die Übersetzungswissenschaften unterscheiden grundsätzlich zwischen ,übersetzen“ (,schriftliche Vermittlung eines Textes in einer anderen Sprache“; Koller 1979:13; im Englischen ,translation') und ,dolmetschen' (,mündliche Vermittlung" eines Textes in einer anderen Sprache“; Koller 1979:13; im Englischen ,interpreting'; siehe dazu auch Stolze 2018:13). Übersetzen meint prototypisch die Übertragung „eines Textes in eine andere Sprache“ (Stolze 2018:9), d. h. den interlingualen Transfer (vgl. auch Jakobson 1987:429). Bezogen auf religiöse Texte entzündet sich die Diskussion dabei nicht nur an der Frage nach der grundsätzlichen Übersetzbarkeit religiöser, mitunter als heilig qualifizierter Texte, sondern auch an der Frage nach dem konkreten Vorgehen. An dieser 
Stelle wird zwischen mehr oder weniger Wort-für-Wort-Übersetzungen und ,inhaltsbearbeitende[n] Übertragungen“ (Koller 1979:89) unterschieden. Weltweit sind die biblischen Texte komplett bzw. teilweise in mittlerweile 3415 Sprachen übersetzt (vgl. Wycliff, Stand 10/2020). ${ }^{3}$ Zudem existieren allein im deutschen Sprachraum über 35 Übersetzungen bzw. inhaltliche Übertragungen, von denen in den letzten Jahren einige eine Revision erfahren haben. ${ }^{4}$ Sowohl in inter- als auch in intralingualen Übersetzungen geht es grundlegend um die „Suche nach Entsprechungen“" (Stolze 2018:54) zwischen der Ausgangssprache (AS) und der Zielsprache (ZS). Die Semantik der übersetzten bzw. übertragenen Begriffe kann dabei unterschiedliche Grade der Äquivalenz aufweisen (siehe zur Diskussion über den Äquivalenzbegriff Stolze 2018:103-106). Diese betreffen sowohl syntaktische als auch semantische und stilistische Aspekte (vgl. Koller 1979:157). Koller unterschiedet in diesem Zusammenhang zwischen fünf Formen der Entsprechung, d. h. potentieller Äquivalente (vgl. Koller 1979:158-168; siehe auch Stolze 2018:55):

- die eins-zu-eins-Entsprechung (ein Ausdruck der AS entspricht genau einem Ausdruck in der ZS),

- die eins-zu-viele-Entsprechung (ein Ausdruck in der AS entspricht mehreren Ausdrücken in der ZS),

- die viele-zu-eins-Entsprechung (mehrere Ausdrücke der AS entsprechen in der ZS nur einem Ausdruck),

- die eins-zu-Null-Entsprechung (ein Ausdruck der AS hat kein entsprechendes Äquivalent in der ZS) und

- die eins-zu-Teil-Entsprechung (der Ausdruck in der ZS entspricht nur einem Teil des Bedeutungsumfangs des Ausdrucks in der AS)

\footnotetext{
${ }^{3}$ Siehe dazu: https://www.wycliffe.net/resources/statistics/ [letzter Zugriff: 04.10.2020] ${ }^{4}$ siehe dazu: https://www.die-bibel.de/bibeln/bibelkenntnis/wissen-bibeluebersetzung/deu tsche-bibeluebersetzungen-im-vergleich/ [letzter Zugriff: 04.10.2020]
} 
In den untersuchten Wortbeiträgen werden von den Predigern sowohl interlinguale als auch intralinguale Übersetzungen genutzt, um als unverständlich zugeschriebene Begriffe aus den biblischen Texten für die Gemeinde verstehbar und anschlussfähig zu machen.

Die nachfolgenden Analysen legen den Schwerpunkt zunächst auf interlinguale Übersetzungen innerhalb der Wortbeiträge christlicher Predigten. Wie die Beispiele zeigen werden, ändert sich in den Wortbeiträgen die typische Richtung interlingualer Übersetzungen, bei der ein unbekannter Begriff einer fremden Sprache in einen Begriff einer bekannten Sprache übersetzt wird. So übertragen die Prediger einen eigentlich bekannten Begriff mit dem Verweis auf die biblischen Originaltexte in den entsprechenden hebräischen oder griechischen Terminus. Einen solchen Fall zeigt der nachfolgende Auszug aus einer evangelischen Traupredigt, die einen Text aus dem ersten Brief des Paulus an die Thessalonicher (den Trauvers des Brautpaares) zur Grundlage hat (1. Thess. 3,12). 
Beispiel 32: Agape

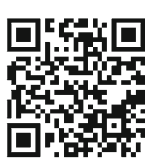

$01 \mathrm{P}$ : < < gelesen>eUch aber lasse der herr WACHsen;

02 und immer REIcher werden;

03 in der liebe untereinANder; $=$

04 =und $\mathrm{zu}$ JEdermann.> (1.0)

$05{ }^{\circ} \mathrm{h}$ das klingt wunderBAR;

06 aber das ist natürlich unglAublich SCHWER. (2.0)

$\rightarrow 07{ }^{\circ}$ hh der apostel paulus schrieb in GRIEchisch,

08 und das grIechische kennt nicht nur verschiedene worte für ARbeit

09 oder GELDverdienen-

10 wie wir ja MERken;

$11{ }^{\circ}$ hh es KENNT auch;

12 verschiedene worte für den begriff LIEbe. (2.0)

13 und so BRÜLLT uns-

$\rightarrow 14$ wenn wir den grIechischen URtext dieses- (.)

15 bibelverses ANschauen;

$16{ }^{\circ} \mathrm{h}$ ein wOrt für LIEbe an;

17 das ganz UnglAublich zu FASsen ist.

$\rightarrow 18$ es heißt (.) a!GA!pe.

19 WÖRTlich übersetzt, (3.0)

20 LIEbe.

21 G: ( (lachen))

22 P: aber eine besondere liebe.(2.0)

23 ein englischer freund hat dieses wort für mich mal überSETZT;

$24{ }^{\circ}$ hh und das hab ich mir geMERKT.

25 den VERS kannst du-

26 mich nachts um zwÖlf WEcken;

27 den kann ich SAgen.

28 agApe ist DIE liebe-

29 die ich dem anderen SCHENke; (--)

30 auch DANN;

31 wenn er gerade nIcht liebenswert IST; (--)

32 aber diese liebe BRAUCHT.

In diesem Auszug ist es der Begriff, Liebe', der zum Gegenstand der Übersetzungstätigkeit des Predigers wird. Auf der Grundlage des zuvor 
gelesenen Bibeltextes (Z.1-4) arbeitet der Prediger die Bedeutung dieses Begriffs heraus, indem er auf den griechischen Originaltext der Bibelstelle verweist (der apostel paulus schrieb in GRIEchisch, Z.7 und und so BRÜLLT uns wenn wir den grIechischen URtext dieses- (.) bibelverses ANschauen, Z.12-14), den relevanten Begriff benennt (es heißt (.) agApe, Z.18), ihn im weiteren Verlauf definiert (agApe ist DIE liebe die ich dem anderen SCHENke; (--) auch DANN; wenn er gerade nIcht liebenswert IST; (--) aber diese liebe BRAUCHT, Z.28-32) und dadurch die unterschiedlichen Bedeutungsdimensionen von ,Agape“ aufzeigt. Nach der Klassifikation von Koller wird dabei zunächst eine eins-zu-eins-Entsprechung zwischen dem Wort ,agape“ (AS Griechisch) und dem Wort ,Liebe', wie es in der vom Prediger genutzten Bibelübersetzung steht (ZS Deutsch), erkennbar: ,es heißt (.) aGApe. WÖRTlich übersetzt, (3.0) LIEbe“ (Z.18-20). Jedoch markiert der Prediger, dass der deutsche Begriff zu unterkomplex sei und bei der Bibelübersetzung Bedeutungskomponenten des Begriffs, agape verlorengegangen sind. Dies ist ein grundsätzliches Problem bei der Übersetzung biblischer Texte (vgl. Stolze 2018:93). Nachdem der Prediger benannt hat, dass der Apostel Paulus in Griechisch geschrieben hat (Z.9), setzt er relevant, dass es im Griechischen verschiedene Worte für den deutschen Begriff ,Liebe gibt (Z.10-13): Das Griechische kennt insgesamt drei unterschiedliche Begriffe für ,Liebe', die jeweils andere semantische Schwerpunkte haben: Eros', die erotische bzw. leidenschaftliche Liebe, ,Philia', die freundschaftliche oder geschwisterliche Liebe und ,Agape،, die Liebe Gottes (vgl. Lattke 1975). Im Neuen Testament werden zwei dieser Begriffe gebraucht: ,philia' und ,agape (vgl. Rienecker/Maier 1998:990, Lattke 1975:11). Damit ergibt sich nach Koller eine eins-zu-viele-Entsprechung zwischen ,Liebe“ (AS Deutsch) und den unterschiedlichen griechischen Begriffen (ZS). Für den hier gezeigten Wortbeitrag ist nun relevant, warum an dieser Stelle des biblischen Textes das Wort ,agape“ steht und nicht ein anderer Liebesbegriff. Der Prediger nimmt zur Verdeutlichung eine inhaltliche Übertragung bzw. Definition vor (Z.28-32). In diesem Auszug ist es also nicht ein Fremdwort, das als unverständlich und schwer nachzuvollziehen markiert wird, sondern ein in der deutschen Bibelübersetzung verwendeter Begriff. Die Besonderheit liegt in den untersuchten Wortbeiträgen gerade darin, dass dieser dann als unterkomplex und in seiner Bedeutung verengt dargestellt wird. Als Lösung für dieses kommunikative Problem wird die Praktik der Rückübersetzung in den biblischen Originaltext und die daran anschließende Definition des Begriffs eingesetzt sowie das dahinterstehende kulturelle und/oder religiöse Konzept vorgestellt. 
Im nachfolgenden Beispiel (siehe auch Beispiel 28) aus einem evangelischen Sonntagsgottesdienst wird der Begriff der Ruhe thematisiert und im Verweis auf den biblischen Originaltext das Konzept des ,Shabbat" vom Prediger eingeführt und diskutiert.

\section{Beispiel 33: Shabbat}

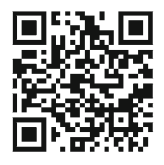

183 es Ist noch eine RUhe vorhanden;

184 für das volk GoTtes; =

185 =ist vielleicht- (.)

186 der (.) bekAnnteste vers aus diesem ABschnitt.

187 DAS kommt unmittelbar zuVOR. (-)

188 und ist noch etwas SCHWER verständlich-(2.0)

189 KLArer wird es aber-(2.0)

$\rightarrow 190$ wenn wir das grIechische originAL heranziehen. (1.0)

191 DA; (-)

192 STEHT; (-)

193 es geht um die ruhe des schaBAT.(1.0)

194 der HEIlige wochentag. (1.0)

195 an dem die Arbeit RUHT, (2.0)

196 von ALlem.(2.0)

$((\ldots))$

212

213

DAS hat dazu geführt dass unsdieser gedanke etwas FREMD geworden ist; = =obwOhl wir ja trotzdem unseren ! SONN! tag haben. (1.5)

215 aber der schabAt in der Jüdischen frömmigkeit;

216 ist noch einmal viel viel intensIver. 217 als unser sonntag.(3.0)

Wie bereits im vorhergehenden Auszug beginnt der Prediger auch hier mit der Lesung aus dem biblischen Text. In diesem taucht der Begriff der ,Ruhe' auf (Z.185), der vom Prediger als ,etwas SCHWER verständlich“ (Z.186) bestimmt wird. Diese Verstehensschwierigkeiten führt der Prediger u. a. auf die genutzte Bibelübersetzung zurück und verweist auf das griechische Original des Abschnitts, in dem von ,Shabbat" bzw. der ,Ruhe des Shabbat" gesprochen 
wird (KLArer wird es aber-(2.0)wenn wir das grIechische origiNAL heranziehen. (1.0)DA; (-)STEHT; (-)es geht um die ruhe des schaBAT.(1.0), Z.187-193). Der Prediger nimmt also eine Rückübersetzung vom deutschen Begriff hin zum hebräischen Begriff, wie er im biblischen Originaltext (griechisch) verwendet wird, vor. Dieses zentrale religiöse Konzept konkretisiert der Prediger nun und erklärt es vor dem Hintergrund der jüdischen Traditionsgeschichte (Kulturwissen) sowie der theologischen Bedeutung (der HEIlige wochentag.(1.0) an dem die Arbeit RUHT, Z.194-195, Religionswissen). Im weiteren Verlauf des Wortbeitrags schreibt der Prediger eine eins-zu-Teil-Entsprechung zwischen dem Begriff des Shabbat und dem Begriff des Sonntags bzw. der Ruhe zu (obwOhl wir ja trotzdem unseren !SONN! tag haben. (1.5)

aber der schabAt in der Jüdischen frömmigkeit; ist noch einmal viel viel intensIver. als unser sonNtag, Z.214-217). Sprachlich markiert wird diese teilweise Äquivalenz durch die adversativisch gebrauchten Konjunktionen ,obwohl' und ,aber'. Als Konsequenz aus dieser Zuschreibung vermittelt der Prediger neue, als unbekannt zugeschriebene Wissensbestände hinsichtlich religiöser und kultureller Aspekte. Die Übersetzung ist also auch hier eine vom Prediger genutzte Praktik, um den biblischen Text für die anwesenden Personen intersubjektiv erfassbar zu machen und bildet u. U. sogar den Ausgangspunkt für die Auslegungen im gesamten Wortbeitrag.

Ähnlich verfährt auch Prediger P2 im nachfolgenden Auszug aus einer Dialogpredigt, bei der zwei Prediger (P1 und P2) gemeinsam einen Wortbeitrag gestalten (siehe Abschnitt 17.4). Im untenstehenden Beispiel stellt P1 eine Frage, auf die P2 antwortet, indem er zur Verdeutlichung seiner Aussage auf den biblischen Originaltext verweist. Neben den bereits vorgestellten Übersetzungsentsprechungen eins-zu-eins, eins-zu-viele und eins-zu-Teil, wird hier eine eins-zu-Null-Äquivalenz deutlich, indem auf einen Begriff verwiesen wird, der im Deutschen im Grunde keine Entsprechung hat. Dass im deutschen Bibeltext dennoch eine Übersetzung vorgenommen wurde, rückt das Entsprechungsverhältnis in die Nähe einer eins-zu-Teil-Übersetzung (vgl. zur Diskussion des Verhältnisses der beiden Entsprechungsformen Koller 1979:167). 


\section{Beispiel 34: Salem 回F稆}

238 P1: wAs ist eigentlich deine beSTIMmung.

$239 \quad(3.0)$

240 P2: ich DENK-(-)

241 an den Anfang der BIbel?

242 da gibts mal so ne AUSsage;

243 die hat mir gehōlfen das so_n bisschen so zu verSTEHen.

$244{ }^{\circ} \mathrm{h}$ da steht dass wir geschAffen sind als (.) BILD.

245 Gottes.

246 oder ebenBILD;

247 als gegenÜber. $=$

248 =und ich hab vor einiger zeit mal gelEsen;

$\rightarrow 249$ dass dort ein wOrt steht im heBRÄischen,

250 SaLEM?

251

252

${ }^{\circ} \mathrm{h}$ was was totAl interessantes beSCHREIBT.

253

und ZWAR-

stellt euch vor die hErrscher (.) der

damaligen ZEIT,

254 die ham überall im königsreich;

255

256

257

dort_a_dort wo sie das SAgen hatten;

258 solche sa! LEMS! aufgestellt.

das waren so ne art STAtuen.

259

und diese st $\bar{A} t u e n$ die hatten die AUFgabe;

260 =sie sollten etwas von dem GLANZ (.) dieses

den herrscher dort zu rEpräsentIEren; =

herrschers signalisieren.

261 sie sollten fÜr ihn dort SEIN;

262

263

so $n$ hInweisschild auf IHN.

264

dort SEIN.(-)

265

266

267

und so geSEhen;

$h^{\circ}$ das wär_ne krasse gescHICHte.

268

wenn wIr solche saLEMS sind;

ja?

269

also- $(-)$

wir sollen-

270

als kInder GOTten;

271

in dieser WELT, (-)

272

so ein hInweisschild auf GOTT sein. 
Auf die Frage ,wAs ist eigentlich deine beSTIMmung“ (Z.238) von P1 antwortet $\mathrm{P} 2$, indem er zunächst auf eine nicht näher bestimmte Bibelstelle verweist $\left({ }^{\circ} \mathrm{h}\right.$ da steht dass wir geschAffen sind als (.) BILD. GoTtes. oder ebenBILD, Z.244-246). Relevant sind dabei die beiden deutschen Begriffe ,Bild Gottes' und ,Ebenbild', denn sie sind es, die der Prediger mit Verweis auf den hebräischen Originaltext zurückübersetzt (dass dort ein wOrt steht im heBRÄischen, saLEM, Z.249250). Diesen Begriff erläutert P2 daraufhin, indem er die kulturelle Bedeutung der damit bezeichneten Gegenstände vermittelt (das waren so_ne art STAtuen. und diese stAtuen die hatten die AUFgabe; den herrscher dort zu rEpräsentIEren, Z.257-259; Kulturwissen). Auf dieser Grundlage zieht er dann eine Analogie zu den anwesenden Personen, indem er seine Aufgabe als Christ mit dem beschriebenen Salem vergleicht (wir sollen als kInder GOTten; in dieser WELT, (-) so ein hInweisschild auf GOTT sein, Z.269-272). Es entsteht ein komplexes semantisches Verhältnis zwischen dem deutschen und dem hebräischen Begriff, denn die Bedeutung des Ebenbildes ist dem Begriff des Salem eingeschrieben, meint darüber hinaus jedoch viel mehr, nämlich einen antiken Gebrauchsgegenstand, den es in der Kultur der Predigtrezipierenden nicht gibt und mit dem sich eine Gesellschaftsstruktur verbindet. ,Salem' ist in dem thematisierten Bibeltext also eine Metapher, die die anwesenden Personen im 21. Jahrhundert nicht mehr entschlüsseln können, die jedoch die Komplexität des Bibeltextes verdeutlicht. In der von P2 in diesem Auszug vorgenommenen Übersetzungsarbeit wird daher eher eine eins-zu-Null-Entsprechung deutlich. Dies verstärkt sich noch dadurch, dass der Prediger den Begriff des Ebenbilds aufgibt und stattdessen den Begriff des Hinweisschilds gebraucht (Z.262 und 272).

Neben der interlingualen Übersetzung spielen in den Wortbeiträgen auch intralinguale Übersetzungen eine Rolle, d. h. die ,interpretation of verbal signs by means of other signs of the same language" (Jakobson 1987:429; Hervorhebung $(D)$. Der gelesene Bibeltext und die darin genutzten Begriffe werden vom Prediger bearbeitet, indem u. a. sinngemäße Übertragungen und Paraphrasierungen vorgenommen werden. Das nachfolgende Beispiel zeigt, wie der Prediger gegenüber den anwesenden Personen zuschreibt, dass der Text aufgrund des in der Bibelübersetzung genutzten Begriffs der Verklärung unverständlich und dadurch langweilig ist. Der Auszug entstammt einer Predigt im Rahmen eines ökumenischen Lobpreisgottesdienstes (Der Videoauszug beginnt in Zeile 19 des Transkripts). 
Beispiel 35: keine Korrespondenz
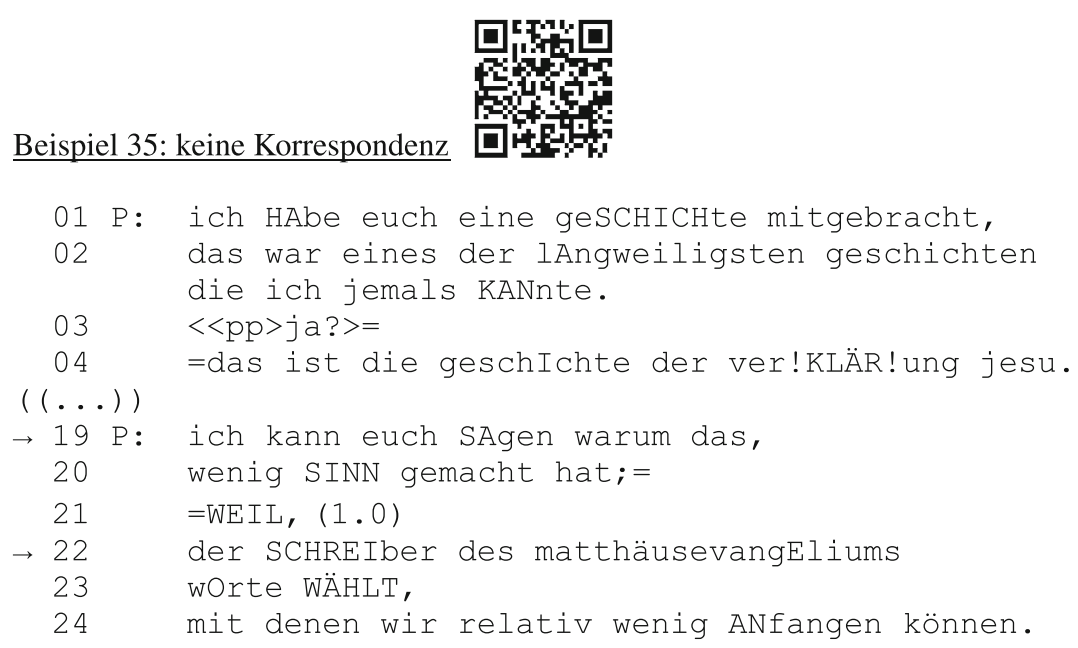

Der Prediger führt den unverständlichen Charakter der biblischen Geschichte auf die Fremdheit der verwendeten Lexik und speziell auf den Begriff der Verklärung zurück, der als abstrakt und nicht im alltäglichen Sprachgebrauch verankert dargestellt wird (ich kann euch SAgen warum das, wenig SINN gemacht hat; WEIL-(1.0) der SCHREIber des matthäusevangEliums WORte wählt, mit denen wir relativ wenig ANfangen können, Z.19-24). Dadurch schreibt der Prediger ein kollektives Verstehensproblem zu (Z.4, K-, D-event). Den Ausgangspunkt für diese Zuschreibung bildet eine von ihm gemachte subjektive Erfahrung mit dem Bibeltext, den er aufgrund der Verstehensprobleme nach eigenen Angaben beim ersten Lesen als langweilig empfunden hat (Z.1-4). Diese Erfahrung überträgt der Prediger nun auf die anwesenden Personen und schreibt ihnen zu, dass es ihnen im Hören des Textes ähnlich gehen wird. Markiert wird dies u. a. durch das Pronomen ,wir“ (Z.23). Der Prediger bestimmt also ausgehend von seinem eigenen ehemals niedrigen epistemischen Status auf Seiten der anwesenden Personen einen niedrigen epistemischen Status hinsichtlich der Kenntnis und des Verstehens des Begriffs, Verklärung' (K-; A-event). Das Ziel des Predigers ist es nun, die Bedeutungsdimensionen dieses Lexems aufzuzeigen und die damit verbundene sprachhistorisch-semantische Distanz zu überwinden, um die Herstellung von Intersubjektivität zu ermöglichen. Dazu paraphrasiert er den Begriff im weiteren Verlauf des Wortbeitrags mit dem Bild des leuchtenden 
Jesus. Darüber hinaus begründet und beschreibt er den allgemeinen Prozess des Lernens mit der Verknüpfung alter und neuer Wissensbestände und spiegelt gleichzeitig die grundlegende Aufgabe der Aktualisierung und Veranschaulichung biblischer Wissensbestände und seine eigene rollenbedingte Positionierung als Experte. Obwohl er zunächst ein kollektives Verstehensproblem zugeschrieben hat, verschiebt der Prediger dieses von einem D-event hin zu einem A-event und konstruiert sich im Verlauf des Wortbeitrags als Experte, der das Problem des Nichtverstehens schon überwunden hat. Aufbauend auf seiner Zuschreibung bearbeitet der Prediger den ganzen Wortbeitrag hindurch den Begriff der Verklärung und dessen semantischen Gehalt.

Der Prediger im nachfolgenden Auszug aus einem ökumenischen Sonntagsgottesdienst verhandelt im Gegensatz dazu einen veralteten Terminus und schreibt dem von ihm gewählten Begriff einen höheren Bekanntheitsgrad unter den Anwesenden zu. Die zentrale Bibelstelle des Wortbeitrags (2. Könige 5) wird, anders als in den bisherigen Beispielen, nicht bereits zu Beginn des Wortbeitrags vorgelesen, sondern Stück für Stück, wobei der Prediger immer wieder unterbricht, um seine Gedanken und Auslegungen vorzustellen. Zudem liest der Prediger den Text nicht nach einer deutschen Übersetzung bzw. Übertragung, sondern aus dem hebräischen Originaltext und übersetzt selbst ad hoc für die anwesende Gemeinde. In diesem Auszug treffen also die interlinguale und die intralinguale Übersetzung zusammen. Dennoch ist vor allem der Prozess der intralingualen Bearbeitung von Interesse, denn der Prediger setzt sich mit seiner eigenen Übersetzung ins Deutsche auseinander. 
Beispiel 36: Naaman
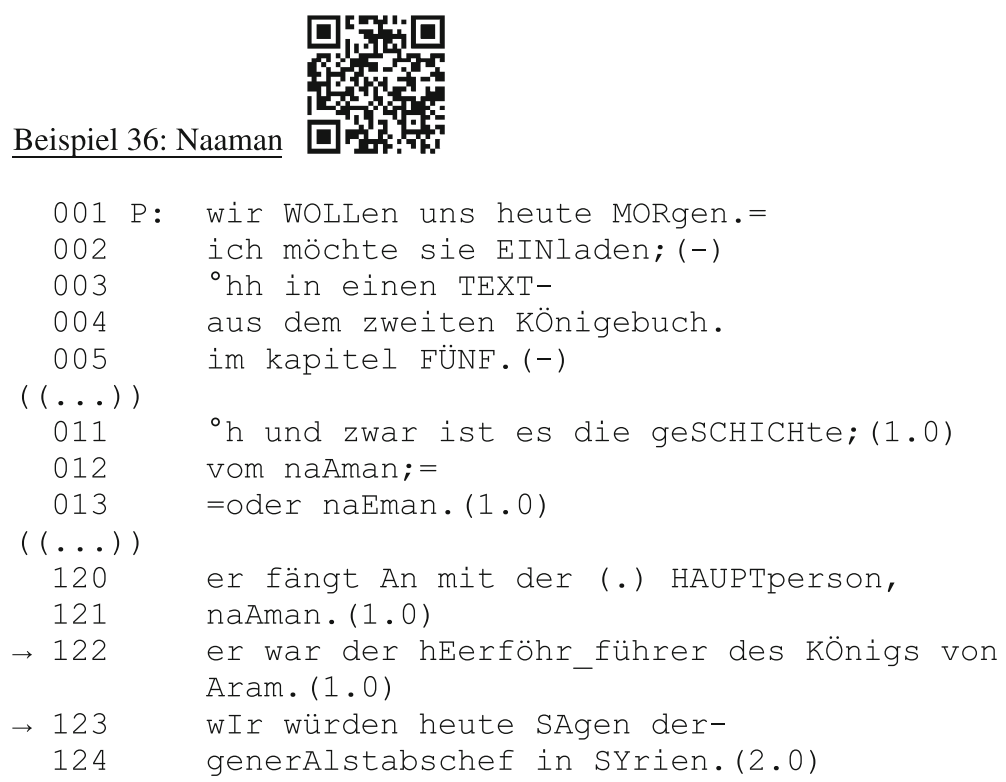

In seinem Wortbeitrag bespricht der Prediger die biblische Geschichte um Naaman und führt in den Bibeltext ein, indem er den Fokus seiner Betrachtungen auf diese biblische Person legt. Der Prediger beginnt den Text vorzulesen und übersetzt dabei aus dem hebräischen Originaltext (Z.123, sar-zewa melek aram) ${ }^{5}$ mit der deutschen Charakterisierung (er war der hEerföhr_führer des KÖnigs von Aram, Z.122). Er formuliert zum einen eine Übersetzung der veralteten militärischen Rangbezeichnung ,Heerführer' mit der von ihm als äquivalent markierten Kategorisierung ,Generalstabschef' und verortet die Geschichte zum anderen in den geopolitischen Grenzen der Gegenwart (generAlstabschef in SYrien, Z.124): Seine Ausführung impliziert, dass das Königreich Aram in einem Gebiet lag, das heute als Syrien benannt ist. Dadurch schafft er für die Anwesenden die Möglichkeit, die Dimensionen der Erzählung lokal und sozial zu erfassen. Auffällig ist der Metakommentar ,wIr würden heute SAgen“"(Z.123), mit dem der Prediger die anschließende Paraphrase einleitet und der sowohl semantische Probleme mit den gewählten Begriffen impliziert als auch die Aktualität und Gültigkeit der

\footnotetext{
${ }^{5}$ Siehe für eine Interlinearübersetzung: https://biblehub.com/interlinear/2_kings/5.htm [letzter Zugriff: 10.08.2020]
} 
im biblischen Text dargestellten Ereignisse betont. Durch das integrierende Personalpronomen ,WIR" kennzeichnet der Prediger sich und die Anwesenden als Teil einer spezifischen Sprachgemeinschaft. Die Temporaldeixis „heute“ stellt den Bezug zur aktuellen Lebenswirklichkeit her. Aufgrund also der zeitlichen Distanz, die zwischen a) den biblisch tradierten Ereignissen, b) der Entstehung des Bibeltextes und der darin verwendeten Begriffe sowie c) der für die Rezipierenden vertrauten Begriffe liegt, nutzt der Prediger die intralinguale Übersetzung, um den Text selbst nachvollziehbar zu machen und Intersubjektivität zu ermöglichen. Dadurch entsteht eine Analogie zwischen dem biblischen und dem gegenwartsbezogenen Begriff.

In den hier untersuchten Wortbeiträgen sind intralinguale Übersetzungen häufig Paraphrasen, bei denen ein (veralteter, abstrakter) Ausdruck mit (nachvollziehbareren, aktuelleren, bekannteren) Synonymen oder Um- bzw. Beschreibungen bearbeitet wird. Da dabei in vielen Fällen auch stilistische Veränderungen vorgenommen werden, wird die intralinguale Übersetzung $\mathrm{zu}$ einer spezifischen kommunikativ-rhetorischen Praktik innerhalb der untersuchten Wortbeiträge, um Intersubjektivität zu erzeugen.

Anhand der gezeigten Beispiele wird deutlich, dass die Prediger mit der Praktik des Übersetzens ein Verfahren nutzen, das den Text in seinem eigenen Recht und in seiner Historizität wahrnimmt und darstellt. So werden explizit und implizit unterschiedliche zeitliche und historische Wissensbestände relevant gesetzt. Die Gründe für die Notwendigkeit einer Übersetzung von Begriffen im Wortbeitrag sind u. a.:

- Die biblischen Texte sind in spezifischen Sprachen verfasst (Hebräisch und Griechisch), die im Laufe der Zeit in unterschiedliche Sprachen übersetzt wurden und die vom Großteil der Gemeinde potentiell nicht gesprochen und/oder verstanden werden.

- Es handelt sich um z. T. sehr alte Texte. Dies zeigt sich gerade in der Verwendung einer spezifischen Lexik, die in ihrer Semantik für die Rezipierenden im 21. Jahrhundert nicht mehr bzw. nicht mehr umfassend selbsterklärend ist. Die genutzten Begriffe und die damit verbundenen religiösen und sozialen Konzepte müssen also von den Predigern aufgeschlossen werden.

- Die jeweils von den Predigern genutzte deutsche Bibelübersetzung bzw. Bibelübertragung transportiert selbst durch die verwendeten Begriffe Bedeutungen, die z. T. nur einen Teil der Bedeutung des Originalbegriffs beinhalten. 
Als Konsequenz daraus verweisen die Prediger auf den Originaltext und nehmen interlinguale Übersetzungen vor. Die Prediger verhandeln in den untersuchten Wortbeiträgen mithilfe intralingualer Übersetzungen die Semantik der in der jeweiligen deutschen Bibelübersetzung genutzten Begriffe und setzen sich zudem mit ihrer Aktualität und Gültigkeit auseinander. Die Frage ist dann, welche überzeitlichen, überkulturellen und überreligiösen grundlegenden (Glaubens)Gewissheiten in den Texten vermittelt werden, und die entsprechend des theologischen und biblischen Tradierungsauftrags auch die Legitimation der Gattung Predigt ausmachen. Bevor dies jedoch näher in den Blick genommen wird, soll ein vierter Aspekt des Bibeltextwissens umrissen werden: das Wissen über biblische Personen.

\subsubsection{Vermittlung von Personenwissen}

Sprachhistorisches Wissen, Kulturwissen und Religionswissen sind sehr eng miteinander verknüpft und werden von den Predigern nur selten isoliert voneinander vermittelt. Besonders deutlich wird dies vor allem dann, wenn die im Bibeltext handelnden Personen von den Predigern vorgestellt, charakterisiert und in ihren sozio-kulturellen, politischen, monetären und spirituellen Positionen und Verhältnissen eingeordnet werden. In den meisten Fällen wird von den Predigern zugeschrieben, dass die anwesenden Personen die biblischen Figuren zumindest namentlich zuordnen können. Anders ist es bei spezifischen Eigenschaften und Handlungen der Personen. Das nachfolgende Beispiel zeigt einen weiteren Auszug aus dem bereits in Beispiel 36 vorgestellten Wortbeitrag, in dem sich der Prediger mit der biblisch tradierten Person des Naaman auseinandersetzt. In seiner Charakterisierung verknüpft er die Vermittlung von Personenwissen mit der semantischen Bearbeitung des Begriffs ,Kriegsmann“. 
Beispiel 37: Kriegsmann
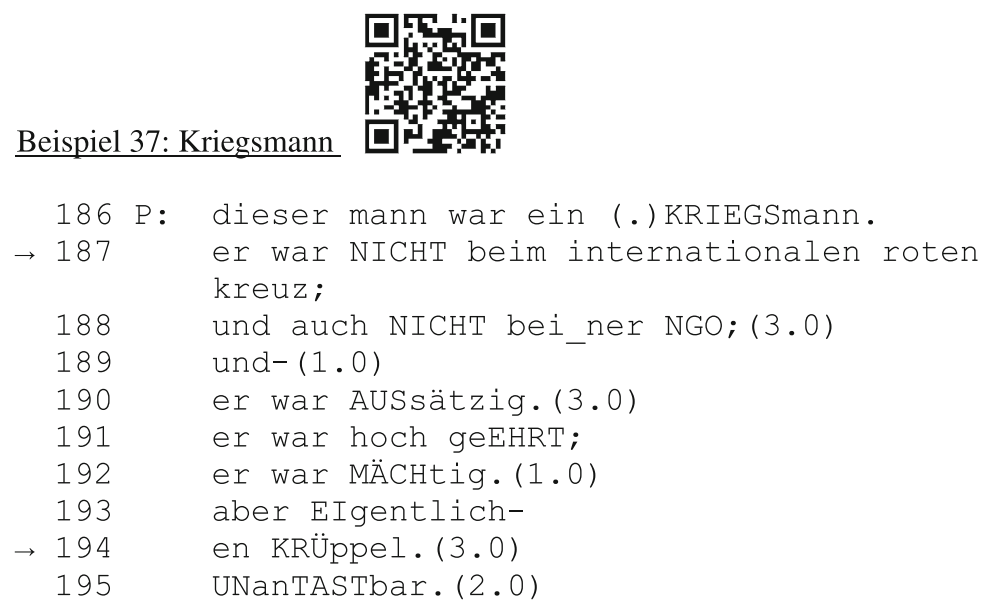

In dem Abschnitt des Wortbeitrags, der diesem Auszug vorausgeht, hat der Prediger bereits eine Charakterisierung dieser Person als ,Heerführer' und ,Generalstabschef' vorgenommen (siehe Beispiel 36) und lässt diese Begriffe nun in der Re-Etablierung des Naaman hyponymisch in der Kategorie ,Kriegsmann“ aufgehen (Z.186). Er paraphrasiert zunächst die Kategorie ,Hauptmann' mit dem Terminus ,Generalstabschef' und verallgemeinert diesen zur Kategorie ,Kriegsmann', die nun keinen militärischen Rang angibt, sondern eine grundlegende Eigenschaft des Naaman als Mitglied des syrischen Militärs. Um diesen Status des Naaman als ,Kriegsmann' zu verdeutlichen und näher zu charakterisieren, formuliert der Prediger abgrenzend: ,er war NICHT beim internationalen roten kreuz; und auch NICHT bei_ner NGO; (Z.187-188). Beides sind Organisationen und Organisationsformen, die erst im 19. und 20. Jhd. gegründet wurden und dem Schutz und dem Frieden von Menschen verpflichtet sind. Damit stehen sie komplementär zum Kategorienset des Militärs, das für die Hauptperson Naaman etabliert wurde. Ein zweites Charakterisierungsset entwirft der Prediger im Anschluss daran anhand des Gesundheitszustands des Naaman. Dazu liest er zunächst wieder den Bibeltext vor (er war AUSsätzig, Z.190). Das Adjektiv (AUSsätzig) markiert er implizit als verhandlungswürdig, indem er den Begriff nicht nur mit einem kolloquialeren Ausdruck paraphrasiert (aber EIgentlich en KRÜppel, Z.193-194), sondern damit auch neue Bedeutungskomponenten einführt, die spezifizieren, was sich die anwesenden Personen unter dem Begriff , aussätzig ' vorstellen müssen. Stil- und Registerwechsel werden vor allem dann genutzt, wenn die Prediger den Bibeltext paraphrasieren, und im Zuge dessen die handelnden biblischen Figuren charakterisieren und/oder deren 
Handlungen für die Rezipierenden nachvollziehbar machen. Dadurch wird ein mehr oder weniger abstrakter und in der Lebenswelt der Gemeinde ungebräuchlicher Begriff in den Vorstellungsrahmen der Anwesenden gebracht. Diesen Begriff kontrastiert er zusätzlich mit der gesellschaftlichen und politischen Stellung der biblischen Figur (Z.190-191). Häufig ist damit nicht nur eine Anknüpfung an die Lebenswirklichkeit der anwesenden Personen verbunden, sondern auch eine Emotionalisierung. Das zeigt auch der nachfolgende Auszug.

Beispiel 38: G7

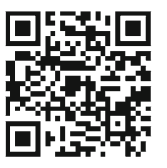

193 P: und dann kommen (.) mose und eLIa.

194 ! DIE! .

195 !ZWEI! .

196 !TOP! .

197 !HEL!den des Alten testaMENTS.

198 und rEden mit JEsus. (-)

$\rightarrow 199$ das ist wIe wenn es an deiner bescheidenen tür KLINGelt?

200 und die bUndeskanzlerin angela MERkel;

201 und der rEst der ge: SIEben,

202 stAatschefs stehen alle geBALLT mit ihren-

203 sicherheitschef vor deiner TÜR;

204 ja? (-)

205 dann passlert was draMAtisches.

206 ja?

207 die kommen NICHT kaffeetrinken; (--)

208 !HIER! -

209 KOMmen-

210 die gE: ZWEI ja?

211 die wIchtigsten (.) personen des alten testaMENTS.

212 erSCHEInen;

213 und sie rEden mit JEsus. 
Zunächst werden die beiden Figuren Mose und Elia relevant gesetzt (Z.193). Die sehr starke Betonung der Worte „, DIE! “, ,! ZWEI !“, „! TOP!“, „!HEL!den“ (Z.194-197) und deren Rhythmisierung kontextualisiert auf vokaler Ebene, dass der Prediger eine hohe Relevanz anlegt. Der Prediger vermittelt dabei ein spezifisches Bibeltextwissen, indem er die Bedeutung des Auftretens der Figuren in der Situation der Geschichte verdeutlicht. Dadurch verortet der Prediger zudem den gelesenen Bibeltext in seinem intertextuellen Kontext und vermittelt Religionswissen über die religions-kulturelle Bedeutung der biblischen Figuren. Die Charakterisierung der Personen wird in einem komplexen Vergleich weiter ausgebaut und veranschaulicht (das ist wIe wenn es an deiner bescheidenen tür KLINGelt?(-) und die bUndeskanzlerin angela MERkel; und der rEst der ge: SIEben, stAatschefs stehen Alle geBALLT mit ihren sicherheitschef vor deiner TÜR, Z.199-203). Handlungen und Eigenschaften der Personen werden mit der aktuellen Lebenswirklichkeit der Anwesenden parallelisiert und verglichen (das ist wIe wenn, Z.199). Der Prediger schreibt hier gleichzeitig ein Nichtwissen (K-) über die Bedeutung und den Stellenwert der im Bibeltext auftretenden Personen zu und vermittelt das entsprechende Personenwissen. Dies ist immer dann besonders erkennbar, wenn die Wortbeiträge an Personen adressiert sind, die eine vermeintlich kurze oder keine Erfahrung mit der Bibel haben (Jugendliche, Personen in evangelistischen Gottesdiensten etc.). Die beiden hier gezeigten Beispiele machen jedoch darüber hinaus deutlich, dass auch in ökumenischen Veranstaltungen und regulären Gottesdiensten mit Personen, denen vom Prediger eigentlich ein hoher epistemischer Status hinsichtlich der Handhabung der Bibel sowie der Kenntnis von Texten und Personen zugeschrieben wird $(\mathrm{K}+)$, Personenwissen vermittelt wird. Ein Grund dafür ist die Nutzung der Wissensvermittlung als Teil des komplexen Veranschaulichungsprozesses, den die Prediger häufig im Zusammenhang mit biblischen Texten durchführen. Dabei verknüpfen sie die Vermittlung des als unbekannt zugeschriebenen Bibeltextwissens mit der Übertragung der dargestellten Ereignisse auf Verhältnisse der Gegenwart. Dazu werden u. a. Vergleiche und Parallelisierungen genutzt. Darüber hinaus setzen sich die Prediger insofern mit Personenwissen auseinander, als sie deren Handlungen zum einen aus menschlicher/weltlicher Perspektive und zum anderen aus göttlicher Perspektive bewerten. Damit eröffnen die Prediger eine weitere Distanz: die moralische Distanz. Anders als die religiöse, historische und kulturelle Distanz, wird diese auch in den biblischen Texten selbst erkennbar. Welche Rolle die Aktualisierung und Vermittlung moralischer Wissensbestände in den untersuchten Wortbeiträgen hat, zeigt das nachfolgende Kapitel. 


\subsubsection{Vermittlung von Moralwissen}

Die christliche Predigt erscheint seit der Forschung Luckmanns zur Moralpredigt und der Arbeit von Ayaß zum Wort zum Sonntag (Ayaß 1997a) als der Inbegriff einer moralischen Gattung. Luckmann etwa geht am Beispiel säkularer Moralpredigten implizit auch dem moralischen Charakter christlicher Predigten nach, wenn er begriffliche und funktionale Verwandtschaftsbeziehungen, aber auch Verschiebungen aufzeigt (vgl. Luckmann 1997:14f und 1999b:85). Die Betrachtungen Luckmanns zur christlichen Predigt erschöpfen sich jedoch mit dem Verweis auf deren moralischen Charakter, der in säkularen Moralpredigten noch einmal deutlich stärker ausgebaut sei, und das Vorhandensein von „Wissen, dass vor allem ,Moral gepredigt" wird" (Luckmann 1999b:85). Durch seine spezifischen Forschungsdaten bleibt der Beleg, dass und wie dies in der gottesdienstlich gerahmten christlichen Predigt geschieht, allerdings aus. Gestützt wird die Annahme der Moralvermittlung auch durch theologische Forderungen, die Predigt solle „einen Beitrag zur Verinnerlichung von Normen und Werten“ (Engemann 2002:103) leisten und gesellschaftliche Ordnungen schaffen und stabilisieren (vgl. Engemann 2002:103).

Moral ist für Luckmann eine kommunikative Hervorbringung der Interagierenden (vgl. Bergmann/Luckmann 1999:19ff) und moralische Kommunikation erst dann gegeben,

wenn in der Kommunikation einzelne Momente der Achtung oder Missachtung, also der sozialen Wertschätzung einer Person, mittransportiert werden und dazu ein situativer Bezug auf übersituative Vorstellungen von ,gut' und ,böse` bzw. vom , guten Leben' stattfinden. [...] Entscheidendes Kriterium für moralische Kommunikation ist somit, dass es zu einer Moralisierungshandlung kommt, also zu sozial wertenden Stellungnahmen, die sich auf Handlungen oder Personen beziehen und geeignet sind, das Ansehen, das Image, die Ehre oder den Ruf der benannten oder identifizierbaren Person zu beeinträchtigen oder zu steigern. Dabei kann sich die Moralisierung ebenso auf vergangene Handlungen bzw. abwesende Personen beziehen wie auf ein aktuelles Geschehen bzw. einen in der Situation Anwesenden. (Bergmann/Luckmann 1999:22f) 
Moral ist dabei etwas, was in die alltägliche Kommunikation eingewoben ist (vgl. Bergmann/Luckmann 1999:13) und nicht nur in institutionalisierten moralischen Gattungen hergestellt und vermittelt wird. In jedem Fall geht es um die Herstellung, Demonstration und Aushandlung moralischer und damit auch deontischer Autorität der an einer Interaktion Beteiligten, d. h. um die Frage, wer beansprucht, ,moralische Ermahnungen und Belehrungen“ (Luckmann 1999b:85) zu formulieren. Theologisch betrachtet ist die Predigt durch einen grundsätzlichen moralischen Überbau gekennzeichnet, denn mit ihr wird die Lehre vom Christ-Sein als dem guten/richtigen Weg zur Erlösung tradiert und auf biblischer Grundlage ein gelingendes Leben skizziert. In der vorliegenden Arbeit richtet sich die Untersuchung jedoch nicht auf den theologischen Anspruch, sondern auf die Frage, wie sich Momente moralischer Kommunikation konkret in den Wortbeiträgen zeigen und welche Praktiken dabei von den beteiligten Personen genutzt werden. In den hier untersuchten Wortbeiträgen christlicher Predigten ist moralische Kommunikation in unterschiedlichen Ausprägungen erkennbar und sehr eng mit der Vermittlung von kontextuellen Wissensbeständen, der Tradierung überzeitlicher Glaubensgewissheiten und der Formulierung von Handlungsanweisungen verknüpft. Zudem werden sie in den meisten Fällen auf der Grundlage biblischer Texte formuliert. Moralische Kommunikation in Sinne Luckmanns, d. h. die Formulierung sozial wertender Stellungnahmen und überindividueller Vorstellungen von Gut/Böse und dessen, was ein gutes Leben ist, werden in den untersuchten Wortbeiträgen vor allem auf zwei großen Unterscheidungsachsen vorgenommen: Zum einen auf der Linie zwischen, weltlich \%,menschlich` vs. ,göttlich` und zum anderen auf der Linie ,sündig' (ein Leben ohne Gott führen) vs. ,schuldfrei/durch Jesus gerettet' (ein Leben mit Gott führen), bzw. abstrakter auf der Linie ,Tod“ vs. ,Leben'. Die Auseinandersetzungen der Prediger beziehen sich in den Wortbeiträgen, die für Christen mit einer mehr oder weniger lange Glaubensbiographie gestaltet sind, vor allem auf folgende Aspekt: Unterscheidung zwischen göttlichen und weltlichen Moralvorstellungen; Darstellung der Lebensrealität als Christ im weltlichen Alltag mit all seinen Anfechtungen (In diesem Zusammenhang thematisieren die Prediger das Leben als Christ mit dem Wissen um göttliche Moralvorstellungen in einer Welt, die z. T. entgegengesetzte Vorstellungen von gut und böse/richtig und falsch/angemessen und unangemessen vertritt); Formulierung des Ziels eines Lebens nach göttlichen Vorstellungen und die Frage, wie dies gelingen kann. Es geht dabei um die Bearbeitung von richtigen und falschen 
christlichen Moralvorstellungen und deren Revidierung auf der Grundlage biblisch tradierter göttlicher Moral. In einer Vielzahl der untersuchten Predigten spielt zudem die Frage danach, welche biblischen Gebote und moralischen Wissensbestände vor dem Hintergrund der bereits vorgestellten drei Distanzen (Zeit, Kultur, Religion; siehe Abschnitt 16.3.1 bis 16.3.4) für die Lebenswelt der anwesenden Personen relevant sind, eine Rolle. Das nachfolgende Beispiel aus einer ökumenischen Sonntagspredigt zeigt die Hauptlinie, an der sozial wertende Aussagen getroffen werden: Die Dichotomie zwischen weltlichen und göttlichen, biblisch tradierten Moralvorstellungen.

Beispiel 39: Weltliche Sicht

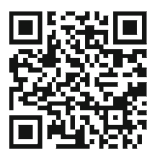

122 P: ihr kEnnt vielleicht das SPRICHwort, (-)

123 vertrAuen ist GUT; $=$

124 =aber kontrolle ist BESser. (2.0)

125 das ist die wEltliche sicht der DINGE. (2.0)

126 aber in der königsherrschaft GOTtes;

127 im reIch GOTtes. (-)

128 in dem WIR leben

129 da HEIBT es, (1.0)

130 jawoll kontrolle ist GUT;

131 keine FRAge.(1.5)

132 aber verTRAUN. (-)

133 GLAUben. (-)

134 ist BESser. (---)

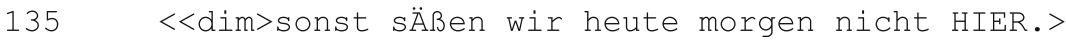

Die „sozial wertende Stellungnahme“ (Bergmann/Luckmann 1999:22) besteht in diesem Auszug aus der Gegenüberstellung weltlicher und göttlicher Handlungsvorstellungen und deren Bewertung durch den Prediger auf der Grundlage überindividueller Glaubensgewissheiten und biblischer Texte. Dazu zitiert der Prediger zunächst ein Sprichwort (vertrAuen ist GUT; aber kontrOlle ist BESser, Z.123-124), das er unter den Anwesenden als potenziell bekannt zuschreibt und es als Teil menschlicher Werte etabliert (das ist 
die wEltliche sicht der DINGE, Z.125). Dieses kontrastiert er mithilfe der adversative Konjunktion ,aber“ mit der göttlichen Perspektive (aber in der königsherrschaft GoTtes; im reIch GoTtes.(-) in dem WIR leben da HEIßT es- (1.0) jawOll; kontrolle ist GUT. keine FRAge.(1.5) aber verTRAUN. (-) GLAUben. (-) ist BESSer, Z.126-134). Durch das Pronomen „WIR“ nimmt er eine Kategorisierung vor, die sowohl ihn als auch die übrigen Anwesenden als im „REICH gottes" lebend - und damit als Christen - positioniert und dadurch den Geltungsbereich der von ihm verhandelten moralischen Implikationen anzeigt. Damit nimmt der Prediger eine klare moralische Bewertung vor, die er mit hoher epistemischer Sicherheit und deontischer Autorität formuliert. Es zeigt sich dabei jedoch, dass diese Autorität nicht allein durch die institutionelle Rolle bedingt wird, sondern sich vor allem auf die Kenntnis biblischer Texte und der darin tradierten göttlichen Aussagen über ein , gutes /richtiges bzw. ,böses ‘/sündiges/falsches Leben stützt.

Ähnlich gehen die Prediger im nachfolgenden Beispiel aus einer Dialogpredigt vor. Die Prediger setzen sich hier mit biblischen Moralgeboten und der Frage auseinander, welche Dimensionen ,Mord“ haben kann. Dabei arbeiten sie gleichzeitig die überzeitliche Relevanz der biblischen Texte heraus. 
Beispiel 40: Was hat das mit uns zu tun

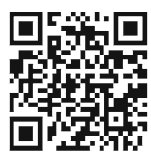

$295 \mathrm{P} 1{ }^{\circ} \mathrm{h}$ ich hab einen bibelVERS, (-)

296 kommt auch an der WAND glaub ich;

297 steht in matthëus FÜNFzehn;

298 vers NEUNzehn.=

299

=denn aus den hErzen kommen die bösen geDANken,

300

301

${ }^{\circ} \mathrm{h}$ und mIt ihnen MO:RD;

302

EHEbruch;

303

sexuelle UNmoral;

304

DIEBstahl.

305

LÜge ;

beLEIdigung;

306

und die liste könnte man noch viel LÄNGer machen; $=$

$307={ }^{\circ} \mathrm{h}$ das sind DIE dinge,

308

die den menschen UNrein machen.

309

310

${ }^{\circ} \mathrm{h}$ das heißt also das sind DIE dinge;

311

die ver!HIN!dern;

dass WIR, (1.0)

312

313

ein hErz bekommen wie s JEsus hat.=

=dass wir zu s diesen dieses Ebenbild wieder

REINkommen. (E)

314 lasst uns mal diesen satz stück für stück ANgucken.

315 matthäus FÜNFzehn.=

316 =denn aus dem hErzen kommen die bösen geDANken;

317 und MIT ihnen-(-)

$318{ }^{\circ} \mathrm{h}$ fangen wir mit MORD an.

319 STEHT dort.

320 joHANnes.

321 was hat_s mit uns zu TUN;

322 MORD.

323 ich hab ne ELSter mal erschossen.

$324 \mathrm{G}:$ ( (lachen))

$325 \mathrm{P} 1$ : aber $\mathrm{h}$ *

326 war vÖllig HELdenhaft.

327 mein vAter hat die vorneweg erSCHLAgen.

328 [( (lachen $))$

329 G: [( l lachen $))$ 
330 P1: und dann lag_se DORT

331 und ich hab mit dem knIcker nochmal

DRAUFgehalten.

332 also da als KIND ne?

$333{ }^{\circ}$ hh wAs hat das jetzt mit MIR [zu tun.

$334 \mathrm{G}:$

[ ( $($ achen $))$

335 P2: ich krieg grad bissel Angst hier auf der BÜHne,

336 [aber-

$337 \mathrm{G}: \quad[($ (lachen) )

338 P1: aber Erst erSCHLAgen;

339 dAnn erSCHIEßen.

340 P2: <<p>erst erschlAgen dann erSCHIEßen.>

341 ja oKAY.

342 also ich DENK das hat was äh-

343 ist ne frage der definition ja?

344 erster johannes DREI,

345 vers FÜNFzehn?

346 wer seinen brUder HASST? (-)

347 der ist ein TODschläger (.) steht dort.

348 [also.

349 P1: [ ( )

350 P2: ziemlich HEFtig ne?

351 wer seinen bruder HASST, (-)

352 der ist ein TODschläger.

353 also im prinzip kommt dort genau das RAUS ne?

354 es geht in gedAnken LOS.

355 und dann ist es manchmal nicht weIt zu WoRten,

356 und am ende vielleicht irgend_ne TAT;

357 =und (.) redet euch jetzt nicht raus dass ihr nur SCHWEStern habt oder sowas.

$358 \quad$ ja?

359 P1: [( lachen) )

360 P2: $\left[\left(\begin{array}{ll}(1) \\ 361\end{array}\right.\right.$

361

362

also es geht im KOPF-

es geht im KOPF los.

363

das ist denk ich das was JEsus hier-(-)

364

uns DEUTlich machen will.(-) 
Zunächst liest P1 den relevanten biblischen Text vor (Z.299-308) und ordnet ihn durch die Benennung der Textstelle im Gesamtgefüge der Bibel ein (Z.297-298). Bereits hier wird deutlich, dass sich die beiden Prediger mit einem Thema auseinandersetzen werden, das moralische Implikationen über eine gute Lebensführung enthält, denn der Text spricht von „bösen geDANken“ (Z.299) und beschreibt die Konsequenzen für das Leben, die aus diesen Gedanken erwachsen (Z.300-305). Im Anschluss daran bewertet P1 das Gelesene und grenzt diese menschlichen Handlungen bzw. Gedanken von dem eigentlichen Ziel eines glaubenden Menschen ab $\left({ }^{\circ} \mathrm{h}\right.$ das heißt also das sind DIE dinge; die ver!HIN!dern; dass wir ein hErz bekommen wie_s JEsus hat, Z.309-312). P1 beginnt dann eine genauere Betrachtung des biblischen Textes und stellt anhand des Beispiels ,Mord' die Frage nach der Relevanz und der überzeitlichen Gültigkeit des Textes an P2 (joHANnes. was hat_s mit uns zu TUN, Z.320-321). Implizit schreibt P1 mit dieser Frage zu, dass die anwesenden Personen selbst noch keinen Mord im engeren Sinne begangen haben und dass deswegen die Relevanz- und Gültigkeitsfrage gerechtfertigt und notwendig ist (D-event). Nach dem Einschub einer persönlichen Beispielerzählung über eine Begebenheit, in der er quasi einen Mord begangen hat (Z.323-332), wiederholt P1 die Frage nochmals (Z.333) und übergibt das Rederecht an P2. Dieser antwortet, indem er zunächst eine weitere Bibelstelle als Replik vorliest (erster johannes DREI, vers FÜNFzehn? wer seinen brUder HASST, der ist ein TODschläger, Z.344-347), durch diesen Bezug der Textstellen aufeinander eine lexikalische Veranschaulichung der Dimensionen des Begriffs ,Mord“ herstellt und sozusagen Vorstufen eines tatsächlichen Mordes benennt (es geht in gedAnken LOS. und dann ist es manchmal nicht weIt zu WORten, und am ende vielleicht irgend_ne TAT, Z.354-356). Gleichzeitig zu dem Geltungsanspruch des biblischen Textes verhandelt er dessen Generalisierungsanspruch, indem er auf die sprachhistorische Dimension der Übersetzung eingeht und die im Bibeltext vorgenommene Eingrenzung auf ,Brüder' ausweitet (und (.) redet euch jetzt nicht raus dass ihr nur SCHWEStern habt oder sowas, Z.357). In ausgebauter Weise wird hier eine aus dem Text heraus entwickelte Frage nach moralischen Vorstellungen und gutem vs. schlechtem Handeln mit dem Text selbst beantwortet. Die beiden Prediger laden dadurch die Bibel mit einer sehr hohen moralischen Autorität auf und übernehmen diese durch die Auslegung. Dasselbe Verfahren spielen 
die Prediger auch mit den Begriffen des Ehebruchs und der sexuellen Unmoral durch (nicht im Transkript). Sie setzen sich in ihrem gesamten Wortbeitrag mit unterschiedlichen menschlichen und göttlichen Moralvorstellungen auseinander und besprechen, wie laut Bibel ein gutes und gesundes Leben entsteht. Die Dichotomie zwischen ,gut ${ }^{*}$ und , schlecht ${ }^{*}$ wird in den meisten der untersuchten Predigten auf der Grundlage biblischer Texte eröffnet. Dadurch legitimiert der Prediger nicht nur die moralische Kommunikation, sondern verhandelt gleichzeitig seinen eigenen epistemischen und deontischen Status hinsichtlich der moralischen Äußerungen.

Aus theologischer Perspektive ist mit der Engführung und Übertragung biblischer Inhalte auf die Gegenwart und dem Aufzeigen von überzeitlichen Glaubensgewissheiten und Moralvorstellungen auch die Frage nach dem Geltungsanspruch sowie dem „Wahrheits-, Richtigkeits- und Wahrhaftigkeitsanspruch“ (Arens 2009:46) der Predigt verbunden. Dies betrifft sowohl die Autorität des biblisch tradierten Wortes als auch die (epistemische und deontische) Autorität der institutionellen Rolle des Predigers als kirchlichem Funktionsträger und/oder theologischem Experten (vgl. Arens 2009:45; siehe dazu auch Daiber 1991:209). Innerhalb der Homiletik haben sich in diesem Zusammenhang unterschiedliche Strömungen und Schulen herausgebildet, die die Person des Predigers zum einen als Experten in der „Pose des Allwissenden“ (Josuttis 2006:81) sehen und zum anderen eine Reduktion der Person diskutierten. Der Prediger ist dann jemand, der sich ,allein auf den biblischen Text bezieht“ (Josuttis 2006:83). In einer dritten Position soll der Prediger als Subjekt und damit auch als Nicht-Experte mit eigenen Unsicherheiten und selbst gemachten Erfahrungen erkennbar sein (vgl. Josuttis 2006:81).

Die gezeigten Beispiele haben bereits deutlich gemacht, dass sich diese epistemische Autorität auf unterschiedliche Wissensterritorien erstrecken kann und von den Predigern unterschiedlich legitimiert wird. So kann ein Wissensvorsprung und ein damit verbundener höherer epistemischer Status des Predigers auf folgende Aspekte zurïckgeführt werden: 
- Eine intensive(re) Auseinandersetzung des Predigers mit dem biblischen Text, der dem Wortbeitrag zugrunde liegt (z. B. ${ }^{\circ} \mathrm{h}$ sind mir noch zwei andere dinge bei paulus AUFgefallen.(1.0) und (.) über die werd ich heute abend (.) n_bissel was erZÄHlen, Beispiel 21), dem dadurch Relevanz zugewiesen wird,

- subjektive Erfahrungen (z. B. ich hab jüdische FREUNde und-(-) wenn wir über GOTT uns unterhalten, Beispiel 27),

- höherer epistemischer Status durch eine mehrjährige Ausbildung als Pfarrer, Prediger, Evangelist, oder, z. B. in freien Gemeinden, aufgrund einer göttlichen Begabung,

- Kontakt zu Experten oder Zugang zu Expertenquellen (wie unterschiedlichen Bibelauslegungen, Untersuchungen von Historikern etc.),

- Zugang zu weiterführender Literatur und Wissensquellen.

In den untersuchten Wortbeiträgen entsteht immer wieder ein Spannungsverhältnis zwischen der rollenbedingten epistemischen und deontischen Autorität der Prediger, die von diesen im Wortbeitrag demonstriert wird, sowie den Erwartungserwartungen der Prediger, d. h. den vom Prediger zugeschriebenen Erwartungen der Gemeinde an seine epistemische und deontische Autorität, und der Zurückweisung dieser Wissenshoheit z. B. in Bezug auf die Auslegung biblischer Texte und der Kommunikation moralischer Implikationen. Dies führt dazu, dass Moralund Weisungsautorität biblisch tradierten göttlichen Geboten und Aussagen zugeschrieben wird, wie dies im vorherigen Beispiel deutlich wurde. Sehr explizit setzt der Prediger auch im nachfolgenden Beispiel diesen Aspekt relevant. 


\section{Beispiel 41: Ich bin befreit $\square$ preft}

01 P: ich schaffe es nicht so zu lEben wie gott das WILL, (-)

02 und ich werde von dIesem bemühen beFREIT.

03 und genau dArum gehts im christenLEben.

$04{ }^{\circ} \mathrm{h}$ es geht NICHT darum-

05 dass du morAlisch Ethisch; (-)

06 oder geIstlich alles auf die REIhe kriegst.

07 alles RICHtig machst.

$08^{\circ}{ }^{\circ}$ es geht dArum dass du genau von diesem

! ZWANG! das tun zu !MÜS!sen;

09 beFREIT bist. (1.0)

10 vergesst wirklich alle die was anderes Sagen-

11 LEHren; $=$

12 =PREdigen.

$13{ }^{\circ} \mathrm{h}$ dAs ist das was die bibel SAGT.

14 das ist originAlton des apostels PAUlus.

$15{ }^{\circ} \mathrm{h}$ die botschaft des neuen testaMENtes,

$16{ }^{\circ} \mathrm{h}$ ist eine BOTschaft,

17 von der ! FREI!heit; (-)

18 vom ZWANG. (-)

19 ich bin beFREIT vom zwang.(1.0)

20 mich entspAnnt das unHEIMlich.=

21 =WISST ihr?

22 ich KENN mich nämlich.

$\rightarrow 23{ }^{\circ} \mathrm{h}$ ich bin keInen deut Anders als IHR.(2.5)!

24 und (.) möchte es aber manchmal gerne SEIN.=

$\rightarrow 25 \quad=$ man ist ja der herr PFARrer ne?

26 mhm? (2.5)

27 und jesus beFREIT mich,

28 mir ist das echt WICHtig.

$\rightarrow 29$ jesus befreit mich von dem zwAng als JUgendp farrer?

30 etwas BESseres zu sein.(2.0)

31 wenn ihr vielleicht in ner Ähnlichen verantwortung steht wie $\mathrm{ICH} ;(1.0)$ 
32 mit den Ansprüchen die an euch heRANgetragen werden; $=$

33 =dann verSTEHT ihr das.

$34{ }^{\circ} \mathrm{h}$ für mich ist das befreIend zu WISsen,

35 dass ich nicht den ZWANG habe alles richtig zu machen.

Der Prediger positioniert sich in diesem Auszug als eine Person, die gegenüber den anwesenden Personen zwischen unterschiedlichen moralischen Anforderungen und institutionell bedingten Ansprüchen und Erwartungen steht. Er trifft dazu die Unterscheidung zwischen seiner Identität als Christ, der wie die anwesenden Personen ein Wissen um biblisch tradierte Moralvorstellungen hat, aber an der konkreten Umsetzung im Alltag scheitert (ich schaffe es nicht so zu lEben wie gott das WILL, Z.1) und Erwartungen und Erwartungserwartungen an seine Rolle als Pfarrer (ich bin keInen deut Anders als IHR. (2.5) und (.) mÖchte es aber manchmal gerne SEIN. man ist ja der herr PFARrer. ne, Z.23-25). Dieser Selbstkategorisierung als sündiger Mensch und scheiternder Institutionenvertreter stellt er eine grundlegende christliche Glaubensgewissheit gegenüber (und genau dArum gehts im christenLEben. $\quad{ }^{h}$ es geht NICHT darum dass du morAlisch Ethisch; (-)oder geIstlich alles auf die REIhe kriegst. alles RICHtig machst. oh es geht dArum dass du genau von diesem !ZWANG! das tun zu !MÜs!sen; beFREIT bist, Z.3-9 und jesus befreit mich von dem zwAng als JUgendpfarrer? etwas BESseres zu sein, Z.29-30). Auch hier werden weltliche und göttliche Bewertungen menschlichen Handelns gegenüber gestellt und von als überzeitlich gültig markierten Glaubensüberzeugungen abgeleitet. Bezugsgröße ist dabei nicht das persönliche (Erfahrungs)Wissen des Predigers, sondern der biblische Text (Z.13-18). Diese biblisch basierten Glaubensgewissheiten formuliert der Prediger mit einer sehr starken epistemischen Gewissheit bezüglich der Richtigkeit seiner Äußerungen. Während er also auf der Ebene der moralischen Weisung seine Autorität zurücknimmt, baut er eine sehr starke epistemische Autorität hinsichtlich der biblisch tradierten Botschaft auf (Z.3-15). In dem vorliegenden Auszug stellt der Prediger also seine eigene epistemische und deontische Autorität der Autorität biblischer Texte gegenüber und lädt die Bibel als Objekt und die darin enthaltenen Texte mit Autorität auf, indem er als Prediger nach eigenen Aussagen hinter die Texte zurücktritt. Der 
Prediger nimmt damit eine ,interaktionale Reproduktion von Institutionalität“ (Schmitt/Knöbl 2014:52) vor, indem er sich als Person in der Abgrenzung zu seiner rollenbedingten Wissensautorität positioniert und diese Autorität zurïckweist. Die Prediger betonen darüber hinaus in einigen Fällen explizit, dass der Zugang zu den biblischen Texten und den tradierten Erzählungen für alle der anwesenden Personen möglich ist. Dadurch werden die geäußerten Gedanken implizit und explizit als durch eigenständiges Bibelstudium überprüfbare subjektive Lesarten erkennbar.

Die Prediger betonen in diesem Zusammenhang, dass die anwesenden Personen das Recht und die Pflicht haben, die Worte des Predigers und dessen Auslegungen des Textes nicht ungeprüft zu akzeptieren, sondern vielmehr seine Worte anhand des Bibeltextes kritisch zu hinterfragen. Damit reduzieren die Prediger zum einen mögliche Erwartungen an ihren Expertenstatus hinsichtlich der Textkenntnis und damit ihrer epistemische Autorität, und machen zum anderen klar, dass sie auch auf deontischer Ebene hinter die Bibel zurücktreten. Dadurch wird dem Buch der Bibel eine hohe letztgültige Autorität zugesprochen. Auch wenn sich die Prediger dennoch an vielen Stellen ihrer Wortbeiträge als Experten positionieren, geht es in christlichen Predigten, so hat die Analyse gezeigt, darum, dass die Prediger in Bezug auf die Bibelkenntnis und die Richtigkeit ihrer Auslegungen den anwesenden Personen zum einen eine hohe Kompetenz zuschreiben und zum anderen Möglichkeiten aufzeigen, wie das entsprechende Wissen erworben werden kann. Die Prediger positionieren sich dabei konfessionenunabhängig explizit und implizit zum einen als institutionell legitimierte Person mit einem gewissen Wissensvorsprung, aber zum anderen auch als Teil der Gemeinde und gegenüber der Bibel als gleichfalls Lernende und nicht nur Lehrende.

Es gibt Wortbeiträge, die sich dezidiert mit moralischen Fragen, mit Gut und Böse, mit Sünde und Gerettetsein auseinandersetzen. Es gibt aber auch Wortbeiträge, in denen diese Dinge nur eine Randerscheinung sind. In diesen geht es dann vor allem darum grundlegende Glaubensgewissheiten zu vermitteln, z. B. Wissen darüber, welche Charaktereigenschaften Gott, Jesus und der Heilige Geist haben, wie sie wirken und was sie wollen. Moralische Komponenten befassen sich in solchen Wortbeiträgen vor allem mit den vom Prediger zugeschriebenen Vorstellungen, die die anwesenden Personen von Jesus oder etwa der Funktion des Heiligen Geistes haben oder welche Gottesbilder existieren und ob diese richtig sind oder falsch. In vielen Fällen bleiben die moralischen Implikationen dann 
implizit und werden lediglich z. B. darin sichtbar, welche Handlungsaufforderungen von den Predigern formuliert werden (siehe Abschnitt 16.6). Moralische Kommunikation ist also ein Teil der Wortbeiträge christlicher Predigten, macht jedoch nicht zwingend den Hauptteil aus. Es entsteht dadurch der Eindruck einer impliziten Moral, die aus der Rekonstruktion biblisch tradierter Ereignisse, der Formulierung von damit im Zusammenhang stehenden, gegenwärtig gültigen Glaubensgewissheiten und dem Verweis auf zukünftige Handlungen entsteht. Anders als im ,heiligen Bogen', wie ihn Ayaß für das Verkündigungsformat, Wort zum Sonntag ' herausarbeitet (vgl. Ayaß 1997a; siehe Kapitel 5), haben Predigten in diesem Zusammenhang keine typische Struktur. Moralische Aspekte können an jeder Stelle des Wortbeitrags vom Prediger formuliert werden. Im Zusammenhang mit den biblischen Texten aktualisieren und tradieren die Prediger göttliche Moralvorstellungen und schaffen dadurch erneut eine Glaubens- und Wissensgemeinschaft unter den anwesenden Personen. Die biblischen Texte werden gerade an diesen Stellen als herausfordernd konstruiert.

Die bisherigen Ausführungen zur Aktualisierung und Vermittlung von Religionswissen, Kulturwissen, Sprachwissen, Personenwissen und Moralwissen haben nicht nur die von den Predigern behandelten Wissensbestände und die zur Vermittlung gebrauchten Praktiken aufgezeigt, sondern auch angedeutet, dass damit immer auch eine Veranschaulichung biblischer Texte für die anwesenden Personen einhergeht. Das nachfolgende Kapitel konzentriert sich noch einmal auf diese Praktiken und Verfahren der Veranschaulichung.

\subsection{Veranschaulichung biblischer Texte}

Im Kontext der Untersuchung medizinischer Sendungen im Fernsehen haben Brünner (2011) und Brünner/Gülich (2002) den Begriff der Veranschaulichungsverfahren geprägt. Er beschreibt Verfahren und Praktiken, die Interagierende gebrauchen, um nicht nur Wissen zu vermitteln, sondern die Wissensbestände nachvollziehbar und vorstellbar zu machen und dadurch in der Interaktion Verstehen her- und sicherzustellen (vgl. Ehmer 2013:2).

Das zentrale Definitionskriterium von Veranschaulichungsverfahren besteht darin, Anschaulichkeit, Bildhaftigkeit/Bildlichkeit, Konkretheit oder Vorstellbarkeit herzustellen. [...] Dabei zielen die unterschiedlichen Veranschaulichungsverfahren in 
jeweils spezifischer Form darauf, eine Anbindung des zu veranschaulichenden Sachverhaltes an den Wissenshintergrund und die lebensweltliche Erfahrung der Beteiligten zu erreichen. (Ehmer 2013:6f)

Gerade bei Themen und Diskursen, die außerhalb der Lebenswelt der Interagierenden liegen, erfordert die Herstellung von Verstehen und die Anschlussfähigkeit an die bereits vorhandenen Wissensbestände der beteiligten Personen einen größeren sprachlichen und interaktiven Aufwand, denn ,Veranschaulichungsverfahren dienen $[\ldots]$ nicht nur dem Ausgleich von Wissensdifferenzen, sondern spielen auch bei der Überbrückung der Welten und der Herstellung sozialer Gemeinschaft eine wichtige Rolle und transportieren auch kulturelle Wissensbestände“ (Brünner 2011:296). Dazu müssen die einzelnen Sachverhalte lokal und rezipientenorientiert bearbeitet werden.

Veranschaulichungsverfahren wurden bisher primär in Kontexten der ExpertenLaien-Kommunikation (z. B. medizinische Talkshows, schulische Interaktion) und damit innerhalb asymmetrischer institutioneller Interaktionen untersucht und herausgearbeitet (vgl. Brünner/Gülich 2002, Brünner 2011, Brünner 2013:19f, Ehmer 2013). In diesem Zusammenhang zeigt Brünner auf, dass vor allem der „Bezug auf das gemeinsame Alltagswissen“ (Brünner 2013:19) von Experte und Laie eine wichtige Rolle spielt.

Die prominentesten Veranschaulichungsverfahren sind zum einen „Veranschaulichungen durch sprachliche Bilder unterschiedlicher Art" (Ehmer 2013:3; siehe dazu auch Brünner/Gülich 2002:24) wie Metaphern, Vergleiche und Analogien, die mithilfe von „Übertragungen aus bekannten Bereichen“ (Brünner 2011:296) unverständliche Sachverhalte vorstellbar machen und dadurch illustrierenden Charakter haben (vgl. Kiel 2009:149). Brünner/Gülich definieren Analogien als ,ausgebaute Vergleiche, in denen strukturelle oder funktionale Beziehungen zwischen Elementen unterschiedlicher Systeme verglichen werden“ (Brünner/Gülich 2002:23). Dabei ist das Verhältnis zwischen Analogie und Metapher nicht abschließend bestimmt. So schreibt Kiel: „das zugrunde liegende Prinzip der Übertragung von einem Primär- auf einen Sekundärgegenstand ist bei Metapher und Analogie gleich“ (Kiel 2009:149). In der Konzeption der Veranschaulichungsverfahren fasst Brünner Metaphern, Vergleiche und Analogien in einer Kategorie zusammen und verweist damit auf deren strukturelle und funktionale Nähe (vgl. Brünner 2011:297).

Eine weitere Gruppe der Veranschaulichungsverfahren sind Beispiele und Konkretisierungen (vgl. Brünner 2013:20, Ehmer 2013:3). Durch diese wird 
„neues, oft abstraktes Wissen auf konkretere, nachvollziehbare Ebenen gebracht" (Brünner 2011:296). Des Weiteren beschreiben die Autoren narrative Verfahren wie Beispielerzählungen und Szenarios, „die an vorhandene Erfahrungen aus dem privaten oder beruflichen Alltagsleben anknüpfen bzw. fiktive Alltagssituationen entwerfen und schildern“ (Brünner 2011:296). Darüber hinaus verweist Brünner auf mediale Ressourcen wie Bilder, Filme, Modelle etc., die zur Veranschaulichung genutzt werden können (vgl. Brünner 2013:20, Ehmer 2013:3).

In den hier untersuchten christlichen Wortbeiträgen werden speziell Analogiebildungen und Vergleiche genutzt, um explizit Parallelen zwischen dem Bibeltext und der Gegenwart sowie der Lebenswirklichkeit der Anwesenden zu ziehen. Kommunikativ wird damit das Problem bearbeitet, dass die biblischen Texte, wie die vorherigen Kapitel gezeigt haben, aus einer für die anwesenden Personen fremden Zeit, einem fremden Kulturkreis und einer fremden Religion stammen und dennoch deren Aktualität und überzeitliche, überkulturelle und überreligiöse Gültigkeit verdeutlicht werden soll. Im nachfolgenden Auszug verknüpft der Prediger eine interlinguale Übersetzung mit dem Veranschaulichungsverfahren des Vergleichs, um das im Bibeltext Dargestellte und die verwendeten Begrifflichkeiten nachvollziehbar zu machen. Nachdem das Predigtereignis eröffnet und ein lautes, unangekündigtes Gebet gesprochen wurde, realisiert der Prediger den Wortbeitrag. Er beginnt diesen, indem er zunächst auf die für die Predigt relevante Bibelstelle hinführt (Mt.17,1-8). Schließlich fordert der Prediger die Gemeinde dazu auf, zusammen mit ihm den zentralen Bibeltext zu lesen, indem er laut liest und die übrigen Anwesenden in ihren eigenen Bibeln und auf den vom Prediger ausgeteilten Textblättern mitlesen sollen (siehe Beispiel 5 und Beispiel 6). Die zuvor gemachte Zuschreibung der Fremdheit des Textes, der darin dargestellten Ereignisse und des Begriffs der Verklärung (siehe Beispiel 35) wird in dem nachfolgenden Auszug vom Prediger wieder aufgenommen und weitergeführt. 


\section{Beispiel 42: Metamorphose}

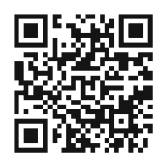

$\rightarrow 50$ P: du hast vOrher geDACHT-

51 ach naja so_ne kleine geschicHte;

52 da leuchtet der jEsus mal so_n BISschen;

53 und dann kam ne WOLke? (-)

54 und kurze zeit spëter erzählt PEtrus; =

55 er hat gesagt Als wir dAs erLEBT haben.

56 hAben wir die !MACHT!; (--)

57 und die !AN!kunft(-) unsres herrn jesus

christus erlebt.

58 und dieses wort ! AN!kunft;

$\rightarrow 59$ das ist ein wort was die leute der damaligen zeit WUSsten

60 das ist WIE-

61 wenn ein (.) ein (.) hoher wÜrdenträger in die stadt REINkommt;

62 dann gibt es pAuken und trompEten;

63 und FAHnen;

64 und LICHT;

65 und ne rIesengroße FEIer;

66 das sind alles gewAltige WoRte.

67 als petrus-

68 dIese geschichte WEItererzählt;

69 erz̈̈HLT er davon,

70 WELCH (.) !MÄCH!tige;

71 und welch unwahrscheinlich gewALtige begegnung es war;

72 dIesen herrn jesus christus verKLÄRT zu sehen.

73 verkL ̈̈Rung?

$\rightarrow 74$ dieses dieses wOrt kommt aus dem griechischen und heißt im griechischen metamorPHOsis.

75 da kommt die metamorphose HER,

76 also wenn sich etwas UMwandelt;

77 äh zum BEIspiel, (1.0)

$\rightarrow 78$ äh so_so_ne rAupe in einen schmetTERling?

79 und wass hiler passiert IST, (-)

80 das für einen kUrzen augenBLICK; (-)

81 die JüNGer?

82 nen EINblick bekommen, 
83 in die gewAltige HERrlichkeit von-

84 dessen wer jEsus IST.

85 die hErrlichkeit die immer schon ihm geHÖRte.

86 aber die aufgrUnd von seiner MENSCHwerdung; (-)

87 verSTECKT war. (-)

88 oder verBoRgen war.

Nachdem der Prediger den Bibeltext laut vorgelesen hat, wiederholt er seine zuvor gemachte Zuschreibung der Unverständlichkeit des biblischen Textes (siehe Beispiel 35), indem er seine eigene Lesart erneut auf die anwesenden Personen überträgt und so den epistemischen Status der Gemeinde gegenüber den biblischen Ereignissen benennt (du hast vOrher gedacht ach naja so_ne kleine geSCHICHte; da leuchtet der jEsus mal so_n BISschen; und dann kam ne WOLke, Z.50-53; K-). Er formuliert dabei die Gedanken der anwesenden Personen als wiedergegebene Rede. Daraufhin setzt er die beiden Begriffe der ,!MACHT!“ (Z.56) und der „!AN!kunft“ (Z.57) relevant und betont vor allem für letzteren eine semantische und kulturelle Differenz zwischen dem Bibeltext und den Assoziationen der anwesenden Personen (und dieses wort ! AN!kunft; das ist ein wort was die leute der damaligen zeit WUSsten das ist wie, Z.59-60). Zur Veranschaulichung der Bedeutungsdimension und der Überwindung der aufgemachten Distanzen, nutzt der Prediger einen Vergleich (das ist wie wenn ein (.) ein (.) hoher wÜrdenträger in die stadt REINkommt, Z.60-61) und baut diesen zu einem Szenario aus (dann gibt es pAuken und trompEten; und FAHnen; und LICHT; und ne rIesengroße FEIer, Z.62-65). Im Anschluss daran konzentriert sich der Prediger wieder auf den Begriff der Verklärung und setzt hier zwei unterschiedliche Praktiken zur Herstellung von Intersubjektivität ein: zum einen verweist er mithilfe einer interlingualen Übersetzung auf die Etymologie des Begriffs und die Originalsprache des biblischen Textes (dieses dieses wOrt kommt aus dem griechischen und heißt im griechischen metamorPHOsis, Z.74). Schließlich führt er einen implizit als bekannt zugeschriebenen etymologisch verwandten Begriff ein (da kommt die metamorphose HER, Z.75), paraphrasiert ihn (also wenn sich etwas UMwandelt, Z.74) und baut diese Erklärung anhand eines Beispiels zur Veranschaulichung weiter aus (äh zum BEIspiel, (1.0) äh so_so_ne rAupe in einen schmetTERling, Z.77-78). Damit nutzt er ein weiteres Veranschaulichungsverfahren neben dem 
Vergleich, um die Frage zu klären, was sich die anwesenden Personen unter der ,Verklärung' und dem Leuchten Jesu vorzustellen haben und warum man daran die Herrlichkeit Gottes erkennen kann. Dem Prediger reichen dafür jedoch die bereits gemachten Beschreibungen nicht aus. Er expandiert und konkretisiert seine bisherigen Ausführungen und formuliert weitere Vergleiche: ,als sie Jesus umgewandelt sehen, leuchtet sein Gesicht wie die Sonne" (nicht im Transkript) und dieses Bild weiter ausbauend: ,das ist so ähnlich wie wenn bei uns zuhause im Dynamostadion plötzlich die Flutscheinwerfer angehen" (nicht im Transkript). Die Begriffe der Verklärung und der Metamorphose werden vom Prediger mit Bezug auf den Bibeltext mithilfe von interlingualen Übersetzungen, Beispielen und Vergleichen bearbeitet und veranschaulicht, um den Text für die Gemeinde verständlich und nachvollziehbar zu machen. Der Prediger inszeniert sich hier als Experte hinsichtlich der Wortbedeutung und schreibt der anwesenden Gemeinde implizit zu, dass sie über diesen Wissensbestand nicht verfügt (A-event), also eine Wissensvermittlung kultureller und semantischer Aspekte und damit ein Ausgleich des Wissensdefizits notwendig ist.

Eine bildliche Konkretisierung und visuelle Vorstellbarkeit der biblisch tradierten Ereignisse wird von einigen Predigern darüber hinaus zum einen mithilfe sprachlicher Szenarios und zum anderen mit multimodalen szenischen (Re)Inszenierungen realisiert. Sprachliche Szenarios sind dadurch gekennzeichnet, dass

die Zuschauer in eine fiktive Situation versetzt [werden], in der sie agieren; diese Situation wird als eine gegenwärtige vorgestellt. Die zu vermittelnden Informationen werden durch das Szenario veranschaulicht und, erfahrbar' gemacht, indem fiktive Ereignisse, Handlungen und Äußerungen des Adressaten verbal geschildert und ausgemalt werden. So wird zum Beispiel (implizit) verdeutlicht, wie man sich in der ausgemalten Situation verhalten soll, wie sich ein bestimmtes Ereignis anfühlt oder wie es überhaupt zu diesem Ereignis kommen kann. Mit Hilfe von Szenarios wird an Betroffene appelliert oder es werden Handlungen verständlich gemacht. (Brünner 2011:321)

In den hier untersuchten christlichen Predigten wurden sprachliche Szenarios vor allem dann eingesetzt, wenn sich die Rezipierenden in eine Situation versetzen sollten, die Parallelen zu der im Bibeltext dargestellten Szenerie aufweist (vgl. Dix 2020). Sehr nah an dem, was Brünner sprachliche Szenarios und Beispielerzählung nennt, sind die Verfahren des Nachspielens einer Begebenheit im Sinne Goffmans (1977) und die sprachliche (Re)Inszenierung im Sinne von LuciusHoene/Deppermann (2002). Im Zuge der Untersuchung von Alltagserzählungen 
beschreibt Goffman das Phänomen des Nachspielens (replay) einer Szene oder Begebenheit wie folgt:

[G]ewöhnlich gibt der Sprecher seinen Zuhörern eine Darstellung dessen, was ihm widerfahren ist. Auch wenn er darauf abzielt, die nackten Tatsachen darzustellen, wie er sie sieht, so können doch seine Mittel in einem gewichtigen Sinne wesentlich theatralischer Art sein, nicht, weil er unbedingt übertriebe oder einem Drehbuch folgte, sondern weil er vielleicht etwas aufführen muss, was eine Dramatisierung ist - die Anwendung seiner Fähigkeiten zum Reproduzieren, zum Nachspielen einer Szene. Er spielt gewissermaßen ein Tonband von einem früheren Erlebnis ab. [...] Eine Geschichte oder Anekdote, d.h. eine Nachspielung, ist nicht bloß ein Bericht über ein früheres Ereignis. Im vollsten Sinne ist es ein Bericht aus der persönlichen Perspektive eines wirklichen oder möglichen Beteiligten, der so situiert ist, dass sich von diesem Ausgangspunkt her eine zeitliche, dramatische Entwicklung des berichteten Ereignisses ergibt. Eine Nachspielung ist deshalb übrigens auch etwas, in das sich der Hörer mitfühlend hineinversetzen kann, er kann das Geschehene selbst nacherleben. Kurz, eine Nachspielung gibt eine persönliche Erfahrung wieder und berichtet nicht bloß über ein Ereignis. (Goffman 1977:539f)

Lucius-Hoene/Deppermann verstehen unter einer sprachlichen ,(Re)Inszenierung * wiederum ein Erzählverfahren, bei dem ,,das vergangene Geschehen so dargestellt wird, als ob es unmittelbar in der Gegenwart, vor den Augen der Gesprächspartner abliefe" (2002:228). Als wichtige Realisierungsmittel nennen sie das szenische Präsens (vgl. Lucius-Hoene/Deppermann 2002:228) und die Wiedergabe von Dialogen bzw. direkter Rede (vgl. Lucius-Hoene/Deppermann 2002:230). In den untersuchten Wortbeiträgen werden sprachliche (Re)Inszenierungen vor allem dann produziert, wenn es um vom Prediger selbsterlebte Ereignisse geht. Alle drei Konzepte (sprachliches Szenario, replay und sprachliche (Re)Inszenierung) legen ihren Schwerpunkt auf primär verbal und vokal realisierte Erzählungen.

Darüber hinaus nutzen einige wenige Prediger neben der rein verbal realisierten Rekonstruktion die Möglichkeit, die biblischen Ereignisse auch mithilfe visuell-leiblicher Ressourcen für die anwesenden Personen erlebbar und nachvollziehbar zu machen. Das nachfolgende Beispiel zeigt eine solche multimodal realisierte ( $\mathrm{Re}$ )Inszenierung eines biblischen Textes bzw. der im Bibeltext dargestellten Ereignisse. 


\section{Beispiel 43.1: Weltenregent}

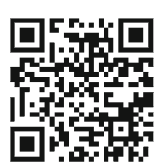

$500 \mathrm{P}$ : und jEsus wurde GRAde; (-)

501 du kOnntest gerade seine herrlichkeit SEHN.

502 du kOnntest grade SEHN-

503 dass ER;

504 der wEltenre!GENT! ist.

505 und pEtrus WEIB das.(----)

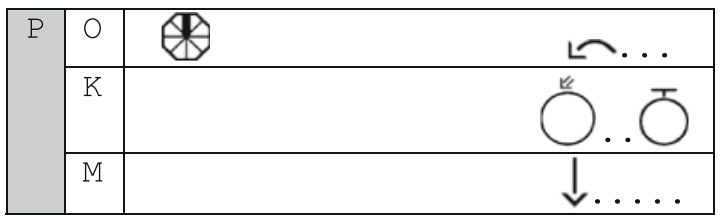

506 und PEtrus,

\begin{tabular}{|l|l|l|}
\hline $\mathrm{P}$ & $\mathrm{O}$ & $\mathrm{V}$ \\
\cline { 2 - 3 } & $\mathrm{M}$ & $\ldots \ldots .$. \\
\hline
\end{tabular}

$507 \mathrm{P}: \quad<<\mathrm{p}>=$ ich brauch nochma_en FREIwilligen. (-) 508 en MANN. (4.0)

509 DU.

\begin{tabular}{|c|c|c|}
\hline & 0 & 8 \\
\hline & $\mathrm{H}$ & $\boldsymbol{4}$ \\
\hline
\end{tabular}

510 bist PEtrus.

511 hEr mein PEtrus. ( (lachen)) (1.5)

512 petrus du hast das vorrecht dich mal hier vorne HINzulegen; (2.0)

513 vor mein leUchtendes ANgesicht=

$514 \quad=$ geNAU.

$\rightarrow 515$ stell dir mal VOR-

516 so wie pEtrus vor dem leuchtenden jesus LIEGT;

517 ja? (2.0)> 
Der Prediger thematisiert in seinem Wortbeitrag die Verklärung Jesu (siehe Beispiel 35 und 42) und nutzt dazu paraphrasierende und interpretierende Elemente, indem das bereits Verdeutlichte nochmals wiederholt und zusammenfasst: ,und jEsuswurde GRAde; (-) du kOnntest gerade seine herrlichkeit SEHN. du kOnntest grade SEHN- dasS ER; der wEltenre!GENT! ist. und pEtrus WEIß das" (Z.501505). Sprachlich auffällig ist, dass die Gemeinde zu einem aktiven Teil der Zusammenfassung wird, die durch den generalisierenden Gebrauch der Personaldeixis „du“ (Z. 501 und 502), das Präteritum und das Verb „, sehn“ (Z.501 und 502), das eine perzeptorische Wahrnehmung innerhalb eines Vorstellungsraums (hier: der biblischen Geschichte) markiert, zu einer sprachlichen (Re)Inszenierung wird. An dieser Stelle bricht der Prediger jedoch ab und formuliert einen längeren Einschub. Dies wird zum einen visuell markiert, indem sich der Prediger von seiner auf die Gemeinde ausgerichteten Position $(\mathbb{A}$, Z. 505) abwendet $(\curvearrowleft$, Z.505), dabei einen Schritt nach hinten auf das Rednerpult zugeht ( $\downarrow$, Z.505) den Kopf senkt ( $\bigcirc^{\circ}$, Z.505) und auf das bewegliche Pult neben ihm schaut. Die Arme senkt er ebenfalls ab. Der Prediger tritt aus dem Vorstellungsraum der Geschichte in den unmittelbaren Wahrnehmungsraum der Kirche ein und formuliert einen Metakommentar zur weiteren Gestaltung des Wortbeitrags (ich brauch nochma_en FREIwilligen.(-) en MANN, Z.507-508), um sich einen Ko-Darsteller aus der anwesenden Gemeinde zu suchen (siehe Kapitel 17). Der Prediger adressiert aus der Gruppe der Anwesenden schließlich einen jungen Mann, den er auffordert sich vor den Prediger hinzulegen (Z.512-514). Vokal gekennzeichnet ist dies durch einen Laustärkewechsel und einer damit einhergehenden Verschiebung der Adressierung von der gesamten Gemeinde hin zu dem jungen Mann, der ein Teil der szenischen (Re)Inszenierung der biblischen Geschichte wird. Der Prediger adressiert ihn zunächst durch das Pronomen „DU“ und eine Zeigegeste $(\downarrow \uparrow, Z$.519) und spricht ihn darüber hinaus nicht mit seinem richtigen Namen an, sondern vollzieht unmittelbar die Umdefinierung hin zu der Rolle, die der junge Mann einnehmen soll, indem er ihm mit dem Namen der biblischen Person benennnt (DU. bist PEtrus. HER mein petrus, Z.509-511). In dieser Rolle verbleibt der junge Mann. Weiterhin findet eine Veränderung des Interaktionsraums statt, denn der Prediger steht nun nicht mehr allein der Gemeinde gegenüber, sondern etabliert einen zusätzlichen Interaktionsraum mit dem jungen Mann. Die Gemeinde wiederum kann dies 
wahrnehmen. Der Prediger konstituiert dadurch nicht nur die Adressierung eines Einzelnen, sondern zeigt den übrigen Anwesenden an, dass nun nicht mehr nur eine Nacherzählung erfolgt, sondern eine szenische (Re)Inszenierung. Es folgt die Begründung für die ( $\mathrm{Re}$ )Inszenierung, die durch den Prediger im konkreten Nachvollzug der biblischen Situation liegt: ,stell dir mal VOR so wie pEtrus vor dem leuchtenden jesus LIEGT; ja?" (Z.515-517). Die Fragepartikel verweist auf die Herstellung von Intersubjektivität des als nun geteilt konstruierten Vorstellungsraums. Die Formulierung „,stell dir mal vor“, wie sie bei sprachlichen Szenarios typisch ist (vgl. Brünner 2011:321), wird auch hier vom Prediger genutzt, um einen Vorstellungsraum zu eröffnen, den Wechsel der aktualen Personen in fiktive Personen einzuleiten und den jungen Mann direkt zum Adressaten seiner Handlungsanweisung zu machen, damit dieser den Rollenwechsel aktiv mitvollzieht (vgl. dazu auch Dix 2020). Gleichzeitig gibt der Prediger aber auch den anderen Anwesenden eine Interpretation der biblischen Situation, die (re)inszeniert werden soll, und eine Beschreibung der unmittelbar hergestellten Szenerie.

Der junge Mann liegt nun auf dem Bauch vor dem Prediger, der mit der Begründung für die Veranschaulichung auch seine eigene Rolle definiert und sich selbst die Figur des Jesus zuordnet. Dies dient der Vorbereitung eines erneuten Rollenwechsels. Dazu knüpft der Prediger zunächst an bereits vorhandenes geteiltes Wissen aus den vorausgegangenen Ausführungen an (die st Imme hat grad !DONN! ernd> zu ihm gesprochen, Z.518). 
Beispiel 43.2: Petrus du fauler Sack

518 P: <<f>die stImme hat grad ! DoNN!ernd> zu ihm gesprochen;

519 und hat gesagt(-)!DIES! ist mein gellebter SOHN. (-)

520 an dem ich WoHLgefallen habe.

521 ! HÖRT! auf IHN. (----------|---------)

\begin{tabular}{|c|c|c|c|}
\hline $\mathrm{P}$ & $\mathrm{O}$ & $\mathbb{\theta}$ & \\
\cline { 2 - 4 } & $\mathrm{M}$ & $\mathrm{I} \ldots \ldots \ldots \ldots \ldots$ \\
\hline
\end{tabular}

522 und jEsus steht HIER;

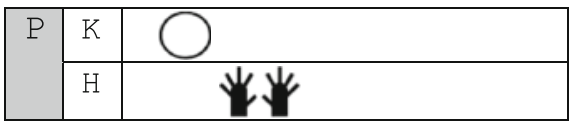

523 ja?

$\rightarrow 524$ und hätte jetzt sagen KÖNNen525 petrus du !FAU!ler sack.

\begin{tabular}{|c|c|c|}
\hline $\mathrm{P}$ & k & \\
\hline & $\mathrm{H}$ & 面 且 \\
\hline & $\mathrm{T}$ & - \\
\hline
\end{tabular}

526 hab ich_s dir nicht geSAGT; [ (4.0)

527 G: [( (lachen))

528 P: !AUF!stehn.

$529<<$ all>NEIN_nein_nein_nein>=

$530=$ =LIEgen blèiben.

531 macht er !NICHT!; (-)

532 macht er NICHT.

533 ja?(1.5)

534 SoNdern-

535 jesus be!RÜHRT! PEtrus. 


\section{$536 \quad j a ?$ \\ 537 er berührt ihn nicht mit em SCHUH; \\ 538 SO HIER- \\ $\rightarrow 539 \quad$ !EY! . \\ 540 !AUF!stehn. \\ 541 mich rUntertragen vom BERG; \\ 542 SoNdern- \\ 543 du musst dir das bIldlich VORstelln.(1.0)}

Nachdem die Szene aufgebaut wurde und der junge Mann am Boden liegt, nimmt der Prediger seine Nacherzählung wieder auf und zitiert den Bibeltext als wiedergegebene direkte Rede der Stimme aus der Wolke (!DIES! ist mein gellebter SOHN. (-) an dem ich WOHLgefallen habe. !HÖRT! auf IHN, Z.519-521). Er tritt danach zurück neben das Rednerpult, gerade auf die Anwesenden und den vor ihm liegenden jungen Mann ausgerichtet, die Ellenbogen in die Hüften gestützt, die Unterarme angewinkelt nach oben gerichtet und die Handflächen zur Gemeinde zeigend (* $w^{*}$, Z.522). Dieser Ortsund Haltungswechsel markiert einen Rollenwechsel von ,Gott‘ zu ,Jesus`, den er sprachlich noch nicht vollzogen hat, sondern erst ankündigt (und JEsus steht hier; ja? und hätte jetzt sagen KÖNN, Z.522-524). In dieser Zeit liegt der junge Mann mit dem Gesicht nach unten vor ihm. Der Prediger vollzieht schließlich den Rollenwechsel auch sprachlich. Dabei spricht er in direkter Rede in der Rolle des Jesus jedoch nicht das, was er im Bibeltext gesagt hat, sondern gerade das, was er nicht gesagt hat. Beides grenzt er mithilfe eines Metakommentars (und hätte jetzt sagen KÖNN, Z.524) und dem stilistischen Wechsel auf eine kolloquialere Ebene (pEtrus du !FAU!ler sack; hab ich_s dir nicht geSAGT, Z.525-526) voneinander ab. Speziell durch die Verwendung des Konjunktivs wird hier deutlich, dass der Prediger zwischen der Re-Inszenierung der biblischen Geschichte und der Inszenierung einer neuen, zum Bibeltext alternativen Episode unterscheidet. Bei dieser (Neu)Inszenierung verändert er seine Armhaltung, stützt sie in die Seite (ํㅣㅁํㄴ, Z.525) und beugt den Oberkörper leicht nach vorn (—, Z.525); dabei ist der Blick auf den am Boden Liegenden gerichtet. Parallel verfährt er auch in einer zweiten Sequenz, in der er wieder einen alternativen Verlauf der biblischen Erzählung inszeniert. Diese beginnt ebenfalls mit einem Metakommentar, der Handlungen thematisiert, die die biblischen Personen nicht ausgeführt haben (er berührt ihn nicht mit_em SCHUH, Z.537) und der Formulierung nicht realisierter Aussagen der Person Jesu (!EY!; !AUF!stehn; mIch RUNtertragen vom BERG, Z.539-541). Anders als zuvor laufen die Bewegungen in dieser Inszenierungsepisode jedoch nicht parallel zum Gesagten, 
sondern diesem entgegen. Der Prediger spricht davon, dass Jesus Petrus eben gerade nicht mit dem Schuh berührt, stößt in der Szene aber den am Boden liegenden Mann mit dem Fuß an.

Der Prediger schließt beide Episoden mit der adversativen Konjunktion „SONdern“ (Z.534 und 542) ab und leitet damit zugleich auf die dritte Inszenierungsepisode über, in der das tatsächliche Geschehen des Bibeltextes dargestellt wird. Zunächst kommentiert er den weiteren Ereignisverlauf, indem er ihn nacherzählt: „JEsus be!RÜHRT! pEtrus.“ (Z.535) und ,der Weltregent kniet sich nieder, denn er muss sich niederknien, um Petrus zu berühren, denn der liegt auf dem Boden" (nicht im Transkript). Im Anschluss daran kniet er sich - wieder in der Rolle ,Jesus“ - nieder und (re)inszeniert die Situation visuell durch die Veränderung der Körperposition, verbal durch die Wiedergabe direkter Rede (,Petrus, hab keine Angst. Los, aufstehen“, nicht im Transkript) und vokal durch eine erneute Veränderung in der Lautstärke (von laut zu leise) und eine weichere Artikulation.

Während der szenischen (Re)Inszenierung der biblischen Geschichte wechselt der Prediger immer wieder zwischen der Rolle des Erzählers, der verkörperten Rolle (Jesus bzw. Gott) und der Rolle des Predigers als Regisseur der Inszenierung (Tabelle 16.1).

Tabelle 16.1 Übersicht Handlungsebenen

\begin{tabular}{|l|l|}
\hline \multicolumn{1}{|c|}{ Zeile } & \multicolumn{1}{c|}{ Handlungsebene } \\
\hline $522-524$ & Animierte Rede (Rolle: Gott) \\
\hline $525-527$ & Metakommentar im Wahrnehmungsraum (Erzähler) \\
\hline $528-530$ & Animierte Rede (Rolle: Jesus) \\
\hline $531-532$ & Metakommentar, Regieanweisung (Regisseur) \\
\hline $533-540$ & Metakommentar im Wahrnehumgsraum (Erzähler) \\
\hline $541-543$ & Animierte Rede (Rolle: Jesus) \\
\hline $544-556$ & Metakommentar im Wahrnehmungsraum (Regisseur) \\
\hline $557-560$ & Animierte Rede (Rolle: Jesus) \\
\hline ab 561 & Interaktion im Wahrnehmungsraum (Prediger) \\
\hline
\end{tabular}

Der häufige Rollenwechsel wird u. a. auch durch die Reaktionen der anwesenden Personen ausgelöst. So reagiert der auf dem Boden liegende junge Mann auf das Lachen der Gemeinde (Z.527) im Anschluss an einen Kommentar der Rolle Jesu, indem er den Kopf hebt und die zum Aufstehen auffordernde Geste des Predigers sieht sowie die verbale Aufforderung (!AUF! stehn, Z.528) zum Anlass nimmt, sich zu erheben. Dies veranlasst den Prediger zu einer Reparatur, zu deren Realisierung er in die Rolle des Predigers als Regisseur der Szene wechselt und 
den Mann wieder zum Hinlegen bewegt ( $<<a l l>~ N E I N \_n e i n \_n e i n \_n e i n>$ LIEgen bleiben, Z.529-530).

Das Beispiel zeigt, dass und wie der Prediger das Verfahren der multimodal realisierten szenischen (Re)Inszenierung nutzt, um ein biblisch tradiertes Geschehen für die anwesenden Personen nachvollziehbar zu machen und dabei gleichzeitig Personenwissen über den Charakter Jesu zu vermitteln. Diese hoch didaktisierte Form der Veranschaulichung ist im gesamten Korpus relativ selten. Es wurde lediglich in zwei Wortbeiträgen die prototypische Form einer szenischen Darstellung biblischer Texte realisiert. In zwei weiteren wurden persönliche Erlebnisse des Predigers oder nicht-biblische Geschichten veranschaulicht (siehe Abschnitt 17.3.3). In allen Fällen kann der Prediger die (Re)Inszenierung sowohl allein als auch zusammen mit mindestens einer weiteren Person aus der Gemeinde realisieren.

Bei den im Wortbeitrag genutzten Verfahren der Wissensvermittlung und der Veranschaulichung geht es vor allem darum, den Nachvollzug und das Verstehen des biblischen Textes selbst zu ermöglichen. Dies ist notwendig, um darauf aufbauend die Übertragung der biblisch tradierten Ereignisse auf die Gegenwart und die zum Zeitpunkt des Wortbeitrags anwesenden Personen im 21. Jahrhundert zu leisten. Nach der textbezogenen Wissensvermittlung folgte also die gegenwartsbezogene Vermittlung und/oder Aktualisierung von überzeitlichen und grundlegenden Glaubensgewissheiten und die Formulierungen von Handlungsanweisungen bzw. Handlungsempfehlungen. Dabei formulieren die Prediger explizite und implizite Äußerungen hinsichtlich der überzeitlichen Gültigkeit biblischer Aussagen, Zusagen und Begebenheiten und stellen ihre eigene epistemische und deontische Autorität zur Disposition, d. h. ihr Recht, z. B. Handlungsempfehlungen auszusprechen. Das nachfolgende Kapitel vertieft diesen Aspekt anhand ausgewählter Beispiele aus dem untersuchten Korpus.

\subsection{Vom Bibeltext zur Gegenwart}

Eng verbunden mit der Veranschaulichung biblischer Texte ist das Herausarbeiten überzeitlicher Glaubensgewissheiten und das Aufzeigen von Handlungsoptionen auf der Grundlage des biblischen Textes. Aus theologischer Perspektive hat die Predigt zwei Wirkrichtungen: nach innen und nach außen - auf den einzelnen Gläubigen und die Identitätsstiftung als Christen genauso wie auf die Öffentlichkeit als „Dienst an der Welt“ (Engemann 2002:102). Dieser Leistung individueller und kollektiver Orientierung (vgl. Engemann 2002:104, Keller 2017:23f) dient 
u. a. die Auslegung der Texte, die Tradierung religions- und glaubenskonstitutiver Wissensbestände und die Verknüpfung des biblischen Textes mit der Lebenswirklichkeit der Anwesenden im Moment der Predigt im 21. Jahrhundert. Der Wortbeitrag soll entsprechend die Bedeutung und die Relevanz der biblisch tradierten Texte und Aussagen für die Gegenwart aufzeigen, obwohl oder gerade weil die religiöse, kulturelle und zeitliche Distanz besteht und als solche von den Predigern explizit und implizit thematisiert wird (vgl. Boyd-MacMillan 2011:203). In der Homiletik spricht man in diesem Zusammenhang von der Inszenierung der Schrift bzw. von einem ,in Szene setzen' der biblischen Texte und von deren Verlebendigung (vgl. Schneider 2016:203, Josuttis 1985:166). In einigen der untersuchten Wortbeiträge formulieren die Prediger zur Bearbeitung dieser Aufgabe explizite Parallelisierungen zwischen dem Bibeltext und der Gegenwart und arbeiten dadurch nicht nur an der Veranschaulichung des Textes, sondern zeigen auch den Geltungsanspruch der biblischen Texte auf.

Beispiel 44: Schon damals
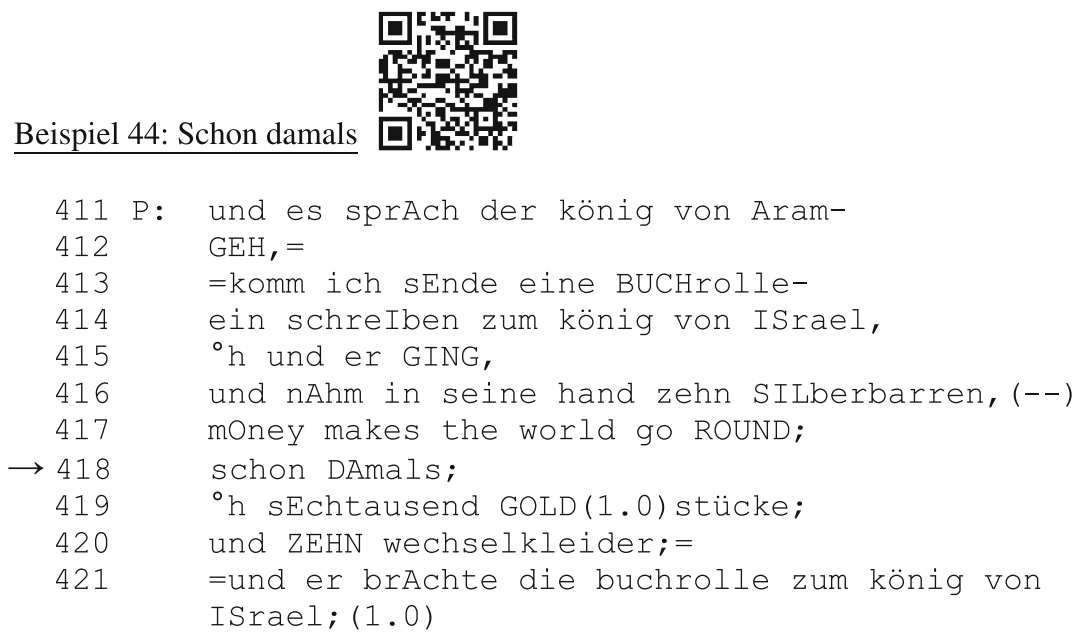

Der Prediger liest die Episode einer Unterhaltung zwischen dem syrischen König und Naaman vor (Z.412-416 und 419-421; siehe Beispiel 36 und 37). In dieses Vorlesen eingeschoben ist ein den Text auslegender Metakommentar des Predigers. Dieser besteht zum einen aus einer idiomatischen Wendung, dem englischen Zitat ,mOney makes the world go ROUND; “(Z.417), und der Parallelisierung „Schon DAmals“ (Z.418). Mit diesem Metakommentar realisiert der Prediger drei unterschiedliche Handlungen: a) er vermittelt implizit Wissen über die gesellschaftlichen Verhältnisse zur Zeit des Bibeltextes, dass Geld 
bei diplomatisch-politischen Beziehungen eine entscheidende Rolle gespielt hat, b) er markiert implizit den überzeitlichen Geltungsanspruch des im Text dargestellten Ereignisses (und nAhm in seine hand zehn SILberbarren, Z.416), bei dem es sich um eine ökonomische Transaktion vor dem Hintergrund politischer Machtverhältnisse (hier zwischen dem König von Aram und dem König von Israel) handelt, indem er die Verhältnisse zur damaligen Zeit mit den gegenwärtigen Verhältnissen parallel setzt, und c) er veranschaulicht den biblischen Text und ermöglicht den Nachvollzug für die Gemeinde.

In ähnlicher Weise nutzt der Prediger im nachfolgenden Auszug die rhetorische Phrase „damals wie heute“, die ebenfalls Parallelität und überzeitliche Gültigkeit postuliert.

Beispiel 45: Damals wie heute

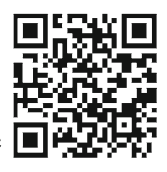

235 P: der hebräerbrief rIchtet sich an MENschen,

236 DIE,

237 in der gedAnkenwelt des jüdischen GLAUbens,

238 zuHAUse waren.=

239 =und GROß geworden waren. (--)

240 dA waren sie HERgekommen.

241 UNsere;

242 KLEIne;

243 Unbekannte christliche geMEINde; =

$244=$ von der am Anfang die REde war;

245 die in der gefAhr steht die KRAFT zu verlieren. (-)

246 DAS war ihre gedankenwelt.

247 die jÜdische FRÖMmigkeit.(1.0)

248 und da spielt der schabbAt eine ganz GROße rolle.(.)

$\rightarrow 249$ dAmals wie HEUte.

250 er WAR,

251 alLEINstellungsmerkmal.(-)

252 sowas hatte NIEmand sonst.

In diesem Wortbeitrag setzt sich der Prediger mit dem Hebräerbrief und der Differenzierung zwischen dem jüdischen Shabbat und dem christlichen Sonntag auseinander (siehe Beispiel 28 und 33). In dem Verweis darauf, 
wer der Adressat des Briefes ist (der hebräerbrief rIchtet sich an MENschen, die in der gedAnkenwelt des jüdischen GLAUbens zuHAUse waren. und GROß geworden waren, Z.235-239), kennzeichnet der Prediger die Notwendigkeit die bestehenden kulturellen und vor allem religiösen Distanzen zu überwinden, indem er entsprechendes Wissen vermittelt (siehe Abschnitt 16.3.1, Religionswissen) und immer wieder auf die Gemeinsamkeiten und Unterschiede zwischen Judentum und Christentum eingeht. Dabei verweist er nicht nur auf Traditionen jüdischer Religionspraxis zum Zeitpunkt des Bibeltextes, sondern verhandelt deren Aktualität und Kontinuität in der Gegenwart (dAmals wie HEUte, Z.249). Durch diese sprachliche Parallelisierung zeigt der Prediger die Gültigkeit des Textes und des Shabbat über die Jahrhunderte hinweg auf und verdeutlich dies, indem er die kulturelle Bedeutung und die identitätsstiftende Funktion des Shabbat darstellt (250-252, Kulturwissen).

Während die Parallelisierung zwischen den biblisch tradierten Ereignissen und der Gegenwart in diesen zwei Auszügen explizit markiert wird, bleibt sie im nachfolgenden Beispiel aus einer evangelischen Sonntagspredigt impliziter. Zudem schwächt der Prediger dadurch seine epistemische Gewissheit über die geäußerte Parallele ab.

Beispiel 46: Riss
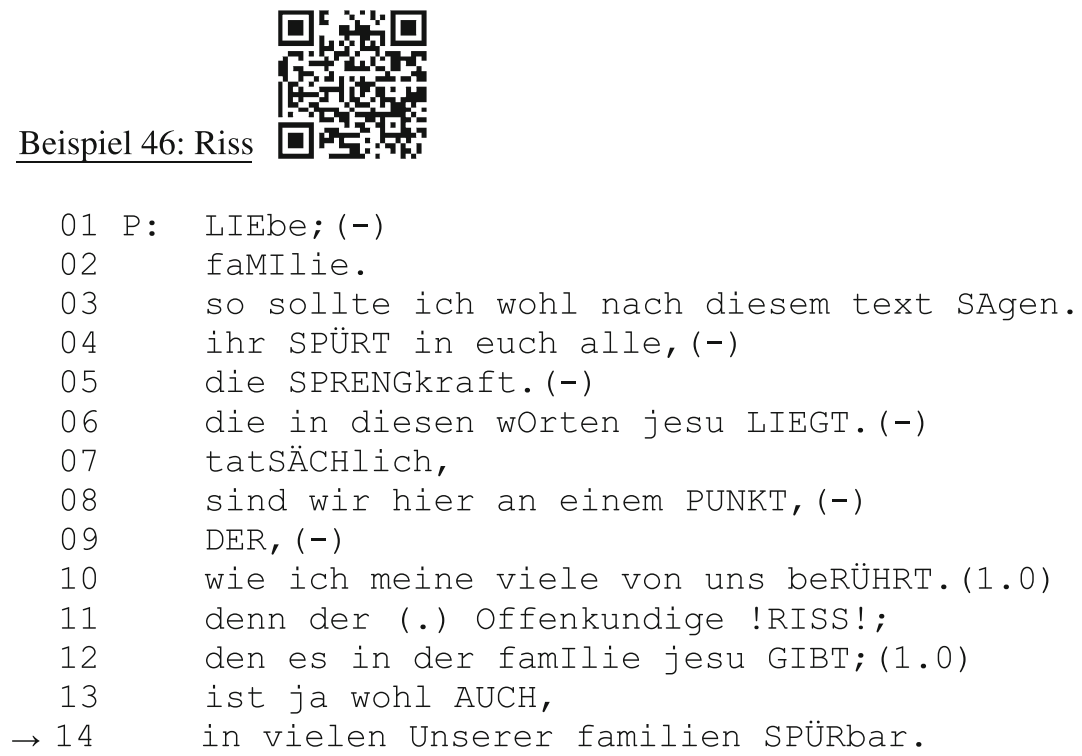
Nachdem der Prediger die biblischen Ereignisse erklärt und Kontextwissen vermittelt hat (nicht im Transkript), setzt er die im Bibeltext geschilderten Ereignisse mit aktuellen Ereignissen parallel: „denn der (.) Offenkundige !RISS!; den es in der famIlie jesu GIBT; (1.0) ist ja wohl AUCH, in vielen Unserer familien SPÜRbar." (Z.11-14). Durch die Partikel „ja“ nimmt der Prediger eine Zuschreibung geteilten Wissens vor, schwächt jedoch gleichzeitig die epistemische Sicherheit über die Gültigkeit seiner Aussage ab, indem er sie als subjektive Vermutung kennzeichnet ( $j a$ wohl AUCH, Z.13) und durch das Zahlwort „,vielen“ die Reichweite seiner Zuschreibung von Parallelität einschränkt (es ist in vielen, aber nicht in allen Familien der Fall). Der Prediger verweist auch hier auf die Aktualität und Lebensnähe des Textes, indem er von einer Äquivalenz zwischen Bibeltext und der Lebenswelt der anwesenden Personen spricht.

Alle untersuchten Prediger sehen sich in der Predigt mit der Aufgabe konfrontiert, die in biblischen Geschichten und Geschehnissen tradierten Wissensbestände aufzubereiten und so zu aktualisieren, dass sie heutigen Lebenswirklichkeiten gegenüber anschlussfähig werden (vgl. Stetter 2011:216). Der Prediger soll im Idealfall an die Lebensumstände der Gottesdienstbesucher anknüpfen und zwischen dem biblischen Geschehen und den aktuellen Verhältnissen vermitteln (vgl. u. a. Härtner/Eschmann 2008:19). Die Prediger in den untersuchten Wortbeiträgen haben die Verknüpfung zwischen Bibeltext und Lebenswirklichkeit auf unterschiedlichen Ebenen und aufbauend auf unterschiedlichen Wissensbeständen hergestellt: politischen, gesellschaftlichen und sozialen Parallelen (Verhältnis zwischen Personen, einer Familie etc.) sowie religiösen Parallelen und den Erfahrungen der anwesenden Personen, die mit den Erfahrungen der biblischen Personen in Beziehung gesetzt werden. Um dies zu erreichen, werden explizit und implizit Praktiken der Wissensvermittlung und Verfahren der Veranschaulichung (wie Analogien und Parallelisierungen) eingesetzt. 


\subsection{Handlungsmöglichkeiten}

Den theologischen Ausgangspunkt für die Formulierung von Handlungsmöglichkeiten im Wortbeitrag bildet die christliche Glaubensüberzeugung eines Gottes, dessen Botschaften und Zusagen überzeitlichen Charakter haben und heute noch genau so gelten wie zu Zeiten des Alten oder Neuen Testaments (vgl. Thiele 2004:30; siehe auch Keller 2017:35). Diese Vorstellung bestimmt in allen Konfessionen das Selbstverständnis der Prediger und deren Arbeit an den Wortbeiträgen. Wie die bisherigen Kapitel gezeigt haben, nutzen die Prediger häufig ein mehrstufiges Verfahren, indem sie zunächst den Bibeltext veranschaulichen und ggf. zusätzliche Wissensbestände vermitteln, daran anschließend Parallelen zwischen dem Text und der Gegenwart herausarbeiten, die die überzeitliche Gültigkeit markieren, und schließlich Konsequenzen aus dieser Überzeitlichkeit für die Gemeinde ableiten, indem sie Möglichkeiten für zukünftige Handlungen aufzeigen. Es ist auffällig, dass die Prediger in diesem Zusammenhang Abstufungen im Appellcharakter und im Grad der Absolutheit der Anweisung ihrer Aussagen vornehmen. In der vorliegenden Arbeit wird daher zwischen Handlungsanweisungen, Handlungsempfehlungen und Handlungsoptionen unterschieden. Während Handlungsanweisungen sehr stark die Notwendigkeit zukünftiger Handlungen markieren, zeigen Handlungsempfehlungen, was zukünftig getan werden sollte. Der präskriptive Charakter der Äußerung ist hier abgeschwächt. Schließlich wird die Formulierung von Handlungsoptionen erkennbar. Hier zeigt der Prediger mögliche Handlungsverläufe auf und stellt sie nebeneinander, ohne zu priorisieren.

Handlungsanweisungen machen deutlich, dass es sich um notwendige zukünftige Handlungen handelt, die sich als direkte Konsequenz aus biblisch tradierten Glaubensgewissheiten und Moralvorstellungen ergeben. Das nachfolgende Beispiel aus einem ökumenischen Sonntagsgottesdienst verdeutlicht dies. 
Beispiel 47: Losgehen

$\rightarrow 162$ P: ich muss verTRAUen und; (.)

163 dem vertrauen folgt das Losgehen.(1.5)

164 so wie ich im hochseilgarten natürlich den

(.) SIcherheitsseil SEhe und-

165 den karaBIner;

166 =und meinen GURT; (--)

167 aber ich sehe nIcht die KRÄFte;

168 die gleich WIRken;

169 wenn ich im SEIL hänge. (1.5)

170 ich muss verTRAUen.

171 ich muss GLAUben,

172 dass das HÄLT;

$173{ }^{\circ} \mathrm{h}$ dass das TRÄGT. (1.0)

174 und im reIch GOTtes. (--)

175 ist es ganz ÄHNlich.(2.0)

176 wir HA:ben,

177 gottes !WORT!.(-)

178 und wir haben seIne verSPRECHen. (--)

179 übrigens nicht nur für die geMEINde;

180 also für die die sich CHRISten nennen.

181 sondern gottes wort gilt ja für ALLE menschen. (1.0)

182 deswegen haben wir in diesen tagen in diese stAdt hiNEINgerufen. (2.5)

$\rightarrow 183$ aber dann muss ich es UMsetzen; (---)

184 Umsetzen was gott WILL. (--)

185 ! AUCH!;

186 wenn ich !NICHTS!;

187 !SE! he.

Der Prediger parallelisiert in diesem Auszug durch einen Vergleich das Vertrauen auf Gottes Führung mit dem Vertrauen auf physikalische Gesetze (Z.164-175). Als Referenz führt der die Autorität biblischer Überlieferungen an (Z.176-181) und formuliert das Wissen über die Tragfähigkeit des Glaubens mit sehr hoher epistemischer Sicherheit, sprachlich realisiert mithilfe 
der Partikel „ja“ als common ground der anwesenden Personen (AB-event). Auf dieser Grundlage formuliert er Handlungsanweisungen hinsichtlich des persönlichen Glaubenslebens jedes Einzelnen (ich muss verTRAUen und dem vertrauen folgt das LOSgehen, Z.162-163 und aber dann muss ich es UMsetzen; (---) Umsetzen was gott WILL, Z.183184). Diese werden durch das Modalverb (,muss“) als notwendige Konsequenz aus einem Leben als glaubender Christ und als Teil der Kausalkette ,Glauben Vertrauen - Handeln' formuliert. Handlungsanweisungen werden aber nicht nur mithilfe des Modalverbs ,müssen " realisiert, sondern auch mithilfe der Form des Imperativs, wie das nachfolgende Beispiel aus einem Jugendgottesdienst zeigt:

\section{Beispiel 48: Freuet euch}
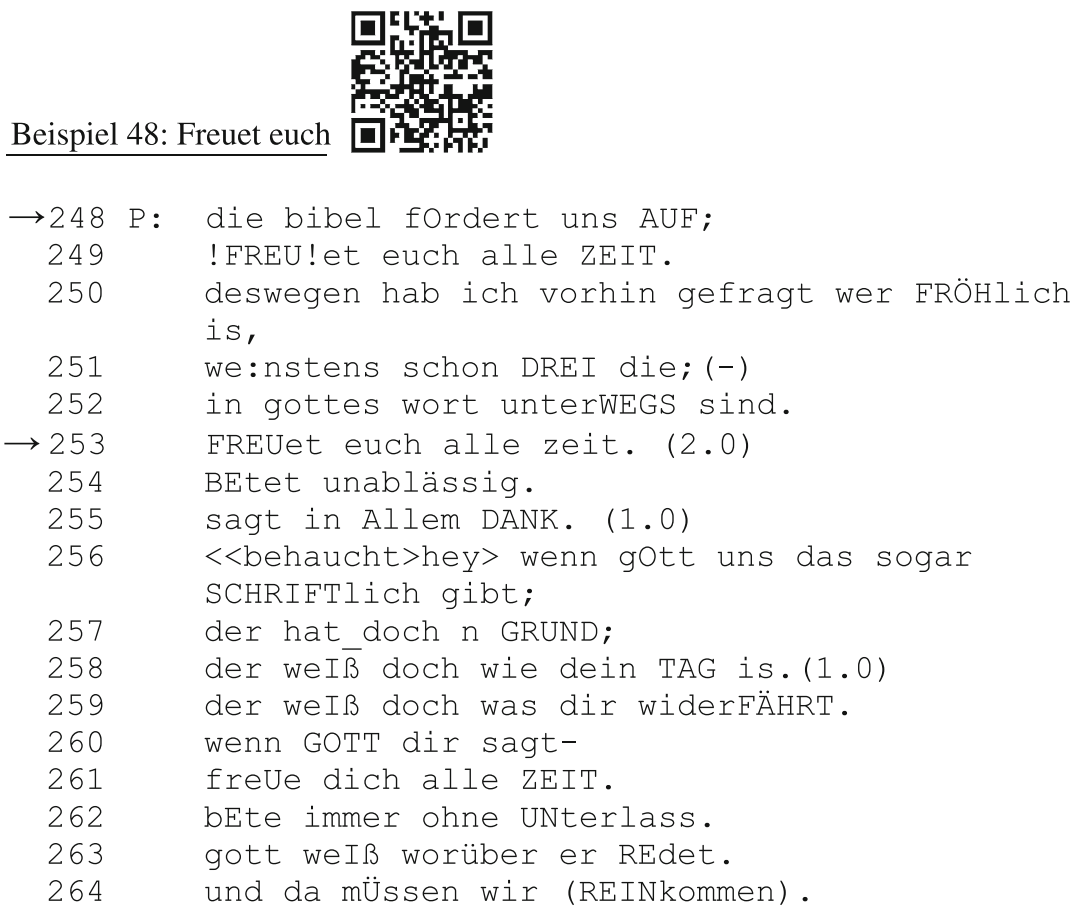
Der Prediger gibt in diesem Beispiel die durch den Imperativ kontextualisierten Handlungsanweisungen sich zu freuen (freUe dich alle ZEIT, Z.253 und Z.261), zu beten (bEte immer ohne UNterlass, Z.254 und Z.262) und zu danken (sagt in Allem DANK, Z.255). Die Handlungsanweisungen verknüpft und begründet der Prediger direkt mit dem biblischen Text (die bibel fOrdert uns AUF, Z.248), indem er die dort genutzten Formulierungen wieder aufgreift. Auf der Grundlage des biblischen Textes etabliert der Prediger also Anweisungen für zukünftige Handlungen als unmittelbare und unumgängliche Konsequenz. Der Prediger nimmt hier explizit die Rolle eines Vermittlers ein, der die biblisch tradierten, göttlichen Anweisungen weitergibt und gegenüber den anwesenden Personen aktualisiert. Er setzt damit die überzeitliche Gültigkeit der biblischen Texte relevant und positioniert sich als jemand, der, wie die Gemeinde, diesen Aufforderungen folgen soll. Es ist dann nicht der Prediger, der das Recht hat, der Gemeinde bestimmte zukünftige Handlungen nahezulegen, sondern der biblische Text. Dieser wird mit einer hohen deontischen Autorität aufgeladen, die durch den Prediger im Wortbeitrag tradiert und vermittelt wird.

Handlungsempfehlungen wiederum werden in den untersuchten Predigten auch aus biblischen Texten und auf Grundlage von Glaubensgewissheiten herausgearbeitet, werden jedoch weniger stark und absolut formuliert. Wie das nachfolgende Beispiel aus einem katholischen Sonntagsgottesdienst zeigt, zieht der Prediger auch hier eine direkte Linie vom biblischen Text, der Überzeugung von dessen Überzeitlichkeit, über die gegenwartsspezifische Aktualisierung und Vermittlung von Wissen bis hin zu zukünftigen Handlungsempfehlungen (das Video beginnt in Zeile 185 des Transkripts). 


\section{Beispiel 49: Lebebuch 回程}

080 P: wie sollen verkÜnder der frohen botschaft SEIN.(-)

081 doch um verkÜNder;

082 seIn (.) zu KÖNnen,

083 muss ich zunächst einmal WISsen.

084 was IST das denn;

085 die frohe BOTschaft.

086 das HEIßt-

$\rightarrow 087$

088 $((\ldots))$ ich muss auch in der BIbel lesen; = =denn dAs ist unsere (.) überLIEferung. (-)

185

186

187

188

189

190

191

192

193

194

195

196

197

198

199

200

201

202

203

204

liebe schwEstern und BRÜdern;

ich meIne wir KÖNnen;

und wir sollten;

noch vIel von DIEsen christen lernen. (-)

was hIndert ! UNS! eigentlich.

zuhause in der familie,

im frEundes und beKANntenkreis,

vielleicht auch im faMIlienkreis;

rEgelmäßig die heilige schrift zur HAND zu nehmen;

und (.) und daraus zu LEsen.(-)

denn wer DAS tut.

der wird auch den REICHtum entdecken,

der in diesem $\mathrm{BUCH}$,

der BÜcher;

STECKT. (-)

und er wIrd sich SELbst;

von den texten stets neu herAUSfordern

lassen.

205

für seinen Alltag;

und für sein CHRISTsein.(-)

eine BIbel,

206

die nur im regAl steht und verSTAUBT; (-)

ist eigentlich NUTZlos. (-) 


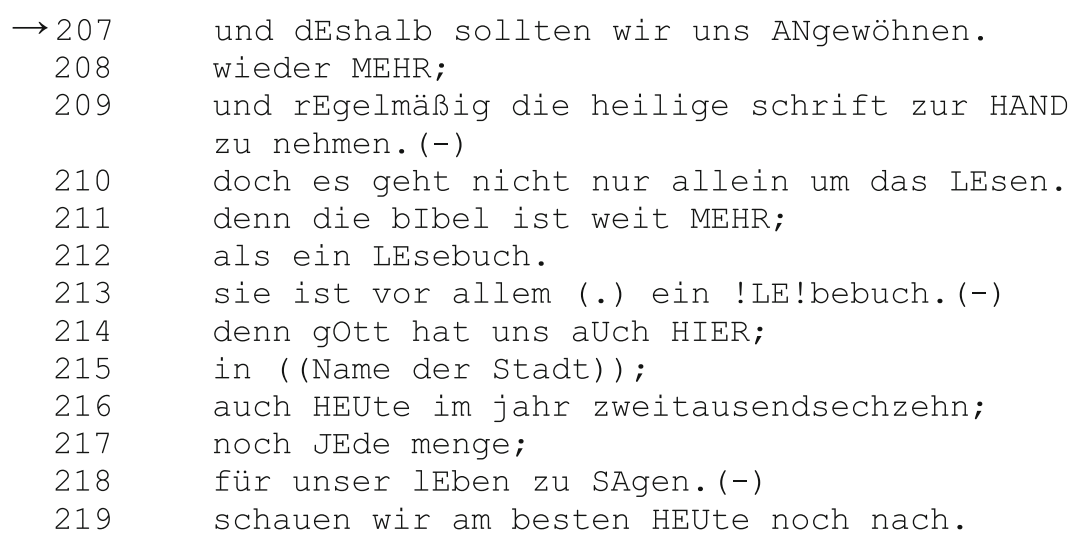

Ausgehend von dem biblischen Missionsauftrag (wir sollen verkÜnder der frohen botschaft SEIN, Z.80) formuliert der Prediger zunächst eine Handlungsanweisung, die als notwendige Konsequenz aus dem Auftrag formuliert wird (doch um verkÜNder; seIn (.) zu KöNnen, muss ich zunächst einmal WISsen. was IST das denn; die frohe BOTschaft. das HEIßt ich muss auch in der BIbel lesen, Z.81-87). Auffällig ist hier wieder die Realisierung der Anweisung mithilfe des Modalverbs ,müssen“. Im weiteren Verlauf des Wortbeitrags greift er diese Handlungsanweisung wieder auf, formuliert sie dann aber als Handlungsempfehlung mit einem abgeschwächten Appellcharakter. Der Prediger nutzt nicht mehr das Modalverb ,müssen“ und den Imperativ, sondern die Modalverben ,sollen' und ,können' im Konjunktiv (und wir SOLlten; noch vIel von DIEsen christen lernen, Z.186-187 unddEshalb sollten wir uns ANgewöhnen. wieder MEHR; und rEgelmäßig die heilige schrift zur HAND zu nehmen, Z.207-209). Der Prediger formuliert mithilfe der Konjunktion „und“ und dem Adverb „dEshalb“ (Z.207) einen direkten kausalen Zusammenhang zwischen dem biblisch tradierten Handlungsauftrag des Weitersagens der biblischen Botschaft und der Handlungsempfehlung des Bibellesens, denn Letzteres bildet so die Grundlage dafür, den Verkündigungsauftrag durchführen zu können. Die Pronomen ,uns“ und ,wir“ sind in diesem Zusammenhang weitere sprachliche Praktiken des Predigers. Mit ihnen integriert sich der Prediger zum einen in die Gruppe derer, denen die Handlungsempfehlung gilt, und lädt gleichzeitig den biblischen Text selbst mit Autorität auf. Der Prediger impliziert damit, dass nicht seine Weisungen entscheidend sind, sondern die Weisungen Gottes, die in den biblischen Texten tradiert sind (denn gott hat uns aUcg HIER; in ((Name der 
Stadt)); auch HEUte im jahr zweitausendsechzehn; noch JEde menge; für unser lEben zu SAgen.(-) schauen wir am besten HEUte noch nach, Z.214-219).

Im Gegensatz zu Handlungsanweisungen und Handlungsempfehlungen geben die Prediger mit Handlungsoptionen unterschiedliche Möglichkeiten vor, wie die Gemeinde im Anschluss an das Gesagte praktisch tätig werden kann. Im nachfolgenden Wortbeitrag aus einer Jugendgottesdienstpredigt setzt sich der Prediger mit dem Thema „Zweifel“ und biblisch tradierter, jüdischer Erinnerungskultur auseinander (Kulturwissen). Aus diesem Rückblick entwirft er nun Optionen für das zukünftige Handeln der anwesenden Personen.

Beispiel 50: Denkmal
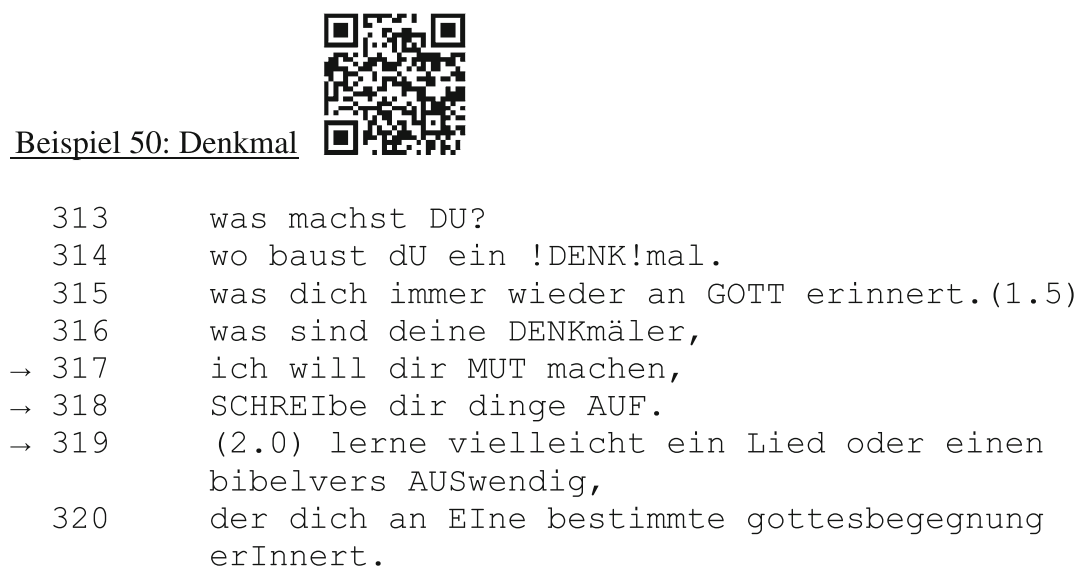

Eingeleitet durch ein Interrogativ (was machst DU? wo baust dU ein ! DENK!mal, Z.313 und 314) zeigt der Prediger in Form von candidat answers auf die Frage verschiedene Handlungsoptionen auf (Z.318-319). Diese werden vom Prediger zwar als Imperativ formuliert (schreibe auf, lerne auswendig), aber durch die Einleitung (ich will dir MUT machen, Z.317) als gleichwertige Optionen gerahmt.

Handlungsaufforderungen, Handlungsempfehlungen und Handlungsoptionen können von den Predigern an unterschiedlichen Stellen innerhalb des Wortbeitrags realisiert werden. In den meisten Fällen werden sie am Ende oder im Verlauf des Wortbeitrags produziert, aber auch zu Beginn kommen sie vor. Die Aufforderungen zu zukünftigen Handlungen können dabei eine unterschiedliche Reichweite haben. Sie können sowohl individuumszentrierte Handlungen umfassen (häufiger/regelmäßiger Bibel lesen, sich bewusst auf Gott verlassen etc.), als 
auch Handlungen thematisieren, die in die Gesellschaft hineinwirken (die frohe Botschaft verkündigen). Verbleiben sie auf der Ebene der einzelnen Person, geht es in vielen Fällen um eigene Glaubenspraktiken und das Verhältnis zwischen der jeweiligen Person und Gott. Im oben gezeigten Beispiel handelt es sich z.B. um eine konkrete Tätigkeit der anwesenden Personen, die im Anschluss an den Gottesdienst vollzogen werden soll (,häufiger Bibellesen'). Aufforderungen und Empfehlungen können sich jedoch auch auf die Änderung von Einstellungen und Überzeugungen beziehen. Der Prediger aktualisiert dann Glaubensgrundsätze in Bezug auf das Verhältnis jedes einzelnen anwesenden Christen gegenüber Gott. Es geht in diesem Zusammenhang nicht zuerst um zukünftige soziale Handlungen, die direkt in die Gesellschaft hineinwirken, sondern um ein kritisches Hinterfragen der eigenen Perspektive und der individuellen Glaubensauffassungen. Diese Perspektive auf die zukünftigen Handlungen des Einzelnen überwiegt in den untersuchten Wortbeiträgen vor der Aufforderung zu Handlungen, die in die Gesellschaft hineinwirken.

\subsection{Wissensgattung Predigt}

Ausgangspunkt für die durchgeführte Analyse war die Beobachtung, dass Wissen auf unterschiedlichen Ebenen und in unterschiedlichen Formen eine konstitutive Rolle für die kommunikative Gattung der Predigt spielt. In der bisherigen wissenssoziologischen und interaktionsanalytischen Forschung in Bezug auf Wissen blieb die Predigt bisher weitgehend unberücksichtigt. Lediglich einige wenige Studien verweisen auf moralische Wissensbestände. Auch die theologischen Betrachtungen nehmen einen durchaus ambivalenten Standpunkt zum Thema, Wissen in der Predigt" ein und diskutieren kontrovers, inwieweit Prediger einen Lehrauftrag haben und wie dieser auszufüllen sei. Vor diesem Forschungshintergrund war es das Ziel der durchgeführten Analyse, den Stellenwert der Wissensvermittlung im Wortbeitrag und die dabei aktualisierten Wissensformen herauszuarbeiten. Auf binnenstruktureller Ebene können so unterschiedliche Wissensbestände und Wissensterritorien ausgemacht werden:

Gattungswissen: Wissen über die Gattung an sich, ihre interaktive Verfasstheit, ihre institutionelle Einbettung, die Kenntnis der typischen Interaktionsordnung etc. Das Vorhandensein dieses Wissens sowohl auf Seiten des Predigers als auch auf Seiten der Gemeinde ist notwendig, um die Gattung erfolgreich etablieren und durchführen zu können. Dieses Wissen wird in den meisten Fällen als bekannt 
vorausgesetzt und innerhalb der Predigt und des Wortbeitrags nicht explizit thematisiert (AB-event). Es verweist auf außenstrukturelle Komponenten wie die Gestaltung und Nutzung des Raumes, die Markierung der institutionellen Rollen (Prediger und Gemeinde) und Erwartungen darüber, wer von diesen zwei Rollen prototypisch über welches Wissen verfügt, $d$. h. Wissensträger ist, Zugang zu den einzelnen Wissensterritorien hat und wer in Bezug auf welches Territorium über epistemische und deontische Autorität verfügt. Dies kann sich auf der situativen Realisierungsebene u. a. in Frage-Antwort-Sequenzen zeigen (siehe Abschnitt 5.3). Das Gattungswissen spielt somit auf allen Gattungsebenen eine Rolle.

Bibelwissen: Wissen über den Aufbau und die Handhabung der Bibel, ggf. auch über historische Fakten zur Entstehung des Bibelkanons etc. Dieses Wissen wird ebenfalls in den meisten Fällen als von allen Anwesenden geteilt zugeschrieben (AB-event). Lediglich in Wortbeiträgen im Rahmen von Evangelisationen fand eine Vermittlung von Bibelwissen statt.

Bibeltextwissen: Wissen über die kontextuelle Einbettung des im Wortbeitrag besprochenen Bibeltextes. Dies umfasst sowohl den intertextuellen Kontext bezüglich des Gesamtaufbaus der Bibel als auch das Wissen über die religiöse, kulturelle und historische Einordnung des jeweiligen Bibeltextes. Bibeltextwissen ist die Wissensform, die am häufigsten Gegenstand in den Wortbeiträgen ist. Sie wird vor allem vermittelt, um die Distanz(en) zwischen Bibeltext und Gemeinde zu reduzieren (A-event und $\mathrm{AB}$-event). Es lässt sich somit vor allem auf der Ebene der Binnenstruktur verorten. Innerhalb des Bereichs des Bibeltextwissens wurden die folgenden Bereiche erkennbar:

- Religionswissen: Dieses Wissen umfasst zum einen Wissen über die (Frömmigkeits)Praktiken, Glaubensgrundsätze und Glaubenstraditionen fremder Religionen, v. a. des Judentums, das in der Abgrenzung zu den religiösen Praktiken des Christentums markiert wird. Zum anderen ist damit das Wissen über grundlegende Glaubensgewissheiten und Glaubenspraktiken der eigenen Religion, d. h. des Christentums, benannt.

- Kulturwissen: Wissen über die sozio-kulturellen, politischen und ökonomischen Verhältnisse zur Zeit der im Bibeltext beschriebenen Ereignisse. Hierzu zählt auch das Wissen über die historische Einbettung des Bibeltextes.

- Sprachhistorisches Wissen: Wissen über Sprachwandel und Prozesse der Bedeutungsveränderung zwischen dem biblischen Originaltext, der im Wortbeitrag vorgelesenen deutschen Übersetzung und dem Sprachgebrauch der anwesenden Personen. 
- Personenwissen: Wissen über biblische Personen, ihre Charakterisierung sowie ihren sozialen, religiösen und ökonomischen Status.

- Exegesewissen: Subjektive Lesarten und Erkenntnisse des Predigers zu und über den biblischen Text im Zusammenhang mit seiner Lektüre bzw. vom Prediger zugeschriebene subjektive Lesarten der anwesenden Personen.

- Moralwissen: Wissen über biblisch tradierte Moralvorstellungen in Abgrenzung zu weltlichen/menschlichen Moralvorstellungen.

Glaubenswissen: Erfahrungswissen des Predigers und der Gemeinde hinsichtlich des eigenen Glaubens, gemachter Gotteserfahrungen und der individuellen Glaubensbiographie (A-event, B-event, AB-event).

Wie die Analyse gezeigt hat, entscheiden die Prediger aufgrund der Annahme über vorhandenes oder nicht vorhandenes Wissen und mit dem Ziel Intersubjektivität zu erzeugen, d. h. Verstehen zu ermöglichen, welche Wissensbestände bei welcher Gemeinde auf welche Art und Weise innerhalb des Wortbeitrags vermittelt werden. Dabei nutzen die Prediger unterschiedliche kommunikative und interaktive Praktiken und nehmen komplexe Zuschreibungen hinsichtlich des epistemischen Status der anwesenden Personen und der Darstellung des eigenen epistemischen Status vor. Zum einen können sie sich selbst einen Expertenstatus zuschreiben und diesen explizit und implizit markieren. Dabei wird den anwesenden Personen ein niedriger epistemischer Status und damit ein großes Wissensdefizit zugeschrieben, das von den Predigern überbrückt wird (A-event). Zum anderen können sich die Prediger selbst einen niedrigen epistemischen Status hinsichtlich bestimmter Wissensterritorien zuschreiben, zu denen sie keinen Zugang haben (B-event). Die explizite Markierung von Nichtwissen legitimiert dann die Vermittlung von Wissen durch den Prediger. Um die Handlungen der Wissensvermittlung und der Veranschaulichung auszuführen, nutzen die Prediger unterschiedliche kommunikative Praktiken, z. B. Übersetzungen, Analogiebildungen, sprachliche Szenarien und multimodale (Re)Inszenierungen. Auch stilistische Variationen und Visualisierungen gehören zu den kommunikativen Praktiken, die von den untersuchten Predigern genutzt werden, um die biblischen Texte für die anwesenden Personen verstehbar zu machen und Distanzen zu überwinden. Dabei konstruieren die Prediger die anwesenden Personen als Wissens- und Praktikengemeinschaft und schließlich auch als Glaubensgemeinschaft mit geteilten Werten und Ideologien. Die Relevanz und überzeitliche Gültigkeit der biblischen Texte wird in einem zweiten Schritt herausgearbeitet. Darauf aufbauend erfolgt die Ableitung von Handlungsmöglichkeiten. In den untersuchten Daten fiel dabei auf, 
dass die Prediger sich nicht allein auf ihre rollenbedingte epistemische und deontische Autorität stützen, sondern vor allem auf die biblisch tradierten Aussagen, die mit letztgültiger Autorität aufgeladen werden. Im Zusammenspiel mit den vorgestellten Praktiken der Wissensvermittlung ergibt sich damit eine prototypische Verknüpfung von Textaktualisierung, Veranschaulichung und der Formulierung von Handlungsmöglichkeiten innerhalb der Wortbeiträge:

1. Aktualisierung des biblischen Textes (Lesung),

2. Herstellung von Intersubjektivität in Bezug auf den Bibeltext (Wissensvermittlung ausgehend von Wissenszuschreibungen des Predigers),

3. ggf. Veranschaulichung der im Bibeltext dargestellten Ereignisse,

4. Anbindung des biblischen Textes an die Lebenswirklichkeit der Gemeinde,

5. Formulierung von Handlungsanweisungen, Handlungsempfehlungen und Handlungsoptionen auf der Grundlage des biblischen Textes.

Die Predigt erscheint in diesem Zusammenhang nicht nur als eine Gattung, in der Wissen aus und über alte Texte systematisch aktualisiert und rekonstruiert wird, sondern auch als eine Gattung, in der die Perspektive auf gegenwärtige und zukünftige Handlungen gerichtet wird, die sich aus der Rekonstruktion des Vergangen ergeben. Dadurch erhält die Predigt einen spezifischen rekonstruktivprospektiven Charakter (Abbildung 16.2).

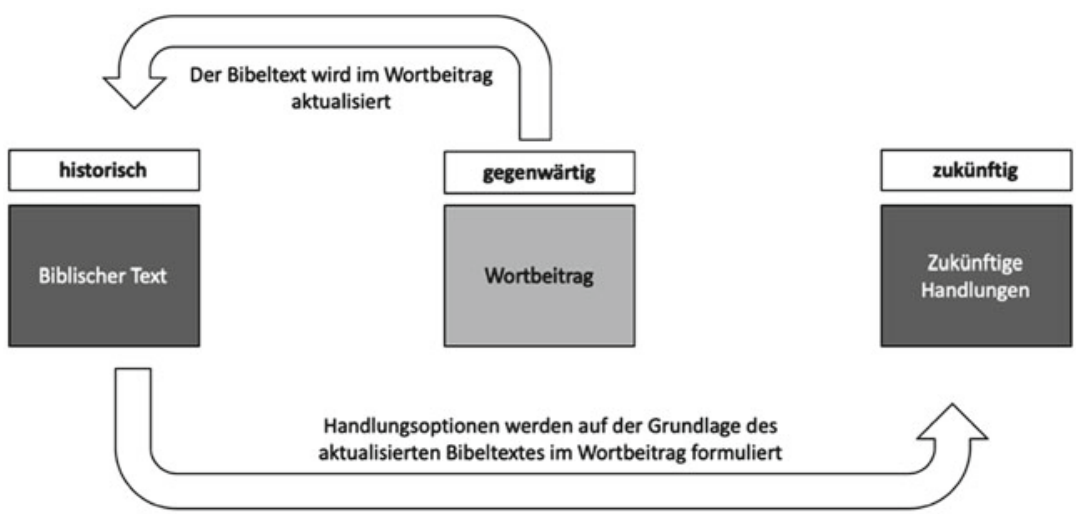

Abb. 16.2 Rekonstruktiv-prospektive Gattung Predigt 
Gattungen, in denen vergangene Ereignisse rekonstruiert und dabei aktualisiert werden (z. B. Konversionserzählungen, Klatsch, Reiseberichte etc.), benennt Luckmann ganz allgemein als rekonstruktive Gattungen und schreibt:

Je nach Lebens- und Handlungslage gewinnen Menschen in verschiedener Hinsicht ein Interesse daran, jüngst oder auch schon längst vergangene Ereignisse zu besprechen. Eigene und fremde Taten werden erzählt. Man fragt nach ihren Folgen, Ursachen, man rechtfertigt sie, verurteilt sie, feiert sie, entrüstet sich über sie. (Luckmann 2002a:174)

Wie die bisherige Analyse gezeigt hat, bildet auch in den Wortbeiträgen christlicher Predigten die Aktualisierung (alter) biblischer Texte, in denen vergangene Ereignisse geschildert werden, und die Vermittlung von damit im Zusammenhang stehenden Wissensbeständen einen wichtigen, wenn nicht zentralen Bestandteil. Es geht um die „kommunikative Vergegenwärtigung von Vergangenem“ (Luckmann 2002a:179) und in einem nächsten Schritt um die Klärung der „Bedeutung des Vergangenen für die Gegenwart“ (Luckmann 2002a:174). Schließlich wird die Frage gestellt, welchen Nutzen das Wissen über vergangene Ereignisse „für das Entwerfen zukünftiger Handlungen" hat (Luckmann 2002a:174). Besonders deutlich wird immer wieder dieser letzte Aspekt: der Entwurf zukünftiger Handlungen und die Formulierung von Handlungsoptionen auf der Grundlage dessen, was aus den biblischen Texten herausgearbeitet wurde. Die Rekonstruktion, Aktualisierung und Tradierung von v. a. biblischen und religiösen Wissensbeständen zum Zweck der Bildung einer Wissens-, Glaubens- und Praktikengemeinschaft qualifiziert die Predigt damit als rekonstruktive Gattung, in der zurückliegende Ereignisse zu „relevante[n] sinnstiftende[n] Gegenstände[n]“ (Schubert 2009:45) werden. In den Wortbeiträgen der hier untersuchten Predigten gehen die Prediger jedoch noch einen Schritt weiter, wenn sie die biblisch tradierten Ereignisse nicht nur an die aktuelle Lebenswirklichkeit der anwesenden Personen rückbinden und gegenwartsbezogen aktualisieren, sondern darauf aufbauend auch auf die Zukunft verweisen, indem sie Handlungsmöglichkeiten aufzeigen und Konsequenzen aus dem vermittelten Wissen darstellen.

Die Luckmannsche Charakterisierungen der christlichen Predigt als moralische und erbauliche Gattung (Luckmann 1997:14 und 2002b:205) müssen also dahingehend spezifiziert werden, dass die Predigt eine rekonstruktiv-prospektive Gattung ist und dass die Vermittlung von Wissen (religiös, kulturell, sprachlich, moralisch etc.) ein zentraler und konstitutiver Bestandteil und eine von Predigern bearbeitete kommunikative Aufgabe ist. 
Open Access Dieses Kapitel wird unter der Creative Commons Namensnennung 4.0 International Lizenz (http://creativecommons.org/licenses/by/4.0/deed.de) veröffentlicht, welche die Nutzung, Vervielfältigung, Bearbeitung, Verbreitung und Wiedergabe in jeglichem Medium und Format erlaubt, sofern Sie den/die ursprünglichen Autor(en) und die Quelle ordnungsgemäß nennen, einen Link zur Creative Commons Lizenz beifügen und angeben, ob Änderungen vorgenommen wurden.

Die in diesem Kapitel enthaltenen Bilder und sonstiges Drittmaterial unterliegen ebenfalls der genannten Creative Commons Lizenz, sofern sich aus der Abbildungslegende nichts anderes ergibt. Sofern das betreffende Material nicht unter der genannten Creative Commons Lizenz steht und die betreffende Handlung nicht nach gesetzlichen Vorschriften erlaubt ist, ist für die oben aufgeführten Weiterverwendungen des Materials die Einwilligung des jeweiligen Rechteinhabers einzuholen.

(c) (9) 